\title{
Physiological and molecular features of glucocorticoid actions in the gastrointestinal tract
}

\author{
Dissertation \\ for the award of the degree \\ "Doctor rerum naturalium (Dr.rer.nat.)" \\ of the Georg-August-University Göttingen \\ within the doctoral program "Molecular Medicine"
}

submitted by

Sybille Dorothee Reichardt, née Putzien

born in

Esslingen, Germany

Göttingen, 2015 


\section{Thesis Committee}

Prof. Dr. Martin Oppermann (Supervisor, First Referee) Institute for Cellular and Molecular Immunology University Medical Center Göttingen

Prof. Dr. Matthias Dobbelstein (Second Referee)

Institute for Molecular Oncology

University Medical Center Göttingen

PD. Dr. Fred Lühder

Department of Neuroimmunology

University Medical Center Göttingen

\section{Additional members of the examination board}

Prof. Dr. Heidi Hahn

Institute of Human Genetics

University Medical Center Göttingen

Prof. Dr. Hubertus Jarry

Department of Clinical and Experimental Endocrinology

University Medical Center Göttingen

\section{Prof. Dr. Lutz Walter}

Department of Primate Genetics

German Primate Center, Göttingen

Day of oral examination: March $24^{\text {th }} 2015$ 


\section{Declaration}

I hereby declare that the work presented in this thesis represents original work carried out by the author and has not been submitted in any form to any other university. It was written independently and with no other sources and aids than quoted.

Göttingen, Germany

Sybille D. Reichardt 
For my family

"There is nothing perfect...only life."

- Sue Monk Kidd, The Secret Life of Bees 
Parts of this work have been published in the following article:

Reichardt, S.D., Weinhage, T., Rotte, A., Föller, M., Oppermann, M., Lühder, F., Tuckermann, J.P., Lang, F., van den Brandt, J., and Reichardt, H.M. (2014).

Glucocorticoids induce gastroparesis through depletion of L-arginine.

Endocrinology 155, 3899-908. 


\section{Table of contents}

1. Introduction

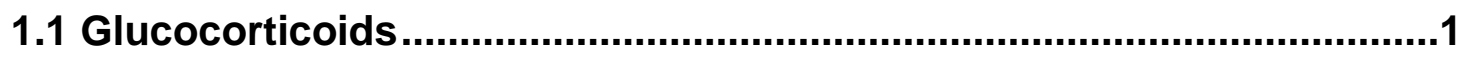

1.1.1 Synthesis of endogenous glucocorticoids ......................................

1.1.2 Structure and function of the glucocorticoid receptor...........................

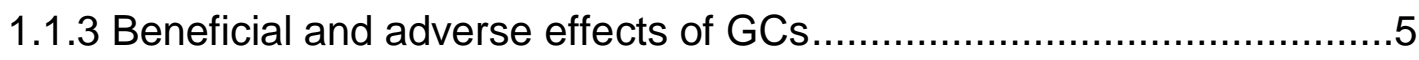

1.1.4 Insights from animal models ......................................................

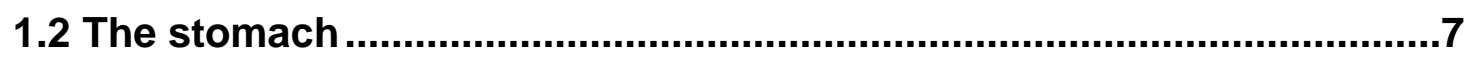

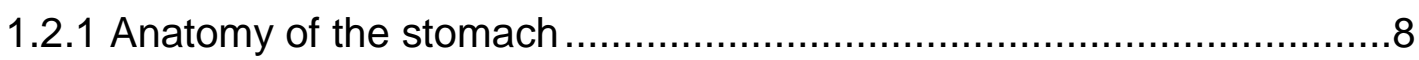

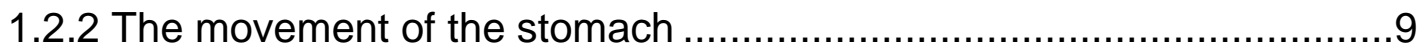

1.2.3 Gastric emptying and gastroparesis ............................................11

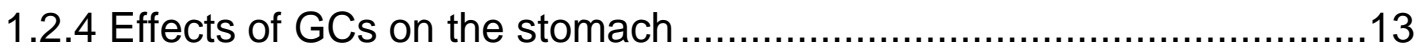

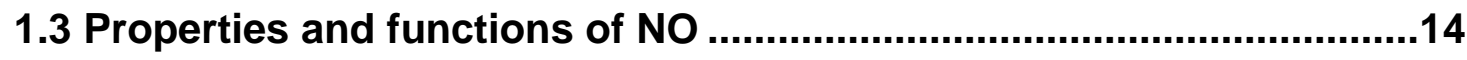

1.3.1 $\mathrm{NO}$ as a signaling molecule .........................................................14

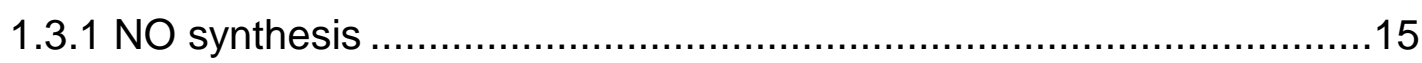

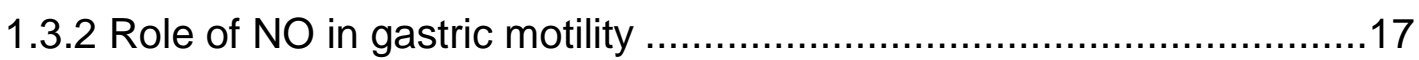

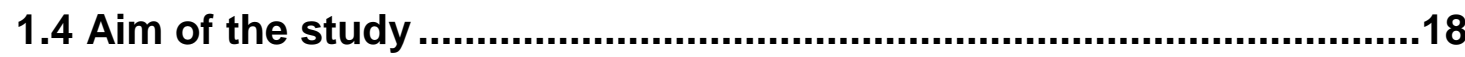

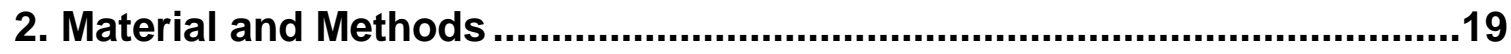

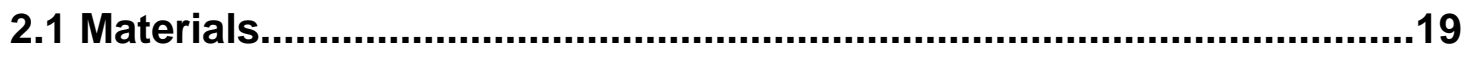

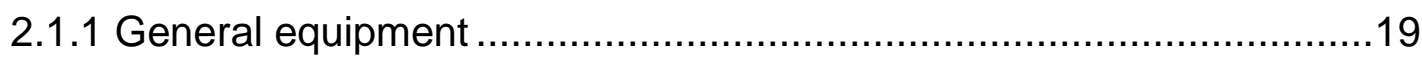

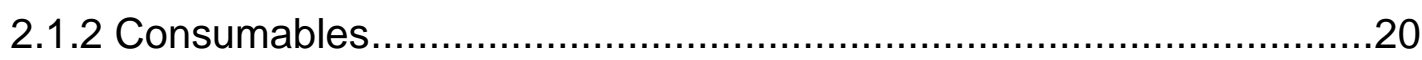

2.1.3 Chemicals and Reagents..........................................................21

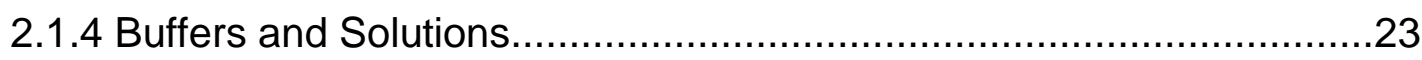

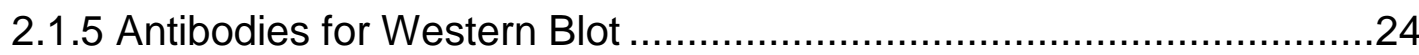

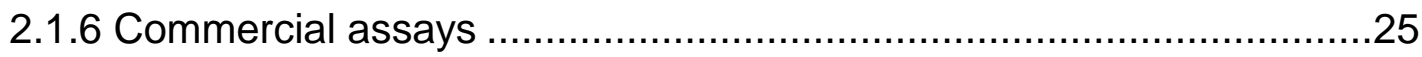

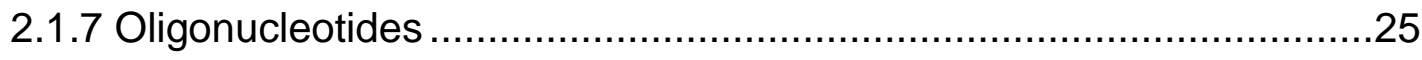

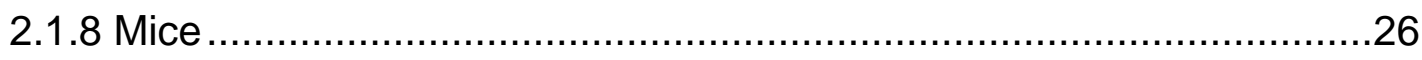

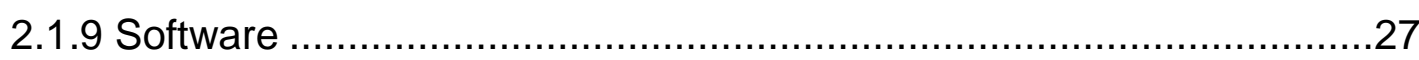




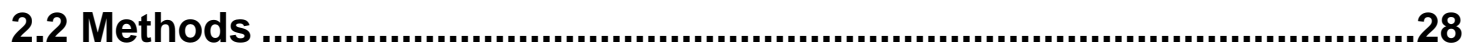

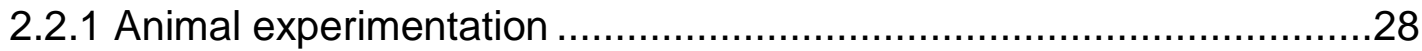

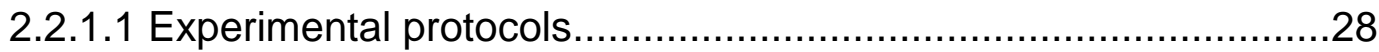

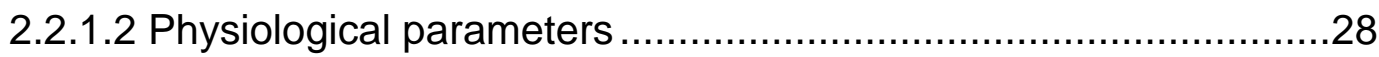

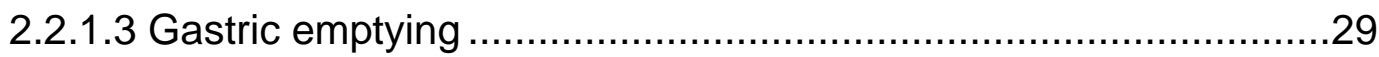

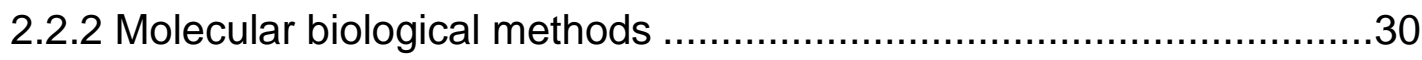

2.2.2.1 Isolation of total RNA from tissue samples................................30

2.2.2.2 Reverse transcription of RNA .................................................

2.2.2.3 Polymerase chain reaction ....................................................

2.2.2.4 Agarose Gel Electrophoresis ................................................32

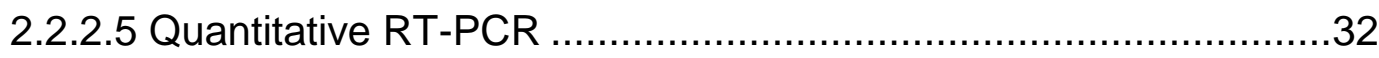

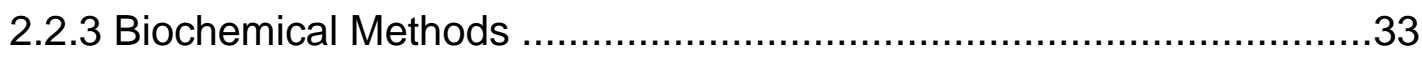

2.2.3.1 Preparation of protein lysates from tissue samples......................33

2.2.3.2 Measurement of protein concentration.........................................33

2.2.3.3 Polyacrylamide Gel Electrophoresis.........................................33

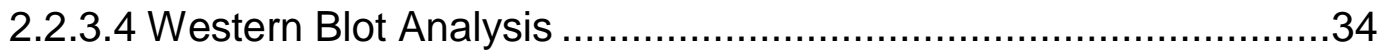

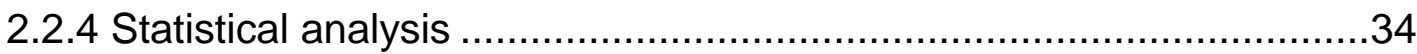

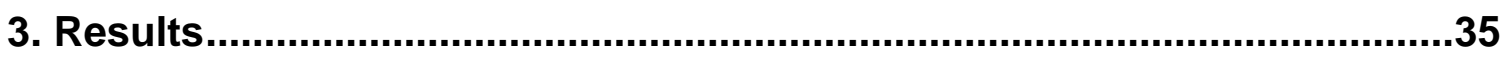

3.1 Oral administration of GCs induces gastroparesis.............................35

3.1.1 High-dose Dex treatment causes an enlargement of the stomach .....35

3.1.2 Dex administration impairs gastric emptying ..................................37

3.1.3 Increase in stomach weight induced by Dex is dose-dependent ........38

3.2 Target organ of GC-induced gastroparesis ..........................................39

3.2.1 Gastroparesis is preserved in $\mathrm{GR}^{\text {vilinCre }}$ mice.................................39

3.3 Molecular mechanism of GC-induced gastroparesis...........................40

3.3.1 $\mathrm{GC}$ treatment of $\mathrm{GR}^{\mathrm{dim}}$ mice does not induce gastroparesis ..............40

3.3.2 GC-induced gastric acid secretion does not influence gastroparesis .42

3.4 The role of macrophages in gastroparesis induction by GCs ............44

3.4.1 Dex-treatment results in altered macrophage polarization .................44

3.4.2 Altered macrophage polarization is not related to gastroparesis ........47

3.5. Role of genes specifically expressed in the gastrointestinal tract....49 
3.6. Role of genes related to the regulation of gastric motility .50

3.6.1 Expression of kallikrein 1, lipocalin 2 and arginase 2 in the stomach . 50

3.6.2 Role of Lcn2 in gastric motility .... .51

3.6.3 Role of Arg2 in gastroparesis .53

3.6.3.1 Regulation of genes related to NO production ...........................53

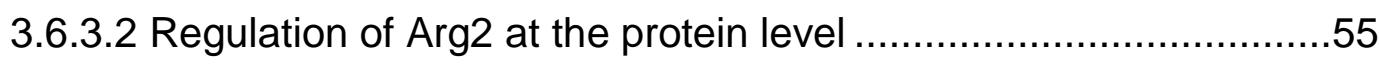

3.6.3.3 L-arginine supplementation prevents $\mathrm{GC}$-induced gastroparesis. 56

3.6.3.4 Inhibition of Arg2 only partially restores gastric emptying .59

4. Discussion .61

4.1 Adverse effects of glucocorticoids in the gastrointestinal tract. .61

4.2 The molecular mechanism of GCs in gastroparesis .63

4.3 The anti-emetic effect of GCs. .65

5. Summary .67

6. References .68

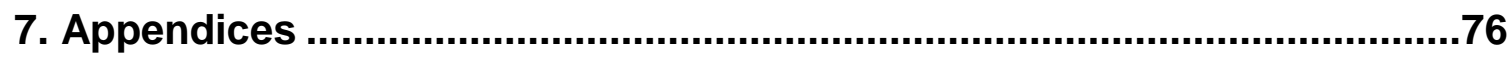

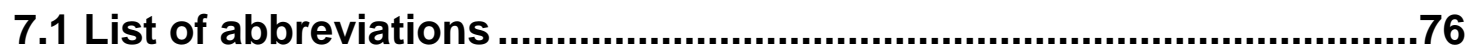

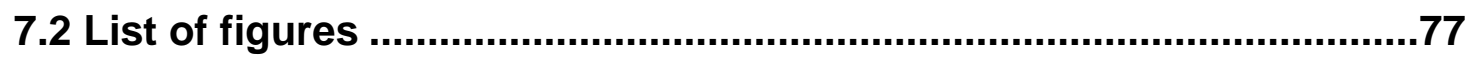

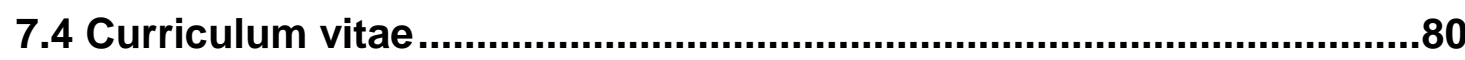




\section{Introduction}

\subsection{Glucocorticoids}

\subsubsection{Synthesis of endogenous glucocorticoids}

Cortisol was first isolated from extracts of the adrenal gland independently in the laboratories of Dr. E.C. Kendall and Dr. T. Reichstein as Compound E and Substance FA, respectively. The synthesis of endogenous glucocorticoids (GCs) is tightly regulated by the hypothalamus-pituitary-adrenal axis (HPA axis), which consists of the paraventricular nucleus (PVN) located in the hypothalamus of the brain, the anterior pituitary and the adrenal glands.

Stimulation of the PVN in the hypothalamus in response either to stress, physical activity, inflammation or the circadian rhythm leads to the secretion of corticotropin-releasing-hormone $(\mathrm{CRH})$, which in turn, stimulates the release of adrenocorticotropin hormone $(\mathrm{ACTH})$ from the anterior pituitary into the circulating bloodstream. Upon reaching the adrenal glands, ACTH then induces the synthesis and release of GCs.

The activity of HPA axis is mainly controlled by the central nervous system but also by other mechanisms including cytokines (Mulla and Buckingham, 1999). In addition, GCs regulate their homeostasis through a negative feedback loop that regulates the HPA axis on the level of the anterior pituitary and the hypothalamus (Webster and Sternberg, 2004; Webster et al., 2002).

\subsubsection{Structure and function of the glucocorticoid receptor}

Endogenous GCs play an important role in the regulation of metabolic, homeostatic, immunological and developmental processes. Both, endogenous GCs like cortisol and synthetic GCs like dexamethasone exert their function through binding to the glucocorticoid receptor (GR). 
The GR is a steroid hormone receptor and belongs to the nuclear receptor superfamily (Beato et al., 1995; Evans, 1988). The members of this family are characterized by a common structural pattern consisting of a variable $\mathrm{N}$-terminal region, a central DNA-binding domain (DBD) and a C-terminal ligand-binding domain (LBD) (Beato, 1989). The general structure of steroid hormone receptors is depicted in Figure 1.

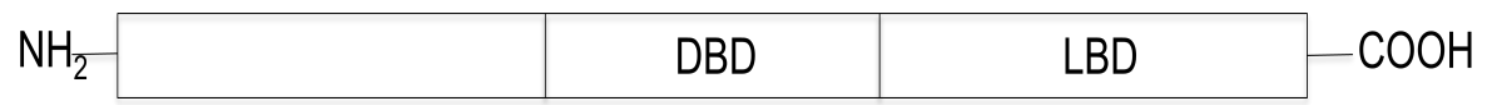

Figure 1. General structure of steroid hormone receptors.

Similar to other steroid hormone receptors, the DBD of the GR contains two zincfinger-motifs that allow for its dimerization at specific DNA-binding sites of GCresponsive genes that contain a palindromic DNA sequence, the so-called glucocorticoid response element (GRE) (Beato and Klug, 2000; Luisi et al., 1991).

Though being able to travel back and forth from the nucleus through the nuclear pore channel, the GR is, in the absence of ligand, mainly located in the cytoplasm (Vandevyver et al., 2013). There it is bound in a chaperone complex consisting of heat shock proteins (hsp90, hsp70) and immunophilins (such as FKBP51, FKBP52) (Pratt and Toft, 2003; Stancato et al., 1993) thus ensuring its stabilization and enabling the maturation to its hormone binding conformation (Cheung and Smith, 2000; Picard and Yamamoto, 1987). Upon ligand binding the GR undergoes a conformational change and translocates into the nucleus. Notably, this process is reversible and the GR translocates back to the cytoplasm upon substrate withdrawal (Freedman and Yamamoto, 2004).

Having entered the nucleus the GR can exert its function through two different mechanisms. The GR may dimerize at a GRE located in the promoter region of its target genes and thereby act in a DNA-binding dependent fashion (DahlmanWright et al., 1990; Schmid et al., 1989). With the help of co-activators, this generally leads to the enhanced transcription of GC-responsive target genes (Beato and Klug, 2000). 
Besides this so-called trans-activation mechanism there also exists a mechanism known as trans-repression, which is independent of dimerization and DNAbinding of the GR (Beato et al., 1995; Herrlich, 2001; Reichardt et al., 1998). Namely, the monomeric GR can interact with transcription factors such as AP-1 (Tuckermann et al., 1999) and NF-kB (Reichardt et al., 2001) in a tethering protein-protein interaction and thereby repress gene transcription. Both, the transactivation or DNA-binding dependent and the trans-repression or DNA-binding independent mechanism are depicted in Figure 2.

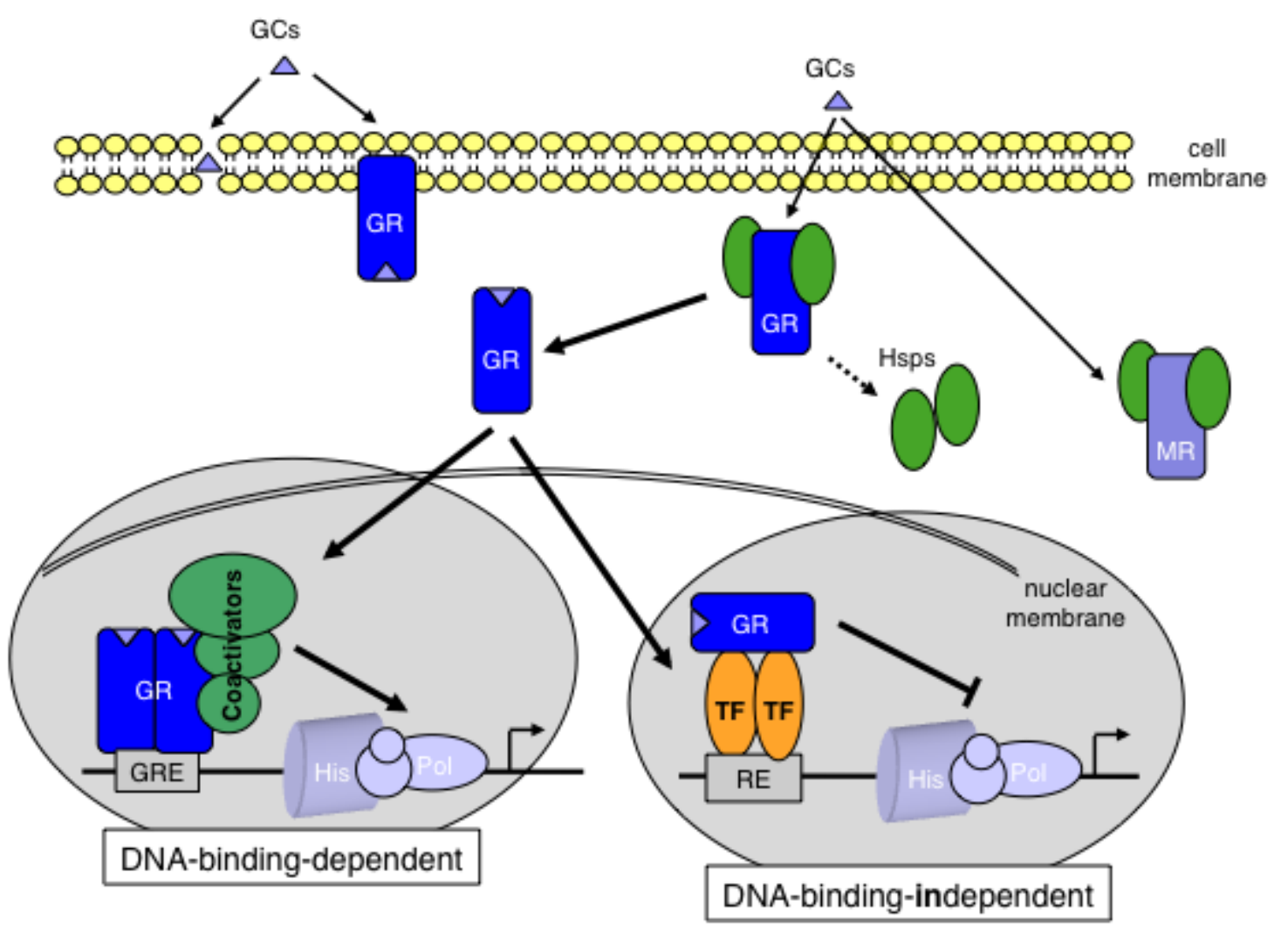

Figure 2. Mechanisms of GC action.

Upon GC binding the GR is released from the heat-shock protein complex (Hsps) and translocates into the nucleus. There it either dimerizes and binds to a GRE located in the promoter or enhancer region of GR target genes, which leads to gene transactivation after coactivator recruitment. Alternatively, the GR interacts as a monomer with other transcription factors (TF) bound to their respective regulatory elements (RE) and subsequently trans-represses gene expression. In both cases, chromatin comprised of DNA and histone proteins (His) needs to be unwinded and RNA polymerase II (Pol) recruited. Alternative modes of GC action include their binding to a membrane-bound GR or to the mineralocorticoid receptor (MR) located in the cytosol. 
Apart from the two aforementioned mechanisms that require the translocation of the GR from the cytoplasm into the nucleus followed by the assembly of a transcriptional complex and the initiation of gene expression (Cato et al., 2002), there also exist more rapid effects of GCs that are commonly referred to as nongenomic GC effects. They can either be mediated by the cytosolic GR or they may even occur at the level of the plasma membrane.

In the first case proteins that are released upon ligand binding from the dissembling heteromeric complex including Src have been found to be responsible for rapid GC effects through activation of signalling pathways such as the MAPKpathway (Croxtall et al., 2000). In the second case, rapid GC effects result from the interaction of GCs with membrane-associated proteins. It has been speculated that a membrane-bound form of the GR may exist and mediate some of the non-genomic activities of GCs. However, evidence for such a mechanism is still scarce.

Due to their lipophilic character GCs can easily attach to lipophilic membranes as well. Hence, besides acting though membrane-proteins GCs can influence the regulation of ion channels and interfere with intracellular calcium mobilization (Buttgereit and Scheffold, 2002; Stahn et al., 2007).

Finally, it is noteworthy that the GR is not the only receptor that is able to mediate physiological effects of GCs. There is also the mineralocorticoid receptor (MR) that can bind GCs thereby leading to the initiation of transcription. However, the MR is expressed in only a limited number of tissues and, in addition, binding of GCs to the MR in some tissues is prevented by a pre-receptor mechanism. Thus, GC effects mediated via the MR are largely restricted to the hippocampus and macrophages (Lim et al., 2007). 


\subsubsection{Beneficial and adverse effects of GCs}

Ever since their first successful isolation and the subsequent discovery of their potent anti-inflammatory properties by applying cortisol to a patient with rheumatoid arthritis (RA) in the year 1948, GCs have been the gold standard in the treatment of many inflammatory diseases, such as RA (Kirwan and Power, 2007), asthma (Adcock and Barnes, 2008) and inflammatory bowel disease (IBD) (Ford et al., 2011; Pithadia and Jain, 2011).

Besides their potent anti-inflammatory properties, GCs are also involved in the regulation of multiple non-immunological processes including the control of various metabolic, homeostatic, cardiovascular and developmental functions. Being expressed in almost every cell type the GR influences and controls multiple signalling pathways. Hence, when GCs are pharmacologically applied during antiinflammatory therapy, this pleiotropy can cause a plethora of potentially serious adverse effects.

In particular, the gastrointestinal tract is an example for the dichotomy of GC action. On the one hand, GCs have been the mainstay in the treatment inflammatory disorders of the bowel such as ulcerative colitis (UC) and Crohn's disease (CD) for over 50 years. On the other hand, it became more and more evident that prolonged application of GCs results in sometimes severe adverse effects such as hypertension, diabetes (Rose and Herzig, 2013), osteoporosis (Rauch et al., 2010) and the formation of peptic ulcers due to enhanced production of gastric acid (Sandu et al., 2007; Schubert, 2008). Especially orally administered GCs at high dose frequently cause pronounced gastrointestinal symptoms (Sellebjerg et al., 1998). Nevertheless, oral application of steroids can often be advantageous to the exhausting and costly intravenous therapy (Burton et al., 2012).

Then again, GCs are also known to possess anti-emetic properties and are widely used as a means to attenuate nausea and vomiting during chemotherapy although the underlying mechanisms remain unclear, so far (Tanihata et al., 2004). Taking into consideration that oral GCs are prescribed about 10 million times in the USA each year (Schäcke et al., 2002) and that there has been a continuous 
increase in GC prescriptions, it appears to be vital to make efforts to further elucidate the mechanistic details of GC action.

\subsubsection{Insights from animal models}

Multiple efforts have been made during the last two decades to mechanistically dissect the side-effects of GCs from their beneficial activities. Most antiinflammatory effects are being thought to be a consequence of inhibition of proinflammatory transcription factors and therefore mediated by the trans-repression mechanism of the GR. In contrast, many adverse effects, for instance those resulting from the induction of genes involved in glucose or protein metabolism, are mediated through trans-activation (De Bosscher and Haegeman, 2009).

To further investigate the molecular mechanism and function of the GR, several mutant mouse models have been developed. The first one was a strain of ubiquitous knock-out mice lacking the GR in all cell types. The mutants were found to die shortly after birth due to respiratory failure (Cole et al., 1995), indicating that GCs play a pivotal role during embryonic development. However, they weren't suitable for further studying the mode of action of GCs in adult mice.

By contrast, mice carrying the A458T point mutation in the second zinc finger of the DBD turned out to be viable and present a very useful model to discriminate between the trans-activation and the trans-repression mechanism of the GR (Reichardt et al., 1998). These so-called GR ${ }^{\text {dim }}$ mice have an impaired dimerization capacity and therefore reduced GR-induced trans-activation of genes. In contrast, trans-repression through interaction with other transcription factors is still intact. With the help of the $\mathrm{GR}^{\mathrm{dim}}$ mice it could be shown that the therapeutic efficacy of GCs in various disease models requires different molecular mechanisms. In a mouse model of irritative skin inflammation for example DNA-binding of the GR was not required for GC therapy. Contrariwise, it has been found that in a murine model of rheumatoid arthritis, dimerization of the GR was essential for GC therapy (Baschant et al., 2011). The same is true for the supression of septic shock by endogenous GCs in mice (Kleiman et al., 2012). With regard to 
common side-effects of GCs, results obtained in $\mathrm{GR}^{\text {dim }}$ mice weren't unequivocal as well. Induction of muscle atrophy for example was abolished in $\mathrm{GR}^{\text {dim }}$ mice and hence requires the DNA-binding function of the GR (Waddell et al., 2008), whereas GC-induced osteoporosis occurs normally in $\mathrm{GR}^{\mathrm{dim}}$ mice (Rauch et al., 2010). Consequently, adverse effects of GCs also involve various and complex mechanisms making their separation from the desired therapeutic effect a difficult task.

To determine the different cell types targeted by GCs, mouse models with cell type-specific depletions of the GR were developed. With the help of GR ${ }^{\text {lckcre }}$ mice, which lack the GR in the entire T cell-lineage (Baumann et al., 2005), it could be shown that therapeutic efficacy of GCs in experimental autoimmune encephalomyelitis (EAE), a rodent model of multiple sclerosis (MS), mainly depends on the repression of T cell function (Schweingruber et al., 2012; Wüst et al., 2008). In contrast, analysis of $\mathrm{GR}^{\text {lysMCre }}$ mice led to the conclusion that myeloid cells are the major target cells of GCs in contact dermatitis (Tuckermann et al., 2007).

$G^{\text {vilincre }}$ mice that specifically lack the GR in enterocytes of the intestinal tract (Madison et al., 2002) were used to tackle the question whether regulation of glucose uptake in the gut by GCs contributed to the development of hyperglycemia as one major side effect of GC therapy. Here it could be shown that the GR in enterocytes was indeed responsible for enhanced intestinal glucose transport mediated by transcriptional regulation of target genes via a dimerization dependent mechanism (Reichardt et al., 2012).

Taken together, the aforementioned studies made it clear that the concept of separating beneficial from adverse GC effects on the basis of the dependency on trans-activation versus trans-repression may not be entirely true and require further study.

\subsection{The stomach}




\subsubsection{Anatomy of the stomach}

The stomach is part of the digestive system and located in the upper half of the abdomen between the esophagus and the small intestine next to liver and spleen. It can be divided into four regions, namely the cardia, the fundus, the corpus or body and the pyloric antrum (Figure 3). Food enters the stomach through the esophagus into the cardia via the cardiac or lower esophagus sphincter. The central part of the stomach, the corpus or body is the place were chemical digestion takes place and the mixture of predigested food, the so-called chyme is transported to the lower portion of the stomach, the pyloric antrum where it leaves the stomach through the pyloric sphincter to enter the duodenum.

Located at the uppermost part of the stomach lies the fundus. Due to its ability to relax and expand it can accommodate excessive food and provide space for the gas produced during digestion, therefore preventing an increase in intragastric pressure. Gastric folds or rugae in the inner wall of the stomach allow for expansion of its surface when needed. In order to protect the stomach against gastric juices that are produced during the digestion process and which mainly consist of hydrochloric acid and pepsins, its inside is protected by mucus.

The stomach wall itself consists of four layers, the innermost being called the mucosa followed by the submucosa, the muscularis externa and the serosa. Towards the lumen the mucosa is lined with epithelial cells. Loose connective tissue, the lamina propria seperates the epithelium from a smooth muscle layer beneath. The submucosa consists of connective tissue and is surrounded by the muscular wall of the stomach that comprises three layers of muscular tissue. First, the inner oblique layer that mechanically breaks up the food by churning. Second, a circular layer that prevents the backward movement of the chyme by creating circular contractions. Third, the longitudinal layer that ensures the forward movement of the stomach content.

Essential for the transportation of food through the stomach to the duodenum are contractive movements of the gastric muscles. The so-called peristalsis consists of permanent contraction and relaxation of the gastric smooth muscle layer to produce a wavelike movement. 


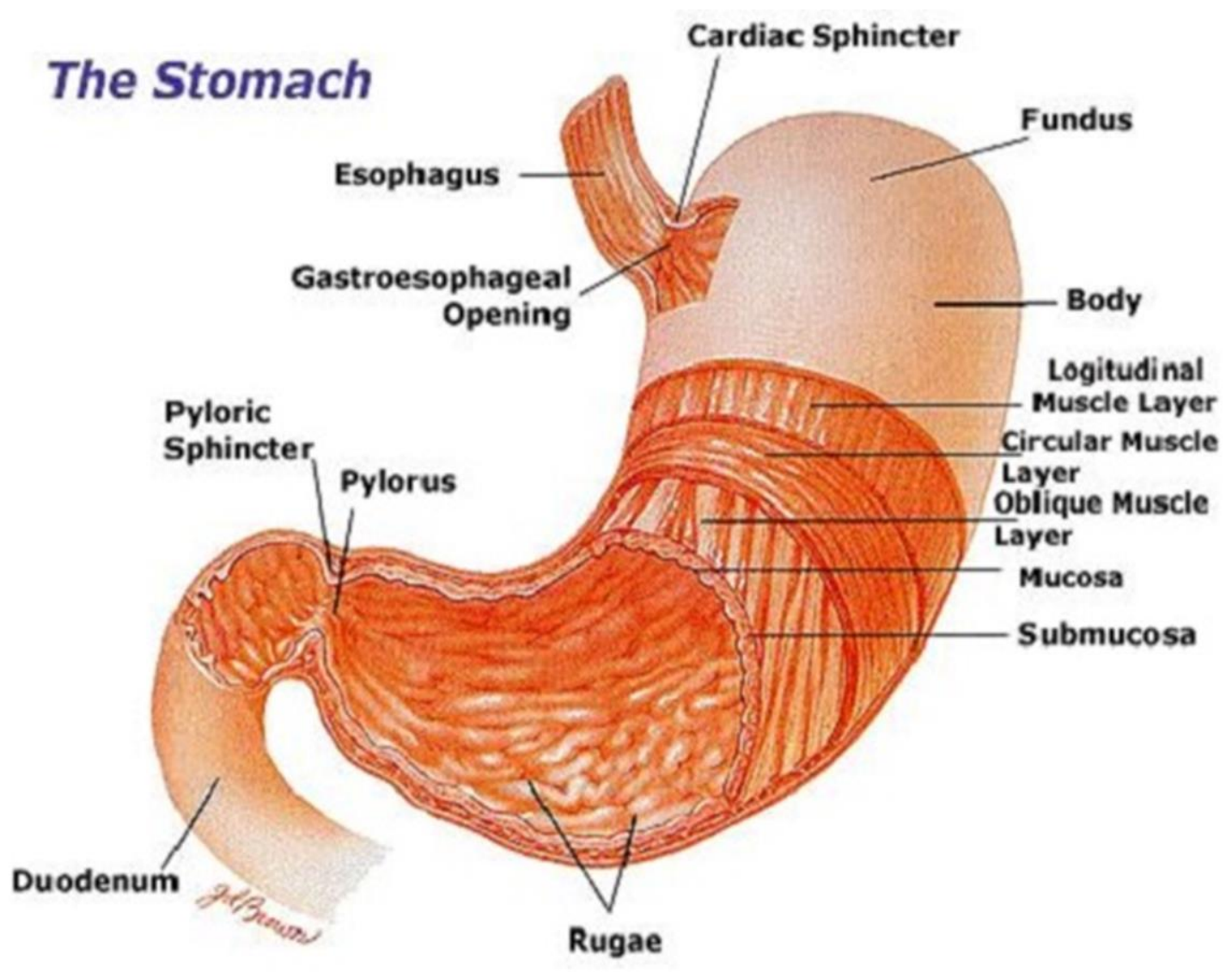

\section{Figure 3. Anatomy of the stomach}

The stomach is divided into for parts: the cardia with the cardiac sphincter, through which food from the esophagus enters the stomach and is accommodated in the fundus. In the corpus the stomach content is predigested and moved onwards to the pyloric antrum before the chyme is released into the duodenum via the pyloric sphincter. The stomach wall comprises three muscular layers, a longitudinal, a circular and an inner oblique layer that is separated from the mucosa by connective tissue. To allow expansion of its surface the mucosa is folded in rugae (adapted from Universalhealthcarela.com).

\subsubsection{The movement of the stomach}


Since the time of Galenos, a Greek physician and scientist living in the second century $A D$, it remained unclear until the $19^{\text {th }}$ century how the movements of the stomach exactly come to pass. Galenos was the first to divide the stomach into four parts and to assign to them the different functions of reception and accommodation of food followed by its digestion and passing on of the modified content into the small intestine (Claudii Galeni opera omnia, Kühn, 1822). It was long believed that the pylorus being a gatekeeper was the crucial player in all the functions of the stomach, ranging from retaining the food, digesting it and finally releasing it into the duodenum.

In the middle of the $18^{\text {th }}$ century in his opus "elementa physiologiae corporis humani" Albrecht von Haller defined the movements of the stomach as an alternation between relaxation and contraction in longitudinal or transverse compressions so that the stomach content is shifted around until either the cardia or the pylorus opens. In the first case food is expelled from the stomach by vomiting whereas in the latter case the chyme enters into the duodenum. Notably, either procedure, the expulsion of stomach contents by vomiting or its transfer to the small intestine, requires a controlled movement of the gastric muscles.

In the years between 1822 and 1833, William Beaumont, an US army surgeon, performed experiments on digestion on his patient Alexis St. Martin who lived with a permanent gastric fistula since when he had recovered from a gunshot in his side. By inserting a tube into the lateral hole of his patient, he was able to deduce the motions of the stomach muscles from the movements of the tube.

In the late $19^{\text {th }}$ century W.B. Cannon decided to further investigate gastric motion with the help of roentgen rays. He therefore mixed food with bismuth oxynitrate and after feeding this mixture to cats he detected the movement of this mass through the stomach by roentgen rays. Using this method he could confirm the earlier findings, namely that the stomach content is mixed and passed forward by constriction waves continually arising and subsiding in the pyloric part of the stomach whereas the function of the fundus is primarily the accommodation of food. Nevertheless, the astonishing new finding was the impact of strong emo- 
tions on gastric peristalsis. Because Cannon had to immobilize the cats during the entire procedure and since male animals didn't tolerate this measure calmly, he observed that strong emotions completely inhibit the motoric gastric function. Having made this observation he performed several other experiments in which he distressed the animals for a brief period of time thus causing the constriction waves to subside. By stroking the animal reassuringly the stomach movements immediately set in again thus proving the extent of nervous influence on gastric motility (Cannon, 1898).

Today it is known that stomach motility is mainly controlled by an autonomic nervous system consisting of an extrinsic (i.e. the vagus nerve) and intrinsic (i.e. the enteric nervous system) innervation pathways (Olsson and Holmgren, 2001).

\subsubsection{Gastric emptying and gastroparesis}

Gastric emptying is a process that normally takes place without noticing. If food enters the stomach a variety of signals regulate the process of gastric emptying that begins with the adaptive accommodation reflex which enables the intake of food without increasing intragastric pressure (Cannon and Lieb, 1911). This is followed by trituration and digestion of the stomach content to produce chyme that is then released through the pyloric sphincter into the small intestine.

To ensure proper functioning of this complex procedure the gut is equipped with an intrinsic nervous system that is located in the lining of the gastrointestinal tract. The neurons of the enteric nervous system (ENS) are collected into the myenteric plexus located in the muscularis externa and the submucosal plexus. Capable of local and autonomous functioning the ENS continuously exchanges information back and forth with the central nervous system (CNS) thus controlling the digestive process (Furness, 2006; Gershon, 2005).

The peristalsis of the stomach is a prerequisit for proper gastric emptying. The wave-like movement of the stomach results from excitatory and inhibitory signals that alternately induce contraction and relaxation of the gastric muscles and in- 
volves several different cell types, like motor neurons, smooth muscle cells and the interstitial cells of Cajal (ICC). Both extrinsic and enteric nerves work in concert to stimulate the gastric muscles together with ICC. The latter are spindle formed cells that have been shown to participate in the signal transduction from the nerve endings to the smooth muscle cells (Sanders, 1996). Figure 4 illustrates the interaction of different cell types involved in the signal transduction that governs gastric motility.

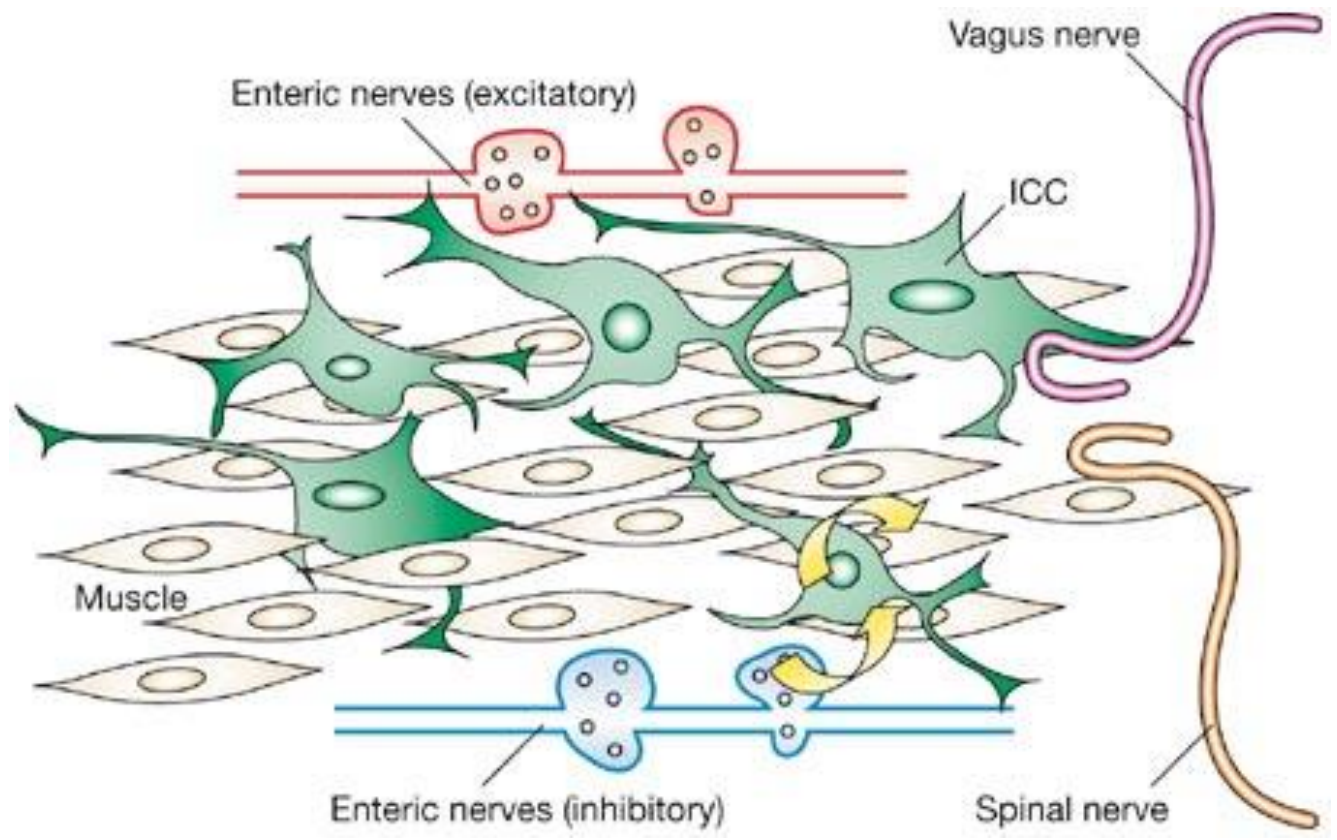

Figure 4. Cells types involved in gastric motility.

Excitatory and inhibitory signals from enteric nerves are transmitted to smooth muscle cells with the help of interstitial cells of Cajal. The vagus and spinal nerve are two types of extrinsic nerves (Vittal et al., 2007).

Even though we are generally not aware of our stomach functions, any malfunction of the digestive process can cause severe discomfort and symptoms ranging from early satiety and stomach pressure to nausea, vomiting and abdominal pain. Although these symptoms apply to various gastrointestinal diseases like gastric ulcer, functional dyspepsia or gastritis, they often correlate with gastroparesis, a disorder of the stomach defined as impaired gastric emptying without mechanical obstructions (Parkman et al., 2004). 
Kassander was the first one to describe impaired gastric emptying as a sideeffect of diabetes (Kassander, 1958) but there is also a large number of patients that suffer from idiopathic gastroparesis. Taking into consideration the complexity of the process of gastric emptying and the many different cell types involved, it is not astonishing that until today the mechanisms of gastroparesis remain partially unclear. There is, however, some evidence that the inhibitory signals of the ENS are responsible for impaired gastric emptying. In particular the neurotransmitters used to mediate the inhibitory nervous signals have recently come into focus. Especially nitric oxide (NO), a small reactive molecule produced by nitric oxide synthase (NOS), an enzyme that is found in inhibitory motor neurons of the ENS, has been shown to play a crucial role in gastroparesis (Rivera et al., 2011; Vittal et al., 2007).

\subsubsection{Effects of GCs on the stomach}

Elevated levels of GCs can lead to enhanced gastric acid secretion and thereby increase the risk of peptic ulcers and bleeding (Cooke et al., 1966; Gray et al., 1951; Hernandez-Diaz and Rodriguez, 2001). Until today the underlying mechanism of this effect is poorly understood. Apart from the stimulation of gastric acid production and inhibition of gastroprotective enzymes like prostaglandin synthetase and peroxidase (Bandyopadhyay et al., 1999) other mechanisms have been proposed including the regulation of genes that take part in the control of energy homeostasis and metabolism.

As mentioned before GCs play a major role in the control of metabolic and homeostatic processes. In response to stress factors such as infection, serum levels of GCs become elevated and foster gluconeogenesis, glycolysis, proteolysis and lipolysis thus activating the energy resources of the organism. In this context, the role of serum and glucocorticoid inducible kinase (SGK), a GCresponsive gene that is highly expressed in gastric tissue, has been explored lately. It has been found that the up-regulation of SGK by GCs enhances gastric acid secretion via the regulation of several transport proteins (Sandu et al., 
2007). However, such an effect is true only for the pharmacological application of GCs. Contrariwise, endogenous GCs have been found to exert rather gastroprotective effects. Namely, induction of corticosterone secretion either by stress or the application of nonsteroidal anti-inflammatory drugs (NSAIDs) can even protect against ulcerogenic actions by increasing mucus production (Filaretova et al., 2002) or reducing gastric hypermotility (Takeuchi et al., 1989).

\subsection{Properties and functions of NO}

\subsubsection{NO as a signaling molecule}

$\mathrm{NO}$ is a highly reactive volatile molecule that naturally occurs as a free radical. Upon contact with water and oxygen it reacts to nitrous acid and is oxidized in air to nitrogen dioxide, a toxic gas. It is therefore not astonishing that when it was first reported to be the substance responsible for nervous transmission of smooth muscle relaxation many scientists remained skeptic about this revelation. Nonetheless, for Robert Furchgott, Louis Ignarro and Ferid Murad it led to the award of the Nobel Prize in Physiology or Medicine in 1998 "for their discoveries concerning nitric oxide as a signaling molecule in the cardiovascular system" (www.nobelprize.org/nobel_prizes/medicine/laureates/1998/). While it was already known that a substance called by then the "endothelial derived relaxing factor" or EDRF was essential for vascular smooth muscle relaxation, they where able to identify this substance as being NO.

Today it is well known that NO plays a key role in the neurotransmission of the central and the peripheral nervous system. One of its key functions in the peripheral nervous system is the regulation of muscle contractility by inducing smooth muscle relaxation. Due to its ephemeral and volatile character it has to be produced on demand and in close vicinity to the recipient smooth muscle cells. It is therefore synthesized at nerve endings from where it diffuses to adjacent cells (Esplugues, 2002).

As a small-sized molecule NO can easily permeate cell membranes to reach its intracellular targets. The major target protein for neuronal NO is soluble guanylyl 
cyclase (sGC) (Esplugues, 2002) which is activated by nitrosylation of its hemegroup. The activation of SGC leads to an increase in intracellular cyclic guanosin monophosphate (cGMP) levels which, in turn, leads to a decrease in intracellular calcium levels and therefore to muscle relaxation (Gangula et al., 2011).

In contrast to other known neurotransmitters there is no need to degrade NO enzymatically in order to terminate its signalling function, as it is rather bound to inactivate itself having reached and reacted with its target (Esplugues, 2002). On the other hand, this fact leaves NO synthesis as the only regulatory mechanism available to control its functional activity.

\subsubsection{NO synthesis}

$\mathrm{NO}$ is synthesized from nitric oxide synthase (NOS) by conversion of its substrate L-arginine to citrulline and NO (Stuehr, 1997). There are three different isoforms of NOS, namely endothelial NOS (eNOS), neuronal NOS (nNOS) and inducible NOS (iNOS). Whilst iNOS expression is almost absent under normal physiological conditions and up-regulated mainly in response to inflammatory signals, the two other isoforms are expressed constitutively (Mungrue et al., 2003).

The main function of eNOS, which is expressed in endothelial cells, is the regulation of the cardiovascular system (Andrew and Mayer, 1999). In contrast, nNOS plays a major role in neuronal signalling in non-adrenergic non-cholinergic (NANC) nerves. Being expressed in peripheral nitrergic nerves, an important function of nNOS is to produce $\mathrm{NO}$ as a signalling molecule to induce smooth muscle relaxation (Esplugues, 2002). All three isoforms of NOS are solely active as homodimers and need the assistance of cofactors such as heme, tetrahydrobiopterin and flavin adenin dinucleotide for the biosynthesis of NO (Andrew and Mayer, 1999).

Although the exact mechanism of NO production remains unclear, the proposed mode of action involves the formation of the intermediate $N^{\omega}$-hydroxy-L-arginine 
and requires nicotinamide-adenin-dinucleotide phosphate as an electron donor (Marletta, 1993). Figure 5 shows the reaction equation for NO biosynthesis.<smiles>N=C(N)NCCCC(N)C(=O)O</smiles>

L-arginine

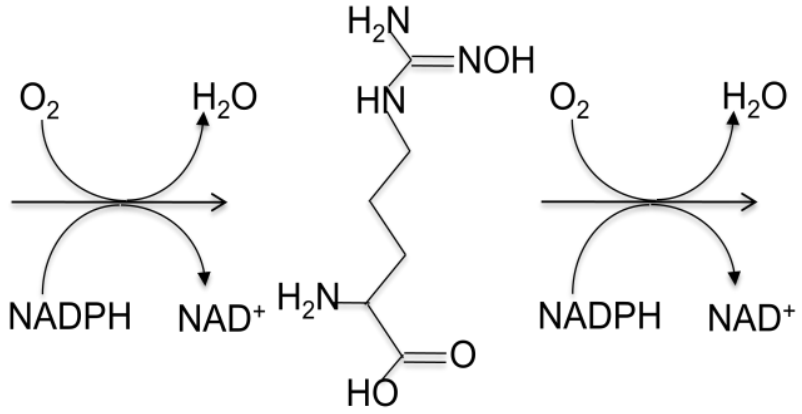

L-N ${ }^{\omega}{ }^{\omega}$-hydroxyarginine

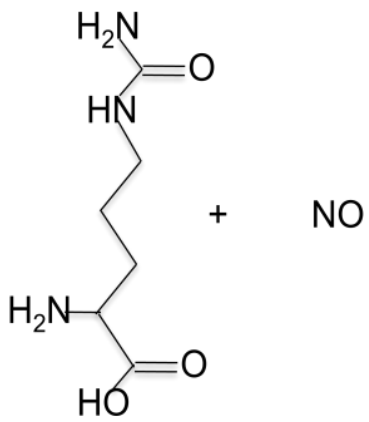

L-citrulline Nitric oxide

Figure 5. Proposed mechanism of NO synthesis.

Oxidation of L-arginine to citrulline and simultaneous production of NO.

As mentioned above the only regulatory mechanism for NO signalling is the control of its biosynthesis. Several arginine derivatives are known to act as inhibitors for NOS. $\mathrm{N}^{\omega}$-monomethyl-L-arginine (LNMA) and L- $\mathrm{N}^{\omega}-\mathrm{N}^{\omega}$-dimethylarginine are naturally occurring amino acids that inhibit NOS by competing with $L$-arginine for the binding site of NOS.

Noteworthy, the substrate L-arginine is not only used for the production of NO from NOS but also by arginase 1 and 2 to produce ornithine which in turn serves as a substrate for ornithine decarboxylase (Odc) in the synthesis of polyamines. High levels of arginase 1 or 2 therefore lead to low substrate availability for NOS. Hence a potential regulatory effect on NO synthesis has been postulated for arginase (Wu and Morris, 1998). 


\subsubsection{Role of NO in gastric motility}

The peristalsis of the stomach is a complex process that is initiated upon food uptake via vagal stimulation. Its main function is to churn the stomach content and to move it forward towards the pylorus. The wave-like movement that is created from alternating constriction and relaxation of the different smooth muscle layers of the stomach is controlled by motoric neurons.

The pivotal role of NO for gastric motility was first demonstrated for the adaptive accommodation reflex that allows for the intake of large volumes of food without increase in intragastric pressure (Cannon and Lieb, 1911). It was shown that relaxation of the stomach upon vagal stimulation is transmitted via NANC nerves using NO as neurotransmitter (Abrahamsson and Jansson, 1969; Wilbur and Kelly, 1973). Moreover, the gastric emptying of solid meals was found to be profoundly reduced upon inhibition of nNOS (Orihata and Sarna, 1994).

A central role of NO for diabetic gastroparesis was proposed after several studies employing animal models of diabetes revealed a reduced nNOS expression and activity in the gastric myenteric plexus (Takahashi et al., 1997). In addition, it was found that diabetic patients suffering from gastric stasis exhibited low levels of NO and nNOS.

The generation of nNOS knock-out mice has offered the opportunity to study the role of this enzyme on gastric emptying. It was found that these mice have a crossly enlarged stomach and exhibit impaired emptying of solids and liquids (Mashimo et al., 2000).

Altogether these studies revealed the significance of NO as a crucial factor for proper functioning of gastric motility. 


\subsection{Aim of the study}

Since the discovery of their potent anti-inflammatory properties GCs have been the mainstay in the therapy of autoimmune diseases, such as RA, IBD, asthma and MS. Nonetheless, prolonged application or high-dose GC therapy can often lead to severe adverse effects like osteoporosis, muscle atrophy, diabetes or gastric ulcer. Especially the oral application of GCs that has some advantages over intravenously applied GC therapy causes severe gastrointestinal symptoms thus seriously affecting the quality-of-life of the patients. On the other hand GCs are known to possess anti-emetic potential and are therefore widely used to treat chemotherapy induced nausea and vomiting (CINV). The underlying mechanism of this effect, however, is yet unknown. The aim of this study was therefore to investigate the impact of oral GC therapy on the stomach and to further elucidate the mode of GC action in the stomach. For this purpose I employed several experimental approaches utilizing different mutant mouse strains in order to discover mechanism and targets of GC function. Since GCs are as yet indispensable for the therapy of many inflammatory disorders and the prescription of oral GCs is continuously increasing a more detailed knowledge might provide a means to reduce side-effects of GC therapy in the future. 


\section{Material and Methods}

\subsection{Materials}

\subsubsection{General equipment}

Table 1. General equipment

Accu-jet ${ }^{\circledR}$ pro pipette controller

Arium ${ }^{\circledR} 611$ laboratory water

Purification system

Balance TE $313 S$

Balance Acculab ALC 3100.2

Balance MC1 RC 210 P-0D1

Chemo Cam Imaging System

Centrifuge 5417R

Centrifuge 5804

Centrifuge multifuge $4 \mathrm{KR}$

Centrifuge Sigma 2-5

Electrophoresis chambers

Type 40-0708, 40-1214, 40-1410

Electrophoresis chamber

Mini-PROTEAN Tetra Cell

Electrophoresis power supply 301

Electrophoresis power supply

PowerPac Basic

Electrophoresis transfer unit

SEMIPHOR TRANSPHOR

Freezer Hera freeze $-80^{\circ} \mathrm{C}$

Freezer Liebherr Comfort $-20^{\circ} \mathrm{C}$
Brand GmbH + CO KG, Wertheim, Germany

Sartorius AG, Göttingen, Germany

Sartorius AG, Göttingen, Germany

Sartorius AG, Göttingen, Germany

Sartorius AG, Göttingen, Germany

Intas Science Imaging Instruments $\mathrm{GmbH}$,

Göttingen, Germany

Eppendorf, Hamburg, Germany

Eppendorf, Hamburg, Germany

Heraeus, Hanau, Germany

Sigma Laborzentrifugen $\mathrm{GmbH}$,

Osterode am Harz, Germany

Peqlab Biotechnology $\mathrm{GmbH}$,

Erlangen, Germany

BioRad Laboratories $\mathrm{GmbH}$, München, Germany

Amersham Biosciences, Freiburg,

Germany

BioRad Laboratories $\mathrm{GmbH}$, München,

Germany

Amersham Biosciences, Freiburg, Germany

Heraeus, Hanau, Germany

Liebherr-International Deutschland GmbH, Biberach an der Riß, Germany 
Micropipette $2 \mu \mathrm{l}, 20 \mu \mathrm{l}, 200 \mu \mathrm{l}, 1000 \mu \mathrm{l} \quad$ Gilson, Middleton,WI, USA

PCR Mastercycler EP Gradient

pH-Meter 766 Calimatic

Photometer Biophotometer

Photometer Nanodrop 2000

7500 Real Time PCR System

Thermomixer comfort

Ultra Turrax IKA ${ }^{\circledR} 18$ basic

UV Transilluminator and Camera system

Vortex Genie-2

Water Bath W 12
Eppendorf, Hamburg, Germany

Knick Elektronische Messgeräte

GmbH\&Co. KG, Berlin, Germany

Eppendorf, Hamburg, Germany

Peqlab Biotechnology $\mathrm{GmbH}$,

Erlangen, Germany

Applied Biosystems, Foster City, CA, USA

Eppendorf, Hamburg, Germany

IKA®-werke GmbH\&Co.KG,

Staufen, Germany

Intas Science Imaging Instruments Gmbh,

Göttingen, Germany

Scientific Industries, Bohemia, NY, USA

Labortechnik Medingen, Dresden, Germany

\subsubsection{Consumables}

Table 2. Consumables

Animal feeding needles $20 \mathrm{G} \times 1,5$ " CryoTube ${ }^{\mathrm{TM}}$ Vials

Disposable cuvettes semi-micro, $1,5 \mathrm{ml}$

Falcon tubes $15 \mathrm{ml}, 50 \mathrm{ml}$

Fine Science Tools, Foster City, CA, USA Nunc, Roskilde, Denmarc

Brand GmbH + CO KG, Wertheim, Germany

Greiner Bio-One GmbH, Frickenhausen Germany

Glass pipettes $5 \mathrm{ml}, 10 \mathrm{ml}$

Brand GmbH + CO KG, Wertheim, Germany

Hybond ECL blotting membrane Amersham Biosciences, Freiburg, Germany

Pipette tips $2 \mu \mathrm{l}, 20 \mu \mathrm{l}, 200 \mu \mathrm{l}, 1000 \mu \mathrm{l} \quad$ Greiner Bio-One GmbH, Frickenhausen, Germany

PCR tubes

Sarstedt, Nürnbrecht, Germany

PCR-plate 96 well, half skirted

Greiner Bio-One GmbH,

Frickenhausen, Germany 
Reaction tubes $1,5 \mathrm{ml}, 2 \mathrm{ml}$

Optical adhesive covers

Whatman ${ }^{\circledR}$ Gel blotting paper

GB005

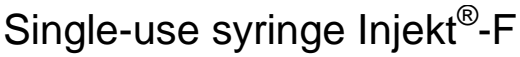

\subsubsection{Chemicals and Reagents}

Table 3. Chemicals and Reagents

Acetic acid glacial

Agarose UltraPure

Ammonium persulphate (APS)

L-Arginine

(S)-(2-Boronoethyl)-L-cystein (BEC)

Bovine serum albumin (BSA)

Bradford reagent

Bromophenol blue

Chloroform

p-Coumaric acid

Dexamethasone, water soluble

Diethyl pyrocarbonate (DEPC)

Dimethyl sulfoxide (DMSO)

DNA ladder $1 \mathrm{~kb}$

Ethylenediaminetetraacetate (EDTA)

Ethanol

Ethidiumbromide

Glycine

Hydrogen peroxide $30 \%$

Igepal ${ }^{\circledR}$ CA-630

Iron(II) gluconate hydrate

Luminol
Greiner Bio-One GmbH

Applied Biosystems, Foster City, CA, USA

Sigma-Aldrich, Taufkirchen, Germany

B.Braun, Melsungen, Germany
Carl Roth, Karlsruhe, Germany

Invitrogen, Carlsbad, CA, USA

Sigma-Aldrich, Taufkirchen, Germany

Sigma-Aldrich, Taufkirchen, Germany

Merck KGaA, Darmstadt, Germany

Carl Roth, Karlsruhe, Germany

Sigma-Aldrich, Taufkirchen, Germany

Merck KGaA, Darmstadt, Germany

Sigma-Aldrich, Taufkirchen, Germany

Sigma-Aldrich, Taufkirchen, Germany

Sigma-Aldrich, Taufkirchen, Germany

Sigma-Aldrich, Taufkirchen, Germany

Carl Roth, Karlsruhe, Germany

Fermentas GmbH, St-Leon-Rot, Germany

Sigma-Aldrich, Taufkirchen, Germany

Carl Roth, Karlsruhe, Germany

Carl Roth, Karlsruhe, Germany

Sigma-Aldrich, Taufkirchen, Germany

Carl Roth, Karlsruhe, Germany

Sigma-Aldrich, Taufkirchen, Germany

Sigma-Aldrich, Taufkirchen, Germany

Serva Electrophoresis $\mathrm{GmbH}$, Heidelberg,

Germany 
$\beta$-Mercaptoethanol

Methyl cellulose

dNTP-Mix, PCR

pfuS DNA polymerase

Phenol Red

5x Phusion® Reaction Buffer HF

Potassium chloride

Potassium dihydrogen phosphate

Potassium hydrogen carbonate

Prestained protein marker, broad range

2-Propanol

Orange $G$

Protease Inhibitor Cocktail

Rotiphorese ${ }^{\circledR}$ Gel 30

Trichloroacetic acid

Tris Pufferan $\AA$

Sodium azide

Sodium carbonate

Sodium chloride

Sodium fluoride

Sodium hydroxide

Sodium laurylsulphate/SDS

Sodium molybdate

Sodium orthovanadate

di-Sodium hydrogen phosphate dodecahydrate

Tetramethylethylenediamine (TEMED)

Tetrasodium pyrophosphate Tween-20
Carl Roth, Karlsruhe, Germany

Sigma-Aldrich, Taufkirchen, Germany

Genaxxon Bioscience, Ulm, Germany

own production

Sigma-Aldrich, Taufkirchen, Germany

Thermo Scientific, Waltham, MA, USA

Merck KGaA, Darmstadt, Germany

Merck KGaA, Darmstadt, Germany

Merck KGaA, Darmstadt, Germany

New England Biolabs GmbH,

Frankfurt a.M., Germany

Carl Roth, Karlsruhe, Germany

Sigma-Aldrich, Taufkirchen, Germany

Sigma-Aldrich, Taufkirchen, Germany

Carl Roth, Karlsruhe, Germany

Merck KgaA, Darmstadt, Germany

Carl Roth, Karlsruhe, Germany

Sigma-Aldrich, Taufkirchen, Germany

Merck KGaA, Darmstadt, Germany

Merck KGaA, Darmstadt, Germany

Merck KgaA, Darmstadt, Germany

Sigma-Aldrich, Taufkirchen, Germany

Carl Roth, Karlsruhe, Germany

Sigma-Aldrich, Taufkirchen, Germany

Sigma-Aldrich, Taufkirchen, Germany

Sigma-Aldrich, Taufkirchen, Germany

Carl Roth, Karlsruhe, Germany

Sigma-Aldrich, Taufkirchen, Germany

Carl Roth, Karlsruhe, Germany 


\subsubsection{Buffers and Solutions}

$\underline{\mathrm{PBS}, \mathrm{pH} 7,3}$

$$
\begin{array}{rl}
80 \mathrm{~g} & \mathrm{NaCl} \\
29 \mathrm{~g} & \mathrm{Na}_{2} \mathrm{HPO}_{4} \times 12 \mathrm{H}_{2} \mathrm{O} \\
2 \mathrm{~g} & \mathrm{KCl} \\
2 \mathrm{~g} & \mathrm{KH}_{2} \mathrm{PO}_{4} \\
\text { ad } 1000 \mathrm{ml} & \mathrm{ddH}_{2} \mathrm{O}
\end{array}
$$

Blotting Buffer

$$
\begin{array}{rl}
2,93 \mathrm{~g} & \text { Glycine } \\
0,58 \mathrm{~g} & \text { Tris } \\
0,375 \mathrm{~g} & \mathrm{SDS} \\
0,1 \mathrm{~g} & \mathrm{NaN}_{3} \\
200 \mathrm{ml} & \text { Methanol } \\
\text { ad } 1000 \mathrm{ml} & \mathrm{ddH}_{2} \mathrm{O}
\end{array}
$$

$\underline{\text { Western Blot Washing Buffer }}$

PBS

$+\quad 0,1 \%$ Tween

$\underline{\text { Western Blot Blocking Buffer }}$

$$
\begin{aligned}
& \text { PBS } \\
+ & 5 \% \text { BSA } \\
+ & 0,1 \% \text { Tween }
\end{aligned}
$$

RadiolmmunoPrecipitation Assay (RIPA) Buffer, $\mathrm{pH} 7,4$

$$
\begin{array}{rl}
8,77 g & \mathrm{NaCl} \\
1,46 \mathrm{~g} & \text { EDTA } \\
1,24 \mathrm{~g} & \text { Tris } \\
0,45 \mathrm{~g} & \mathrm{Na}_{4} \mathrm{P}_{2} \mathrm{O}_{7} \times 10 \mathrm{H}_{2} \mathrm{O} \\
0,42 \mathrm{~g} & \mathrm{NaF} \\
\text { ad } 1000 \mathrm{ml} & \text { dd H}_{2} \mathrm{O}
\end{array}
$$

Protein Lysis Buffer

$$
\begin{array}{rl}
500 \mu \mathrm{l} & 2 \times \mathrm{RIPA} \text { Buffer } \\
100 \mu \mathrm{l} & \mathrm{NP} 40,10 \% \\
25 \mu \mathrm{l} & \text { Protease Inhibitor } \\
20 \mu \mathrm{l} & \mathrm{Na}_{3} \mathrm{VO}_{4} 50 \mathrm{mM} \\
1 \mu \mathrm{l} & \mathrm{Na}_{3} \mathrm{MO}_{4} 10 \mathrm{mM} \\
354 \mu \mathrm{l} & \mathrm{dd}_{2} \mathrm{O}
\end{array}
$$

NP40, 10\%

$$
\begin{array}{ll}
5 \mathrm{ml} & \text { Igepal CA-630 } \\
45 \mathrm{ml} & \mathrm{dd}_{2} \mathrm{O}
\end{array}
$$

$\underline{\text { TAE Buffer }}$

$$
\begin{aligned}
4,8 \mathrm{~g} & \text { Tris } \\
1,1 \mathrm{~g} & \text { Acetic acid glacial } \\
0,29 \mathrm{~g} & \text { EDTA } \\
\text { ad } 1000 \mathrm{ml} & \mathrm{H}_{2} \mathrm{O}
\end{aligned}
$$


$\underline{\text { Laemmli Buffer }}$

20ml Glycerine

$20 \mathrm{ml}$ SDS, $10 \%$

6,25ml 1M Tris- $\mathrm{HCl}, \mathrm{pH} 6,8$

$5 \mathrm{ml} \beta$-Mercaptoethanol

$5 \mathrm{ml}$ Bromophenolblue 0,5\% ad $100 \mathrm{ml} \quad \mathrm{ddH}_{2} \mathrm{O}$

Western Blot Lower Buffer, $\mathrm{pH} 8,8$

$$
\begin{aligned}
90 \mathrm{~g} & \text { Tris } \\
20 \mathrm{ml} & \text { SDS, } 10 \% \\
\text { ad } 500 \mathrm{ml} & \mathrm{ddH}_{2} \mathrm{O}
\end{aligned}
$$

Western Blot Staining solution A

250mg Luminol

ad $1000 \mathrm{ml} \quad 0,1 \mathrm{M}$ Tris, $\mathrm{pH} 8,6$

Development solution

$$
\begin{aligned}
2 \mathrm{ml} & \text { Solution A } \\
200 \mu \mathrm{l} & \text { Solution B } \\
1,2 \mu \mathrm{l} & \mathrm{H}_{2} \mathrm{O}_{2}, 30 \%
\end{aligned}
$$

SDS Running Buffer

$$
\begin{array}{rl}
14,4 \mathrm{~g} & \text { Glycine } \\
3 \mathrm{~g} & \text { Tris } \\
1 \mathrm{~g} & \mathrm{SDS} \\
\text { ad } 1000 \mathrm{ml} & \text { dd }_{2} \mathrm{O}
\end{array}
$$

Western Blot Upper Buffer, $\mathrm{pH}$ 6,8

$$
\begin{array}{rl}
6,06 \mathrm{~g} & \text { Tris } \\
4 \mathrm{ml} & \mathrm{SDS}, 10 \% \\
\text { ad } 100 \mathrm{ml} & \mathrm{ddH}_{2} \mathrm{O}
\end{array}
$$

Western Blot Staining solution B

$$
\begin{aligned}
0,11 \mathrm{~g} & \text { p-Coumaric acid } \\
\text { ad } 100 \mathrm{ml} & \text { DMSO }
\end{aligned}
$$

Gastric emptying solution

$$
\begin{aligned}
40 \mathrm{ml} & \mathrm{ddH}_{2} \mathrm{O} \\
1,5 \mathrm{~g} & \text { Methyl cellulose } \\
\text { ad } 100 \mathrm{ml} & \mathrm{ddH}_{2} \mathrm{O} \\
50 \mathrm{mg} & \text { Phenol red }
\end{aligned}
$$

\subsubsection{Antibodies for Western Blot}

\section{Primary antibodies}

Arg2: $\quad$ arginase II $(\mathrm{H}-64)$, rabbit polyclonal antibody, Santa Cruz Biotechnology, Inc., Heidelberg 
ERK: $\quad$ ERK-1 (C-16), rabbit polyclonal antibody,

Santa Cruz Biotechnology Inc., Heidelberg

$\beta$-tubulin: $\quad \beta$-tubulin (TUB 2.1), mouse monoclonal antibody

Sigma-Aldrich, Taufkirchen, Germany

GR:

GR (M-20): sc-1004, rabbit polyclonal antibody,

Santa Cruz Biotechnology Inc., Heidelberg

\section{Secondary antibodies}

Rabbit IgG, $(\mathrm{H}+\mathrm{L})$ : ImmunoPure ${ }^{\circledR}$, Goat Anti-Rabbit IgG, peroxidase conjugated, Pierce Biotechnology, Rockford, IL, USA

Mouse lgG $\mathrm{G}_{2 \mathrm{a}}$ : $\quad$ ImmunoPure ${ }^{\circledR}$, Goat Anti-mouse IgG, peroxidase conjugated, Pierce Biotechnology, Rockford, IL, USA

\subsubsection{Commercial assays}

Table 4. Commercial assays

iScript cDNA Synthesis Kit

RNeasy ${ }^{\circledR}$ Plus Universal Mini Kit

Bio-Rad laboratories, München, Germany

Power SYBR Green PCR Mastermix Qiagen, Hilden, Germany

Applied Biosystems, Foster City, CA, USA

\subsubsection{Oligonucleotides}

Table 5. Oligonucleotides

Target gene

Sequence $\left(5^{\prime}-3^{\prime}\right)$

Arginase type1 (arg1)

Fwd: AGCCCGAGCACATGCAGCAG

Rev: ACCCCTCCTCGAGGCTGTCCT 


\begin{tabular}{ll}
\hline Target gene & Sequence (5' - $^{\prime}$ ) \\
\hline Arginase type2 (arg2) & Fwd: TCCTTGCGTCCTGACATCCG \\
& Rev: AGGTGGCATCCCAACCTGGAGAG \\
\hline CD163 antigen (CD163) & Fwd: GAAGCCCACAAAGAAGCTG \\
& Rev: TGCACACGATCTACCCACAT \\
\hline CD74 antigen (CD74) & Fwd: ACCGAGGCTCCACCTAAAGTACTGA \\
& Rev: TCGCACTTGGGACGGAACGC \\
\hline Chemokine (C-X-C motif) ligand 13 & Fwd: GCCTCTCTCCAGGCCACGGTAT \\
(Cxcl13) & Rev: AGCCATTCCCAGGGGGCGTA \\
\hline Gasmodermin C2 (Gsdmc2) & Fwd: GATGAGCTGCGAAAGGATTC \\
\hline Gasmodermin C3 & Rev: TGGGTATCACTCAGCACCAA \\
(Gsdmc3) & Fwd: ATCCCTGGACATTCCCTTC \\
\hline Histocompatibility 2, & Rev: CCTGGGATTATTCAGCTCCA \\
class Il antigen A, alpha (H2-Aa) & Fwd: TGATTCTGGGGGTCCTCGCCC \\
\hline Histocompatibility 2, & Rev: ACGTGGTCGGCCTCAATGTCG \\
class II antigen A, beta1 (H2-Ab1) & Fwd: GGCTGCGTGCTTGGGGTGA \\
\hline Hypoxanthine-guanine- & Rev: GGCCTCGAGGTCCTTTCTGACT \\
Phosphoribosyltransfrase (HPRT) & Fwd: GTCCTGTGGCCATCTGCCTA \\
\hline Kallikrein 1 (Klk1) & Rev: GGGACGCAGCAACTGACATT \\
\hline Lipocalin 2 (Lcn2) & Fwd: ATACCCAGAGCTCCAGTGTGTG \\
\hline Neuronal Nitric oxide synthase & Fwd: CAGTGGAGAGCCCTGGCTTGC \\
(nNOS) & Rev: AGGCCTGTCCCACTGTCCGC \\
\hline & \\
\hline & Rev: GCGCATCCCAGTCAGCCACA \\
\hline
\end{tabular}

All oligonucleotides were purchased from Metabion, Martinsried, Germany. 


\subsubsection{Mice}

All mice used in this study were female and either on a Balb/c or C57BI/6 background. Mice were kept under specified-pathogen-free (SPF) conditions in individually ventilated cages at our own animal facilities in Göttingen. Mice were maintained under a standard 12 hour light-dark-circle with unlimited access to food and water.

Wildtype Balb/c and C57BI/6 mice were either purchased from Charles River (Sulzfeld, Germany) or bred at our own facility.

$\mathrm{GR}^{\mathrm{dim}}$ mice that are deficient in DNA-binding dependent gene regulation by the GR (Reichardt et al., 1998) had been backcrossed to the Balb/c background for more than 10 generations.

Mice with a myeloid cell-specific knockout of the GR or MR, namely GR ${ }^{\text {lysMcre }}$ (Tuckermann et al., 2007) and MR ${ }^{\text {lysMcre }}$ (Usher et al., 2010) mice, were obtained by crossing $\mathrm{GR}^{\text {floxflox }}$ and $\mathrm{MR}^{\text {floxflox }}$ mice, respectively, with LysMcre transgenic mice.

$\mathrm{GR}^{\text {villincre }}$ mice that specifically lack the GR in enterocytes were kindly provided by our cooperation partner in Jena (Jan Tuckermann, Leibniz Institute for Age Research, Jena).

All animal experimentation was conducted according to accepted standards of humane animal treatment and approved by the appropriate authorities in Lower Saxony (LAVES).

\subsubsection{Software}

Table 6. Software

Adobe Photoshop ${ }^{(} \mathrm{CS} 4$

Graph Pad Prism ${ }^{\circledR}$ version 4.0c

Intas GDS

7500 SDS Software version 1.4.0.25
Adobe Systems, San José, CA, USA

Graph Pad Software, La Jolla, CA, USA Intas, Göttingen, Germany

Applied Biosystems, Foster City, CA, USA 


\subsection{Methods}

\subsubsection{Animal experimentation}

\subsubsection{Experimental protocols}

To mimic a standard high-dose oral GC therapy, mice were treated with watersoluble dexamethasone (Dex) via the drinking water at a concentration of 50 $\mathrm{mg} / \mathrm{L}$ for three consecutive days, which was changed once on the second day. Based on a daily drinking volume of approximately $5 \mathrm{ml} \pm 0,7 \mathrm{ml}$ this treatment corresponds to an effective dose of about $10 \mathrm{mg} / \mathrm{kg}^{*} \mathrm{~d}$ (Reichardt et al., 2012). In some experiments, Dex was applied at lower concentrations as indicated in the Results section.

L-Arginine at a concentration of $1 \%$ was added to the drinking water one day prior to Dex and changed once on the second day. Iron(II) gluconate hydrate was added at a concentration of either $600 \mathrm{mg} / \mathrm{L}$ or $1200 \mathrm{mg} / \mathrm{L}$ one day prior to Dex and changed once every second day. Based on a drinking volume of $5 \mathrm{ml} \pm$ $0,7 \mathrm{ml}$ this treatment corresponds to an effective dose of $150 \mathrm{mg} / \mathrm{kg}^{*} \mathrm{~d}$ or 300 $\mathrm{mg} / \mathrm{kg}^{*} \mathrm{~d}$, respectively.

A volume of $100 \mu \mathrm{l}$ of BEC at a concentration of $1 \mathrm{mg} / \mathrm{ml}$ was given once a day by oral gavage.

\subsubsection{Physiological parameters}

To determine the weight of the filled stomach, mice were sacrificed by inhalation of carbon dioxide. After opening the abdomen the stomach was clamped at the cardiac and pyloric sphincter, carefully removed and then weighed. The stomach weight was normalized to the body weight as follows: stomach weight $[\mathrm{mg}] /$ body weight $[\mathrm{g}] / 10=$ normalized stomach weight.

The daily intake of food and drinking water was determined by providing the mice access to a defined amount of food and water. The difference in weight and volume every day was then measured and the average daily intake calculated. 
Determination of the dry weight of the feces was accomplished by their daily collection followed by an overnight drying in an oven at $60^{\circ} \mathrm{C}$ and subsequent weighing.

\subsubsection{Gastric emptying}

To determine the rate of gastric emptying I modified a previously published method (Martinez et al., 1997). In principle this method is based on determination of gastric emptying by feeding a defined volume of a stained meal of stable viscosity followed by subsequent photometric detection of the amount of retained meal in the stomach.

To prepare a liquid meal of stable viscosity an aqueous solution of $1,5 \%$ methyl cellulose was prepared. To this end, 1,5 g methyl cellulose were dissolved in 40 $\mathrm{ml}$ distilled water at a temperature of about $80^{\circ} \mathrm{C}$ under continuous stirring until all particles were dispersed. The remaining amount of water was added at a temperature below $10^{\circ} \mathrm{C}$ and the solution was stirred and cooled for at least another 30 minutes at a temperature below $10^{\circ} \mathrm{C}$. In this step the dispersed methyl cellulose particles become hydrated and an increase in viscosity can be observed. In a final step $50 \mathrm{mg}$ phenol red were dissolved in $100 \mathrm{ml}$ of the resulting solution thus ensuring the later photometric detection of the remaining stomach content.

For the determination of gastric emptying mice were fasted overnight and then given $150 \mu$ of the prepared gastric emptying solution by gavage.

Thirty minutes after force-feeding the mice were sacrificed in an atmosphere of excessive carbon dioxide and the abdominal part was opened. The stomach was clamped at the cardiac and pyloric sphincter, carefully removed and placed into $4 \mathrm{ml} 0,1 \mathrm{~N} \mathrm{NaOH}$ before homogenizing it with the help of an Ultra Turrax.

After the addition of another $6 \mathrm{ml} 0,1 \mathrm{~N} \mathrm{NAOH}$ the solution was thoroughly mixed and subsequently centrifuged at $3000 \mathrm{rpm}$ for 10 minutes at $4^{\circ} \mathrm{C} .1 \mathrm{ml}$ of the supernatant was added to $100 \mu \mathrm{l}$ of $20 \%$ trichloro-acetic acid, vortexed and centrifuged at $3000 \mathrm{rpm}$ at $4^{\circ} \mathrm{C}$ for 2 minutes. A volume of $500 \mu \mathrm{l}$ was removed from the clear supernatant and mixed thoroughly with another volume of $400 \mu \mathrm{l}$ of $0,5 \mathrm{~N} \mathrm{NaOH}$. 
The absorption of the sample was measured at a wavelength of $562 \mathrm{~nm}$ (A562) in a photometer. For baseline control some mice were killed immediately after force-feeding and the absorption of the stomach content was determined likewise.

The rate of gastric emptying was then calculated according to the following equation: (1-[A562 of test sample]/[A562 of baseline control]) $\times 100$

\subsubsection{Molecular biological methods}

\subsubsection{Isolation of total RNA from tissue samples}

For the isolation of total RNA from tissue samples the Qiagen RNeasy ${ }^{\circledR}$ Mini Kit was used. Therefore, the frozen tissue samples were placed into $900 \mu \mathrm{l}$ of QIAzol ${ }^{\boxplus}$ lysis reagent and homogenized with the help of an Ultra Turrax. To remove genomic DNA $100 \mu$ l of DNA-eliminator solution was added and the mixture vortexed. After the addition of $180 \mu \mathrm{l}$ chloroform and vortexing, the homogenates were incubated for three minutes at room temperature before centrifugation at $12,000 \mathrm{~g}$ for 15 minutes at $4^{\circ} \mathrm{C}$. The upper aqueous phase containing the RNA was placed in another tube mixed with 1 volume of $70 \%$ ethanol by pipetting up and down. A volume of $700 \mu \mathrm{l}$ of the mixture was transferred to a spin column and centrifuged at $\geq 8,000 \mathrm{~g}$ for 20 seconds. After discarding the flow-through this step was repeated with the remainder of the sample. In three consecutive steps the column membrane was washed by first adding $700 \mu \mathrm{l}$ of wash-buffer to the column before centrifugation at $\geq 10,000 \mathrm{~g}$ for 20 seconds. For each step a different wash buffer was used and the flow-through discarded. Afterwards the RNA was eluted twice with $35 \mu \mathrm{l}$ RNase-free water by centrifugation at $\geq 8000 \mathrm{~g}$ for 1 minute. An aliquot of the sample was used for measuring the concentration and the samples were frozen immediately. 


\subsubsection{Reverse transcription of RNA}

For further analysis by quantitative reverse-transcription polymerase chain reaction (qRT-PCR) the RNA samples were transcribed into complementary DNA (cDNA). This was accomplished with the help of the iScript cDNA synthesis Kit. In brief, $1 \mu \mathrm{g}$ of RNA was mixed with $0,25 \mu$ l Reverse transcriptase and $4 \mathrm{ml}$ of iScript reaction mix. RNA-free water was added to a final volume of $20 \mu \mathrm{l}$. The samples were held at $25^{\circ} \mathrm{C}$ for 5 minutes before incubating them at $42^{\circ} \mathrm{C}$ for 30 minutes. In a final step the reaction was stopped by incubation at $85^{\circ} \mathrm{C}$ for 5 minutes.

\subsubsection{Polymerase chain reaction}

Successful reverse transcription into cDNA was checked with the help of a polymerase chain reaction (PCR) aimed to amplify the housekeeping gene Hypoxanthine-guanine phosphoribyl-transferase (HPRT). To this end $1 \mu$ of cDNA was added to a volume of $19 \mu \mathrm{l}$ of the following master mix:

$$
\begin{aligned}
12,7 \mu \mathrm{l} & \text { ddH }_{2} \mathrm{O} \\
4 \mu \mathrm{l} & \text { Buffer HF } \\
1 \mu \mathrm{l} & \text { dNTP's } \\
0,5 \mu \mathrm{l} & \text { HPRT Primer forward } \\
0,5 \mu \mathrm{l} & \text { HPRT Primer reverse } \\
0,3 \mu \mathrm{l} & \text { pfuS DNA polymerase }
\end{aligned}
$$

The tubes were then transferred into a PCR Mastercycler and the PCR was conducted according to this protocol:

\begin{tabular}{ccc|c} 
Initialization step & $98,5^{\circ} \mathrm{C}$ & 2 minutes & \\
Denaturation step & $98,5^{\circ} \mathrm{C}$ & 20 seconds & \\
Annealing step & $64^{\circ} \mathrm{C}$ & 15 seconds & 30 cycles \\
Elongation step & $72^{\circ} \mathrm{C}$ & 20 seconds & \\
Final elongation & $72^{\circ} \mathrm{C}$ & 2 minutes &
\end{tabular}




\subsubsection{Agarose Gel Electrophoresis}

Analysis of the PCR products was done with the help of agarose gel electropheresis. To this end $7 \mu$ l of loading buffer consisting of a $30 \%$ solution of Orange $\mathrm{G}$ in DMSO was added to the samples which were then loaded onto a $2 \%$ agarose gel in a electrophoresis chamber filled with TAE buffer. According to the size of the gel, the electrophoresis was run at $120 \mathrm{~V}$ and $230 \mathrm{~mA}$, for small gels or at $150 \mathrm{~V}$ and $290 \mathrm{~mA}$, for large gels, respectively. After 35 minutes electrophoresis was stopped and the gel was placed on a UV screen to detect the seperated fragments.

\subsubsection{Quantitative RT-PCR}

To study changes in the relative expression level of genes qRT-PCR was used. RNA from tissue samples was isolated and subsequently transcribed into CDNA as described above. A mastermix of $11 \mu \mathrm{l}$ distilled water, $12.5 \mu \mathrm{l}$ SYBR-Green reaction mix and $0.25 \mu \mathrm{l}$ of the respective forward and reverse primer of the gene of interest each (at a concentration of $10 \mu \mathrm{M}$ ) was prepared. $1 \mu \mathrm{l}$ of cDNA was added to each well of a 96 well PCR plate and subsequently $24 \mu \mathrm{l}$ of the Mastermix was added to each well. Following centrifugation the plate was placed into a 7500 Real Time PCR System and the PCR was performed following the following protocol:

\begin{tabular}{|c|c|c|c|}
\hline Enzyme activation & $50^{\circ} \mathrm{C}$ & 2 minutes & \\
\hline Initial denaturation & $95^{\circ} \mathrm{C}$ & 20 seconds & \\
\hline Denaturation & $95^{\circ} \mathrm{C}$ & 15 seconds & \\
\hline \multirow[t]{2}{*}{ nealing and elongation } & $60^{\circ} \mathrm{C}$ & 60 seconds & 40 cycles \\
\hline & $95^{\circ} \mathrm{C}$ & 15 seconds & \\
\hline \multirow[t]{2}{*}{ Dissociation } & $60^{\circ} \mathrm{C}$ & 60 seconds & \\
\hline & $95^{\circ} \mathrm{C}$ & 15 seconds & \\
\hline
\end{tabular}

For evaluation of the relative expression of genes the $\Delta \Delta \mathrm{ct}$ method was employed. The housekeeping gene HPRT served as an endogenous control for normalization. 


\subsubsection{Biochemical Methods}

\subsubsection{Preparation of protein lysates from tissue samples}

Protein lysates were prepared from the stomach of mice by homogenizing tissue samples in $500 \mu \mathrm{l}$ freshly made protein lysis buffer with the help of an Ultra turrax. The resulting homogenates were then put on ice for at least one hour before centrifugation at $12,000 \mathrm{~g}$ for 20 minutes at $4^{\circ} \mathrm{C}$. The supernatant was removed and the concentration measured using the Bradford protein assay.

\subsubsection{Measurement of protein concentration}

Protein lysates were diluted 10 -fold in RIPA buffer before adding $25 \mu \mathrm{l}$ of the sample to $750 \mu \mathrm{l}$ Bradford reagent. A blank solution was prepared by adding of $25 \mu \mathrm{l}$ RIPA buffer to $750 \mu \mathrm{l}$ Bradford reagent. The absorption of the samples at $595 \mathrm{~nm}$ was measured in a Nanodrop 2000 photometer and the concentration was calculated with the help of a standard curve.

\subsubsection{Polyacrylamide Gel Electrophoresis}

For further analysis of protein levels in tissues by Western Blot, protein lysates were separated by sodium dodecyl sulfate polyacrylamide gel electrophoresis (SDS-PAGE). To this end separating and stacking gels were prepared according to the following table:

Table 7. Preparation of WesternBlot Gels

Lower Buffer

Upper Buffer $1950 \mu \mathrm{l}$

Rotiphorese ${ }^{(} \mathrm{Gel} 30$ $2025 \mu \mathrm{l}$ $938 \mu \mathrm{l}$

$\mathrm{H}_{2} \mathrm{O}$ $3975 \mu \mathrm{l}$ $600 \mu \mathrm{l}$

TEMED $7,5 \mu \mathrm{l}$ $2205 \mu \mathrm{l}$ APS (10\%), added shortly $49,95 \mu \mathrm{l}$ $3,75 \mu \mathrm{l}$ before casting 
The separating gel was casted between plate and spacer plate at a thickness of $0,75 \mathrm{~mm}$ and allowed to polymerize for 10 to 20 minutes before the stacking gel was poured and a comb inserted. After solidifying the gel was placed in a electrophoresis chamber filled with SDS Running Buffer. An amount of $20 \mu \mathrm{g}$ protein lysate was added up to a volume of $10 \mu$ with RIPA Buffer and mixed with $2 x$ Laemmli Buffer before heating to $95^{\circ} \mathrm{C}$ for 5 minutes. The samples were then loaded onto the gel and the electrophoresis was run at a constant current of 20 $\mathrm{mA}$ for 50 minutes.

\subsubsection{Western Blot Analysis}

After separation by SDS-PAGE the proteins were transferred to an ECL nitrocellulose membrane. Therefore, a Whatman ${ }^{\circledR}$ blotting paper soaked with blotting buffer was placed in a SEMIPHOR transfer unit before sandwich-like the nitrocellulose membrane, the separating gel and another Whatman® paper was each put on top. To transfer the proteins to the membrane a voltage of $16 \mathrm{~V}$ was applied for one hour. The membrane was then blocked for another hour with $5 \%$ BSA solution and subsequently washed 3 times with PBS/Tween before incubation overnight at $4^{\circ} \mathrm{C}$ with the primary antibody. The secondary antibody was applied after washing 3 times with PBS/Tween and incubated for one hour at room temperature. After adding the freshly prepared development solution the protein bands were visualized using a Chemo Cam Imaging system.

\subsubsection{Statistical analysis}

Statistical analysis was performed by either 2-way ANOVA followed by Bonferroni multiple comparison test, unpaired $t$ test or Mann-Whitney $U$ test as indicated in the respective figure legends. Data are depicted as mean \pm SEM. $P$ values below 0.05 were considered significant and are indicated as follows: ${ }^{*} p<0.05$; ${ }^{* *} p<0.01 ;{ }^{* *} p<0.001$. For all statistical analyses Graph Pad Prism® software was used. 


\section{Results}

\subsection{Oral administration of GCs induces gastroparesis}

\subsubsection{High-dose Dex treatment causes an enlargement of the stomach}

GCs are the mainstay in the treatment of inflammatory diseases such as MS, RA or IBD. Nevertheless, pharmacological application of GCs can lead to severe side-effects including diabetes, muscle atrophy, osteoporosis (Rauch et al., 2010; Rose and Herzig, 2013; Watson et al., 2012) as well as the formation of gastric ulcers (Sandu et al., 2007). Administration of GCs, in particular orally, can lead to gastrointestinal disturbances with symptoms ranging from early satiety and bloating to nausea. In fact, patients often range gastrointestinal symptoms as one of the most important adverse effect because they pose a serious disadvantage on their daily life (Sellebjerg et al., 1998). On the other hand oral therapy has major advantages over intravenous therapy. It does not require hospitalization or daily appointments for treatment in the clinic, which may be cumbersome and wearing for the patients especially in rural regions with less health facilities. Furthermore oral treatment is a far less exhausting method of application for the patients and it is therefore often the method of choice.

Previous experiments performed by Toni Weinhage in my group had revealed that an enlargement of the stomach was a so far unknown gastrointestinal effect caused by GCs. It was therefore the aim of this work to follow up this observation and to explain it on a mechanistic level. In my experiments I initially mimicked high-dose oral GC therapy by treating female wildtype Balb/c mice with $50 \mathrm{mg} / \mathrm{l}$ Dex in the drinking water for three consecutive days with a change of drinking water on the second day. On the third day the mice were sacrificed and the stomachs removed and weighed. The relative stomach weight was calculated as the percentage of body weight to take differences between individual mice into account. In agreement with the previous observation, the weight and size of the stomach was strongly increased after oral treatment with Dex as compared to untreated mice (Figure 6). 
A

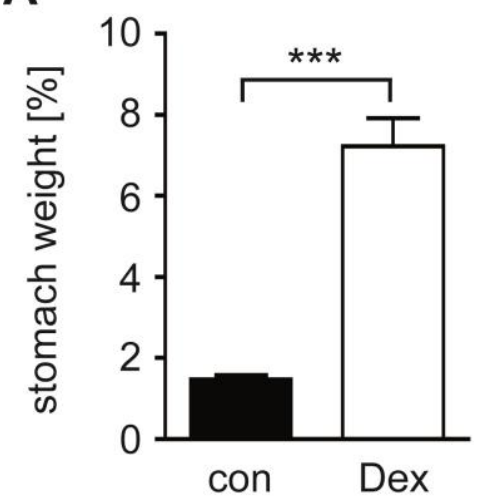

B

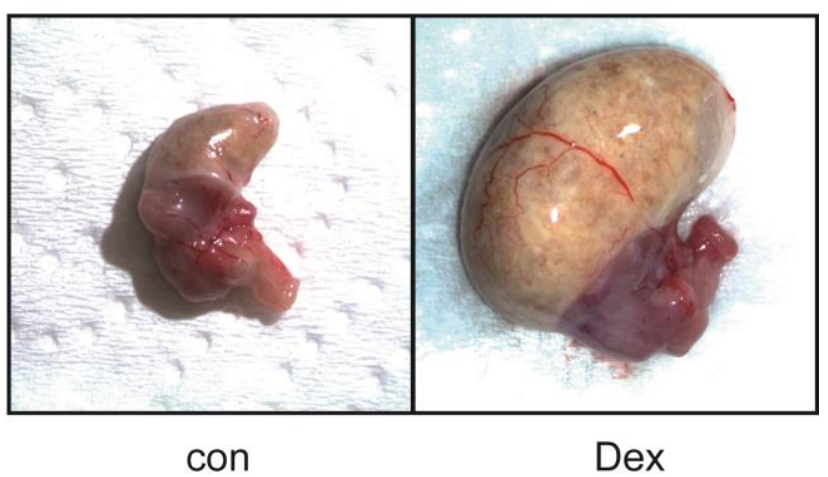

Figure 6. Oral Dex treatment leads to an increase in stomach weight and size.

Female Balb/c mice were given $50 \mathrm{mg} / \mathrm{l}$ Dex via the drinking water or left untreated (con). A, the relative stomach weight of the mice is depicted as the percentage of body weight; $\mathrm{N}=7$. Statistical analysis was performed by unpaired $t$ test, ${ }^{* * *}, P<.001$. B, representative pictures of mouse stomachs illustrating the size increase after Dex treatment compared to control (con). The photographs shown in panel B were kindly provided by Toni Weinhage (Reichardt et al., 2014).

Noteworthy, the observed effect was accompanied by a slight increase in drinking volume but no change in food intake or dry feces as shown in Figure 7.
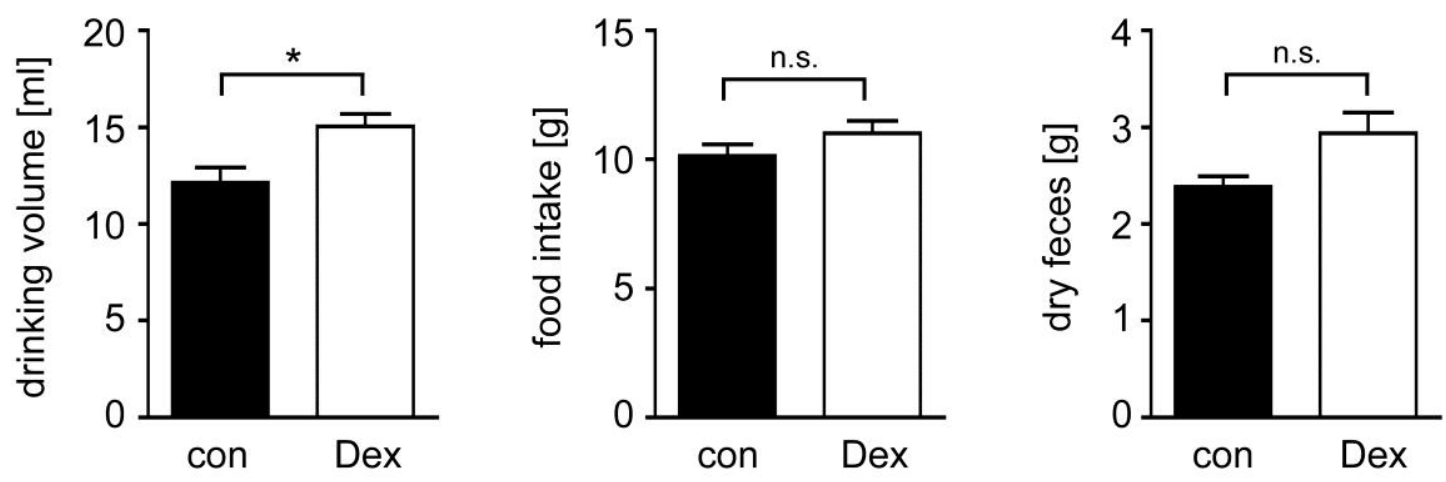

Figure 7. Oral administration of Dex for three days does not alter food intake or dry feces and only leads to a slight increase in water intake.

Mice were treated with $50 \mathrm{mg} / \mathrm{L}$ Dex in the drinking water or were left untreated (con). The left panel shows the total drinking volume during three days of treatment $(N=8 / 13)$. Food intake and dry feces weight were measured for each individual mouse and are shown in the middle $(N=6 / 12)$ and right panel $(N=4)$, respectively. Statistical analysis was performed by unpaired $t$ test, ${ }^{*}, P<.05$; n.s., not significant. These data were kindly provided by Toni Weinhage (Reichardt et al., 2014). 


\subsubsection{Dex administration impairs gastric emptying}

Having excluded altered excretion or feeding behaviour as a potential cause of stomach enlargement after Dex administration, I suspected a reduced gastric emptying rate as the underlying mechanism. To confirm this hypothesis a method for the measurement of gastric emptying was established. To this end mice were fasted overnight and then force-fed a liquid test meal consisting of a methyl cellulose solution of stable viscosity. To be able to later detect the remains of the meal in the stomach it was stained with phenol red prior to feeding by oral gavage. Either immediately as a baseline control or after 30 minutes the mice were sacrificed and the stomach clamped, removed and homogenized before the absorption of the remaining stomach content was measured (Figure 8A). The reduced absorption observed after 30 minutes in control mice indicates that part of the meal has been removed from the stomach as a result of normal gastric motility.

A

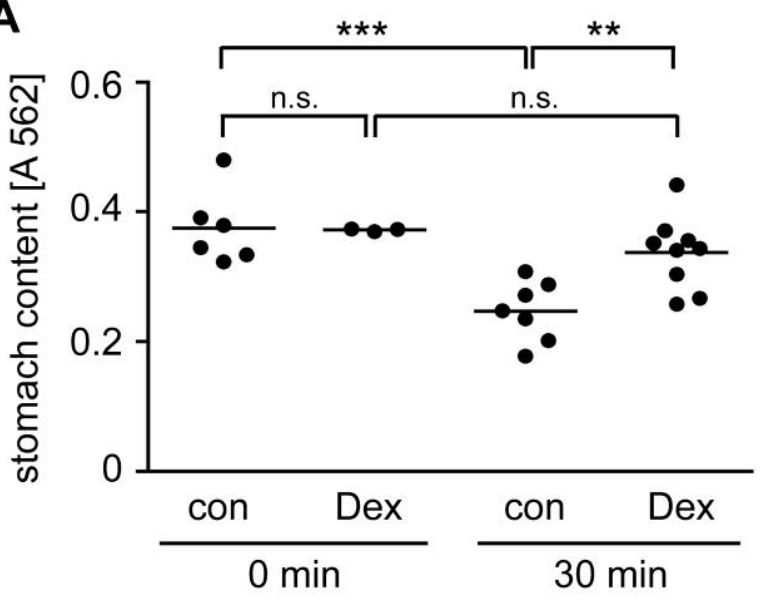

B

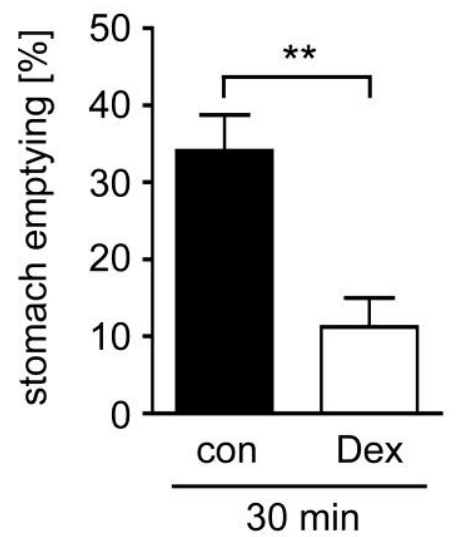

Figure 8. Oral Dex treatment induces gastroparesis in mice.

A, Dex treated and untreated (con) mice were fasted for 20 hours before force-feeding a test meal of methyl cellulose stained with phenol red. Some mice were sacrificed immediately $(0 \mathrm{~min})$ and some after 30 minutes. The stomach was clamped, removed and homogenized. The remains of the stained meal in the stomach were determined by photometry based on the absorption at 562nm (A 562), which is depicted for each mouse ( $\mathrm{N}$ $=3-9$ ). B, The rate of gastric emptying was calculated as the ratio between the absorption after 30 minutes and the value at time point zero and is shown as percentage of gastric emptying. Statistical analysis in both panels was performed by unpaired $t$ test, ${ }^{* *}$, $P<.01,{ }^{* \star *}, P<.001$, n.s., not significant (Reichardt et al., 2014). 


\subsubsection{Increase in stomach weight induced by Dex is dose-dependent}

Although the initially administered high concentration of Dex indeed relates to doses given to patients suffering from chronic inflammatory diseases such as MS, I wanted to explore the dose dependency of gastroparesis induced by Dex. To rule out that the observed effect was strain-specific I conducted the experiment using both Balb/c and C57Bl/6 mice. Different concentrations of Dex were provided via the drinking water for three days, ranging from $50 \mathrm{mg} / \mathrm{L}$ to $2 \mathrm{mg} / \mathrm{L}$. It turned out that a significant increase in the stomach weight could be seen even at the lowest dosage in both strains (Figure 9).

A

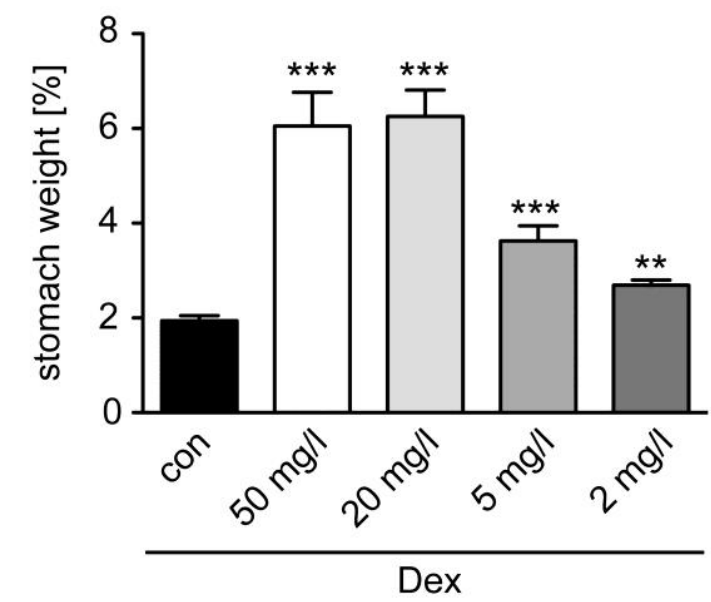

B filled stomach (female C57BI/6)

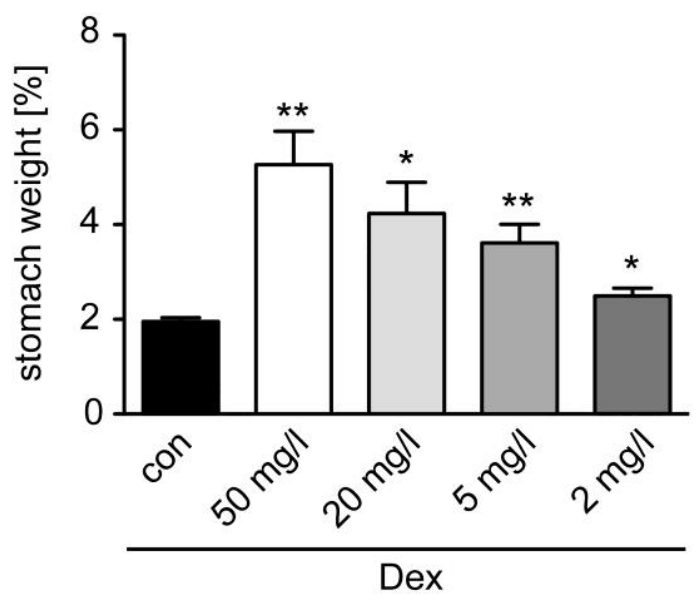

Figure 9. Dex-induced gastroparesis is dose-dependent.

Female Balb/c (A) or C57BI/6 (B) mice were orally administered Dex at concentrations of $50,20,5$ or $2 \mathrm{mg} / \mathrm{L}$ for three days or left untreated (con). The relative stomach weight is depicted as the percentage of body weight. $\mathrm{N}=4-8(\mathrm{~A}), \mathrm{N}=3-5$ (B). Statistical analysis by unpaired $t$ test, ${ }^{*}, P<.05,{ }^{* *}, P<.01,{ }^{* * *}, P<.001$ (Reichardt et al., 2014).

Of note, the weight increase of the filled stomach was slightly more pronounced in Balb/c than in C57BI/6 mice. Nevertheless, I conclude that Dex induces gastroparesis independently of the genetic background of the mice and in a dose dependent manner, with a decrease of stomach enlargement corresponding to a decline in Dex concentration. 


\subsection{Target organ of GC-induced gastroparesis}

\subsubsection{Gastroparesis is preserved in $\mathrm{GR}^{\text {villincre }}$ mice}

GCs are known to influence many functional properties of the intestine amongst others the uptake of glucose from enterocytes (Reichardt et al., 2012). For this reason I wanted to know whether the observed GC-induced gastroparesis was a direct effect on the stomach or rather an indirect effect resulting from so far unknown GC activities in the intestine. I thus made use of $\mathrm{GR}^{\text {villincre }}$ mice that lack the GR in the intestine but not in the stomach. By using Western Blot I could show that indeed protein expression of the GR was absent in the jejunum and ileum of $\mathrm{GR}^{\text {villinCre }}$ mice, whereas it was normally expressed in the stomach of the mutant mice (Figure 10).

A

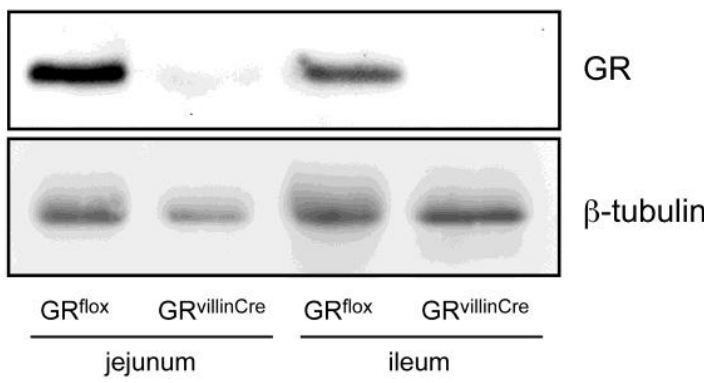

B

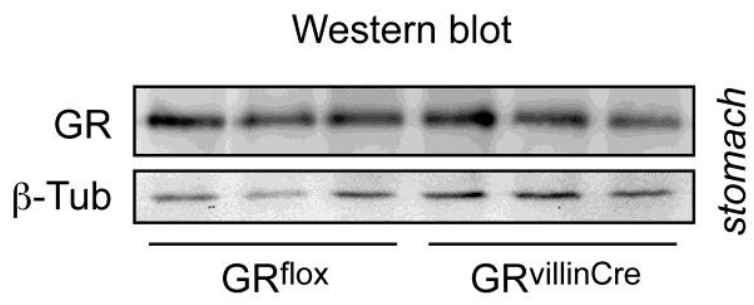

Figure 10. GR protein expression in the intestine and stomach of $\mathrm{GR}^{\text {villincre }}$ mice. GR protein levels were determined in the intestine $(A)$ and the stomach $(B)$ of $G R^{\text {villincre }}$ as well as $\mathrm{GR}^{\text {flox }}$ control mice by Western blot. $\beta$-tubulin served as a control. One representative experiment is shown each (Reichardt et al., 2012; Reichardt et al., 2014).

Having confirmed the absence of GR protein in jejunum and ileum of GR $\mathrm{R}^{\text {vilinCre }}$ mice and its presence in the stomach, I next tested whether GC effects on the intestine were responsible for the induction of gastroparesis by orally applying 50 $\mathrm{mg} / \mathrm{L}$ Dex to $\mathrm{GR}^{\text {vilinCre }}$ mice as well as $\mathrm{GR}^{\text {flox }}$ wildtype littermates. Importantly, the stomach of both control and knock-out mice showed a significant increase in the weight of the filled stomach after three days (Figure 11).

This suggests that gastroparesis is mainly a direct effect of GCs on the stomach rather than an indirect effect on the intestine. 


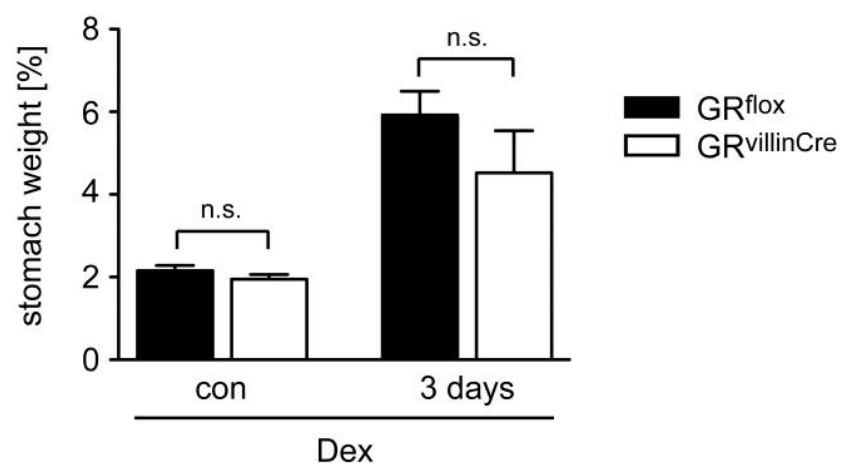

Figure 11. The GC-induced increase in stomach weight is preserved in enterocytespecific GR knock-out mice.

Mice were orally administered $50 \mathrm{mg} / \mathrm{L}$ Dex for three days or left untreated (con). The relative stomach weight of $\mathrm{GR}^{\text {flox }}$ control and $\mathrm{GR}^{\text {villincre }}$ knock-out mice was determined and is depicted as percentage of body weight; $N=5-9$. Statistical analysis was performed by 2-way ANOVA followed by Bonferroni multipe comparison test, n.s., not significant (Reichardt et al., 2014).

\subsection{Molecular mechanism of GC-induced gastroparesis}

\subsubsection{GC treatment of $\mathrm{GR}^{\mathrm{dim}}$ mice does not induce gastroparesis}

GCs exert most of their functions through binding to the GR. Upon ligand binding and translocation to the nucleus the GR can either trans-repress gene transcription independently of DNA-binding, or it can trans-activate genes which requires DNA-binding of the GR. GR ${ }^{\text {dim }}$ mice carry the A458T point mutation in the second zinc finger of the DBD, which impairs the ability of the GR to dimerize and therefore to modulate gene transcription in a DNA-binding dependent manner. Having found that GC-induced gastroparesis is a direct effect on the stomach I set out to determine the underlying molecular mechanism by employing $\mathrm{GR}^{\mathrm{dim}}$ mice.

To this end, GR ${ }^{\operatorname{dim}}$ and $\mathrm{GR}^{\text {wt }}$ mice were treated with $50 \mathrm{mg} / \mathrm{L}$ Dex for up to three days followed by the analysis of the stomach weight. A slight increase was observed for both genotypes already after one day of Dex treatment. However, when I treated the mice with Dex for three consecutive days the stomach of 
wildtype mice was strongly enlarged whereas $\mathrm{GR}^{\mathrm{dim}}$ mice showed only a minor increase in stomach weight and size (Figure 12A).

Subsequently I also determined the gastric emptying rate for $\mathrm{GR}^{\mathrm{wt}}$ and $\mathrm{GR}^{\mathrm{dim}}$ mice after Dex treatment as described previously. While control mice showed severe gastroparesis as expected, the gastric emptying rate of $\mathrm{GR}^{\mathrm{dim}}$ mice remained unaltered (Figure 12B).

A

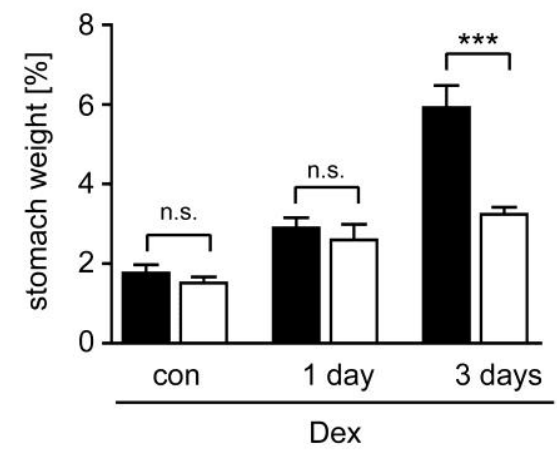

B

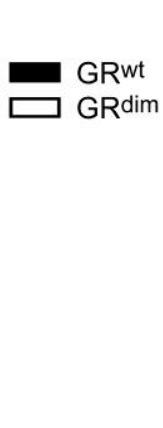

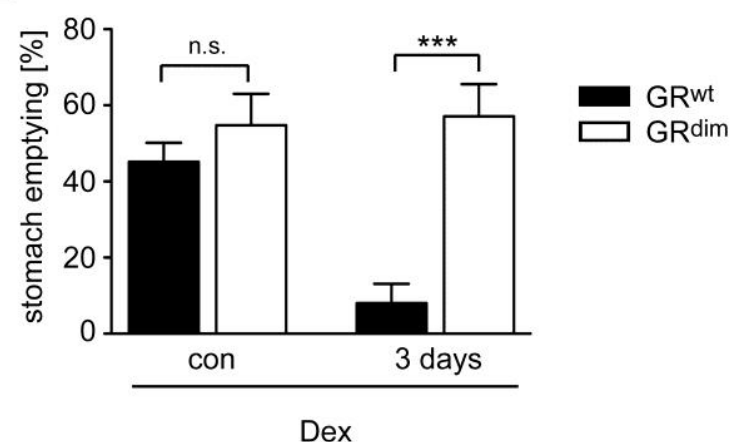

Figure 12. GC-induced gastroparesis is mediated by a DNA-binding dependent mechanism of the GR.

$\mathrm{GR}^{\text {wt }}$ and $\mathrm{GR}^{\text {dim }}$ mice were orally administered $50 \mathrm{mg} / \mathrm{L}$ Dex or left untreated (con) for up to three consecutive days. A, the relative stomach weight was determined after 1 and 3 days and is depicted as percentage of body weight, $N=5-9 . B$, Gastric emptying was determined after three days of treatment using a photometric assay. In brief, mice were force-fed a methyl cellulose solution stained with phenol red after being fasted for 20 hours. The remains of the stained test meal were determined on the basis of the absorption at $562 \mathrm{~nm}$. For baseline control some mice were sacrificed immediately. The ratio of stomach emptying was calculated and is depicted as percentage of stomach emptying after 30 minutes $\mathrm{N}=4-6$. Statistical analysis by 2-way ANOVA followed by Bonferroni multiple-comparison test, ${ }^{* *}, \mathrm{p}<.001$; n.s., not significant (Reichardt et al., 2014).

Taken together, these findings indicate that GC-induced gastroparesis is mediated by DNA-binding dependent GR trans-activation. 


\subsubsection{GC-induced gastric acid secretion does not influence gastroparesis}

Augmented secretion of hydrochloric acid $(\mathrm{HCl})$ in the stomach is a well-known consequence of either elevated levels of endogenous GCs after stress or following pharmacological administration of synthetic GCs. In collaboration with the group of Professor Dr. Florian Lang (University of Tübingen) the mechanism by which GCs impact $\mathrm{HCl}$ secretion were studied. In addition, it was tested whether $\mathrm{HCl}$ production is linked to $\mathrm{GC}$-induced gastroparesis.

For that reason $\mathrm{GR}^{\mathrm{wt}}$ and $\mathrm{GR}^{\mathrm{dim}}$ mice were treated with Dex via the drinking water for three consecutive days or left untreated. Subsequently the change in $\mathrm{pH}$ value in the stomach per minute was measured. As expected, the secretion of $\mathrm{HCl}$ was more pronounced in Dex-treated than in untreated wildtype mice. Moreover, increased gastric acid secretion after Dex treatment could be counteracted by administering the proton pump inhibitor omeprazole. In contrast to wildtype mice, the $\mathrm{HCl}$ secretion in the stomach of $\mathrm{GR}^{\mathrm{dim}}$ mice remained almost unaltered after three days of Dex treatment (Figure 13A).

These findings confirm the well-known capacity of GCs to enhance gastric acid secretion and indicate that dimerization of the GR and thus trans-activation of GR target genes is required to achieve this effect.

Taking into consideration that both the stimulation of gastric acid secretion and the induction gastroparesis by GCs were abolished in mice carrying the A485T mutation of the GR, it was conceivable that there was a connection between these two effects. However, previous work of my group could exclude such a potential link between gastroparesis and $\mathrm{HCl}$ secretion.

Namely, in a former experiment female Balb/c mice had been treated with Dex for three and ten days respectively. To counteract GC-induced gastric acid secretion some mice had additionally received a daily injection of omeprazole, a treatment that effectively abolishes enhanced gastric acid secretion after Dex treatment (Figure 13A). Notably, a significant increase in stomach weight occurred in both groups regardless of the additional treatment with omeprazole (Figure 13B). 
A

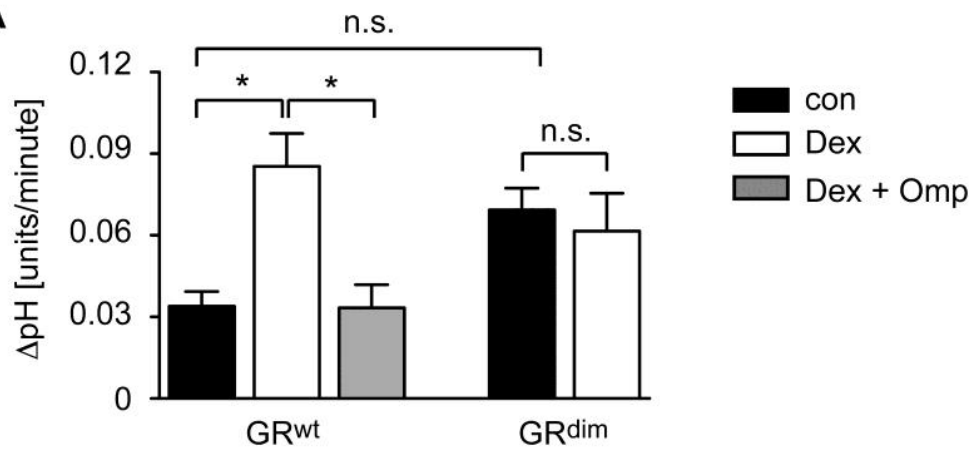

B

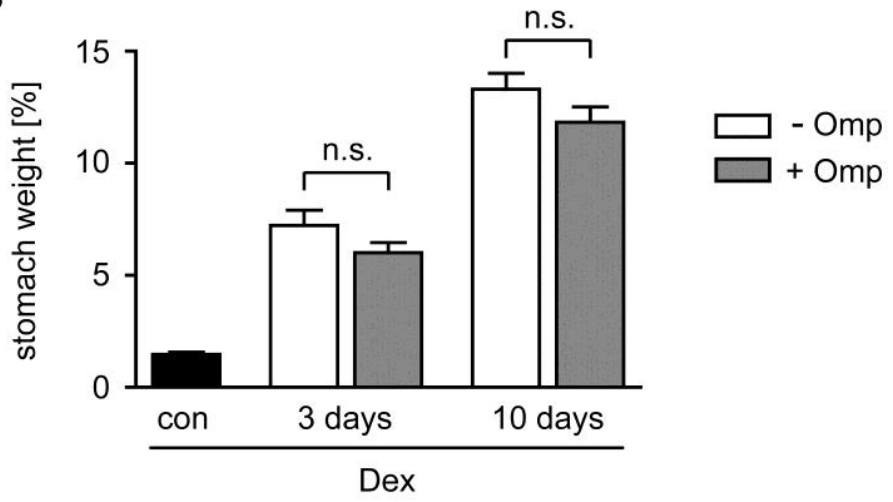

Figure 13. Enhanced gastric acid secretion is not linked to GC-induced gastroparesis.

$A$, The change in $\mathrm{pH}$ value per minute in the stomach is shown for $G R^{\mathrm{wt}}$ and $G R^{\mathrm{dim}}$ mice. Mice were either left untreated (con, black bars), treated with Dex for three days (white bars) or treated with Dex and omeprazole (Omp, grey bar). $\mathrm{N}=6-12$. B, Wildtype mice were treated with Dex for three or ten days or left untreated (con). Some of the mice were daily injected with $40 \mathrm{mg} / \mathrm{kg}$ omeprazol in addition. The relative stomach weight is depicted as percent body weight, $N=5-7$. Statistical analysis by 2-way ANOVA followed by Bonferroni multiple comparison test, ${ }^{*}, P<.05$, n.s., not significant. Data kindly provided by Florian Lang (13A) and Toni Weinhage (13B) respectively (Reichardt et al., 2014).

From these data it was concluded that GC-induced gastroparesis occurs independently of the stimulation of gastric acid secretion albeit both effects are abolished in $\mathrm{GR}^{\mathrm{dim}}$ mice. 


\subsection{The role of macrophages in gastroparesis induction by GCs}

\subsubsection{Dex-treatment results in altered macrophage polarization}

Having found that GC-induced gastroparesis is mediated via a mechanism that involves dimerization of the GR and therefore transcriptional regulation, I set out to identify genes in the stomach the expression of which was altered by GC treatment. To address this question a genome wide expression profiling employing microarrays was carried out. Hereby data were obtained about the genes that were differentially regulated in mice treated with Dex for three days as compared to untreated mice. An excerpt of the in total 52 genes that were identified as being up- or down-regulated by Dex more than two-fold in the stomach is given in Table 8 and 9 , respectively.

Table 8. Genes that are up-regulated in the stomach after Dex treatment.

Macrophage-specific genes that were further studied by qRT-PCR are highlighted in orange, other genes in yellow. Microarray data were kindly provided by Toni Weinhage.

\begin{tabular}{|llr|}
\hline Symbol & Name & \multicolumn{2}{c|}{$\begin{array}{c}\text { fold } \\
\text { expression }\end{array}$} \\
\hline Serpina3n & serine peptidase inhibitor, clade A, member 3N & 5,30 \\
\hline Klk1 & kallikrein 1 & 4,78 \\
\hline Lcn2 & lipocalin 2 & 4,40 \\
\hline Hmgcs2 & 3-hydroxy-3-methylglutaryl-Coenzyme A synthase 2 & 4,30 \\
\hline Fmo2 & flavin containing monooxygenase 2 & 3,68 \\
\hline Fkbp5 & FK506 binding protein 5 & 3,36 \\
\hline Arg2 & arginase type II & 2,98 \\
\hline Sult1a1 & sulfotransferase family 1A, phenol-preferring, member 1 & 2,96 \\
\hline Pdk4 & pyruvate dehydrogenase kinase, isoenzyme 4 & 2,92 \\
\hline Lox & lysyl oxidase & 2,85 \\
\hline CXCL13 & chemokine (C-X-C motif) ligand 13 & 2,43 \\
\hline Lyve1 & lymphatic vessel endothelial hyaluronan receptor 1 & 2,30 \\
\hline CD163 & CD163 antigen & 2,05 \\
\hline
\end{tabular}


Table 9. Genes that are down-regulated in the stomach after Dex treatment. Macrophage-specific genes that were further studied by qRT-PCR are highlighted in blue, other genes in green. Mircoarray data were kindly provided by Toni Weinhage.

\begin{tabular}{|llr|}
\hline Symbol & Name & $\begin{array}{l}\text { fold } \\
\text { expression }\end{array}$ \\
\hline H2-Ab1 & histocompatibility 2, class II antigen A, beta 1 & $-2,36$ \\
\hline H2-Aa & histocompatibility 2, class II antigen A, alpha & $-2,58$ \\
\hline Gbp4 & guanylate binding protein 4 & $-2,65$ \\
\hline Nr1d1 & nuclear receptor subfamily 1, group D, member 1 & $-2,66$ \\
\hline Nr1d2 & nuclear receptor subfamily 1, group D, member 2 & $-2,73$ \\
\hline Gsta3 & glutathione S-transferase, alpha 3 & $-2,83$ \\
\hline Akr1b8 & aldo-keto reductase family 1, member B8 & $-2,87$ \\
\hline Igh-2 & immunoglobulin heavy chain 2 (serum IgA) & $-2,95$ \\
\hline H2-Ea & histocompatibility 2, class II antigen E alpha & $-3,95$ \\
\hline CD74 & $\begin{array}{l}\text { CD74 antigen (invariant polypeptide of major histocom- } \\
\text { Nq01 }\end{array}$ & NAD(P)H dehydrogenase, quinone 1 \\
\hline Gsdmc2 & gasdermin C2 & $-4,21$ \\
\hline Gsdmc3 & gasdermin C3 & $-4,76$ \\
\hline
\end{tabular}

Strikingly, amongst the differentially expressed genes I identified some that are specific for macrophages. GCs are known for their ability to impact macrophage function, in particular by polarizing them from a pro-inflammatory M1 phenotype towards an anti-inflammatory M2 phenotype (Varga et al., 2008). Accordingly, genes that are specific for M2 polarized macrophages were up-regulated (highlighted in orange in Table 8), and those ones, which are specific for a M1 polarization of macrophages, were down-regulated (highlighted in blue in Table 9).

To confirm the results from the microarray analysis I performed a qRT-PCR analysis. Therefore mice were administered Dex via the drinking water or left untreated. After three days the stomachs were removed and RNA was isolated from the stomach corpus, reverse transcribed into cDNA and qRT-PCR per- 
formed using primers designed for the specific detection of the genes encoding H2-Aa, H2-Ab1 and CD74 as well as CXCL13 and CD163.

Importantly, my results were completely in line with the findings made by microarray analysis. Expression of CD163 and CXCL13, which are characteristic for a M2 polarization of macrophages, were up-regulated in the stomach after Dex treatment (Figure 14A), whereas the MHC class II genes H2-Aa, H2-Ab1 as well as CD74 were down-regulated (Figure 14B). Hence, GC treatment of mice alters the phenotype of macrophages in the stomach, which could presumably contribute to the induction of gastroparesis.

A

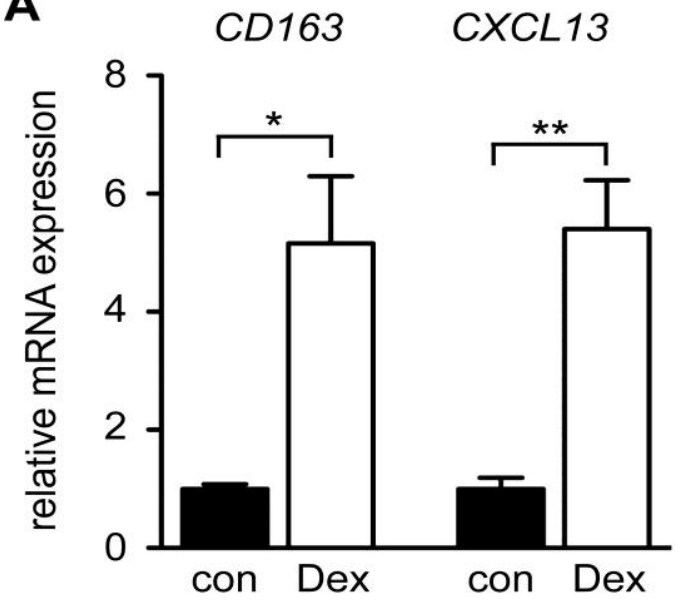

B

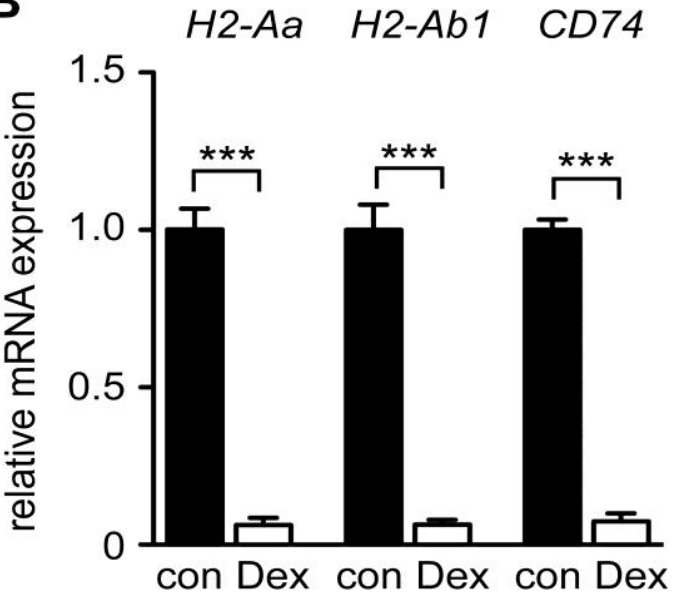

Figure 14. Oral Dex treatment of mice induces a M2 polarization of macrophages in the stomach.

Mice were treated with Dex via the drinking water or left untreated (con) for three days. RNA was prepared from tissue samples from the stomach corpus and reverse transcribed into cDNA. Subsequently, qRT-PCR was performed using gene-specific primers and the expression of the housekeeping gene HPRT was used for normalization. A, genes specific for a M2 polarization of macrophages are up-regulated. B, genes specific for a $\mathrm{M} 1$ polarization of macrophages are down-regulated, $\mathrm{N}=3-6$. Statistical analysis by unpaired $t$ test, ${ }^{* * *} p<.001 ;{ }^{* *} p<.01 ;{ }^{*} p<.05$ (Reichardt et al., 2014). 


\subsubsection{Altered macrophage polarization is not related to gastroparesis}

To test whether the change in phenotype of the macrophages that are resident in the stomach wall might be connected to Dex-induced gastroparesis, I took advantage of two different strains of conditional knock-out mice. GCs can exert their function either through binding to the GR or the MR, both of which are expressed by macrophages (Lim et al., 2007). To further investigate the role of altered polarization of macrophages in the induction of gastroparesis by GCs I made use of $\mathrm{GR}^{\text {lysMCre }}$ and $\mathrm{MR}^{\text {lysMCre }}$ mice, two mouse strains that specifically lack the GR or the MR, respectively, in myeloid cells. Thus, $50 \mathrm{mg} / \mathrm{L}$ Dex were administered to $\mathrm{GR}^{\text {lysMCre }}$ or MR ${ }^{\text {lysMCre }}$ mice via the drinking water for three days or the mice were left untreated. $\mathrm{GR}^{\text {flox }}$ and $\mathrm{MR}^{\text {flox }}$ littermates were treated likewise and served as controls. The mice were sacrificed on day 3 , the stomachs removed and weighed. Interestingly, stomach weights were increased in both strains of knock-out mice to a similar extend as in wildtype control mice after Dex treatment as shown in Figure 15.

A

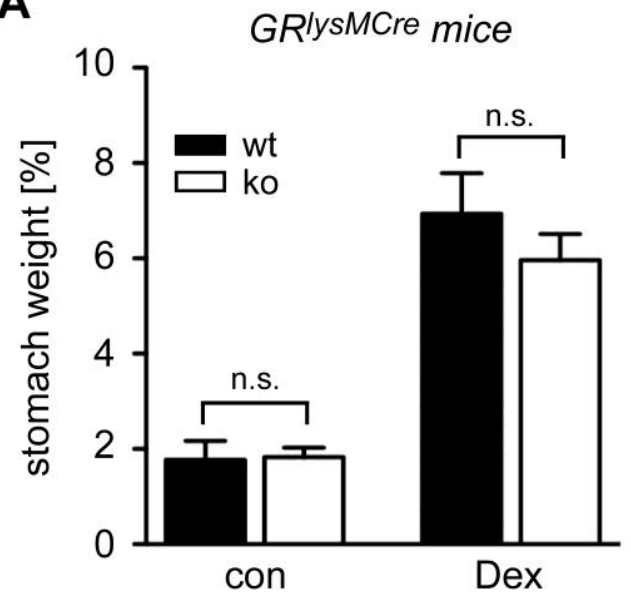

B

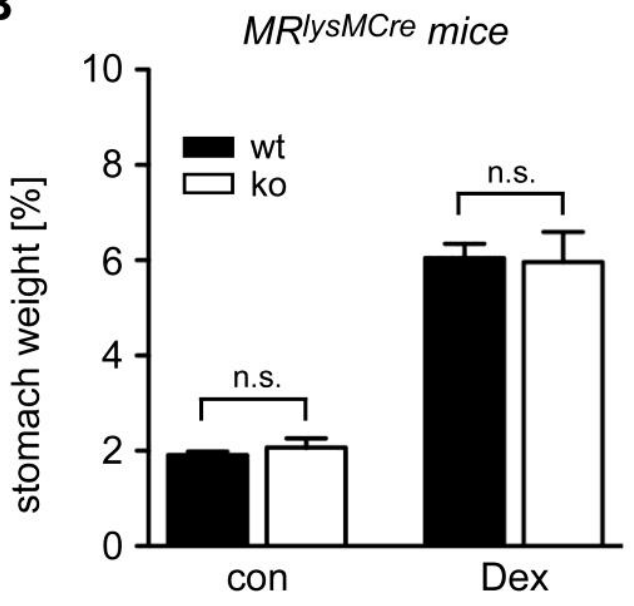

Figure 15. Induction of gastroparesis by GCs is retained in mice specifically lacking the GR or MR in macrophages.

$\mathrm{GR}^{\text {lysMcre }}$ or MR ${ }^{\text {lysMcre }}$ mice were treated with $50 \mathrm{mg} / \mathrm{L}$ Dex for three days or left untreated (con) along with the respective $\mathrm{GR}^{\text {flox }}$ and $\mathrm{MR}^{\text {flox }}$ littermates as a control. The stomach weight was determined as percentage of body weight and is depicted in $(A)$ for $G R^{\text {lysMcre }}$ mice (ko) and $\mathrm{GR}^{\text {flox }}$ mice (wt), $\mathrm{N}=5-7$, in (B) for $M R^{\text {lysMcre }}$ mice (ko) and $M R^{\text {flox }}$ mice (wt), $N=9-10$. Statistical analysis was performed by 2-way ANOVA followed by Bonferroni multiple comparison test, n.s., not significant (Reichardt et al., 2014). 
To confirm that the absence of the GR or MR in myeloid cells indeed resulted in a differential regulation of macrophage-specific genes after Dex-treatment, I exemplarily determined the expression of CD163 and CD74 in the two strains of mice and their respective controls. As expected, CD163 was up-regulated and CD74 down-regulated by Dex in wildtype control mice of both strains (Figure 16A, B). Importantly, in GR ${ }^{\text {lysMCre }}$ mice both effects of Dex were lost whereas the absence of the MR in MR $R^{\text {lysMCre }}$ mice had no impact on the regulation of these two genes (Figure 16).

Figure 16. CD163 and CD74 are differentially regulated in the stomach of myeloid cell-specific GR and MR knock-out mice after Dex treatment.

$\mathrm{GR}^{\text {lysMCre }}$ and MR ${ }^{\text {lysMCre }}$ mice (ko) and the corresponding littermate controls $\mathrm{GR}^{\text {flox }}$ and $M R^{\text {flox }}$ mice (wt) were orally administered $50 \mathrm{mg} / \mathrm{L}$ Dex for three days or left untreated. RNA was isolated from the stomach corpus and analyzed by qRT-PCR for altered mRNA expression of CD163 (A) or CD74 (B). Normalization was achieved by comparing the expression levels to those of HPRT, N = 3-6. Statistical analysis was performed by unpaired $t$ test. ${ }^{*}, \mathrm{p}<.05$; n.s., not significant (Reichardt et al., 2014).
A

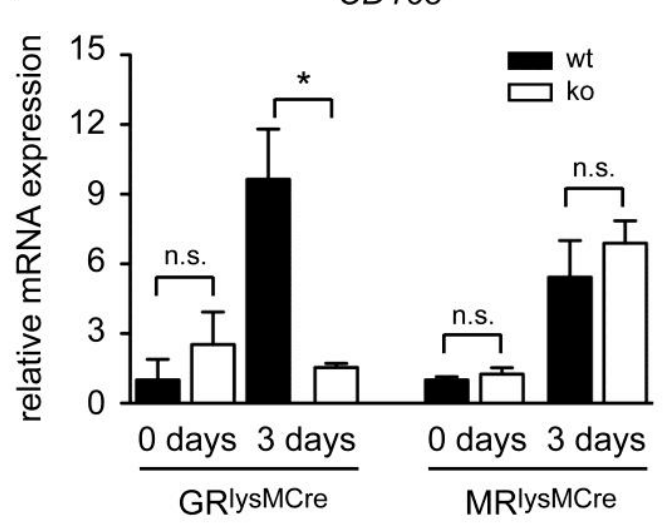

B

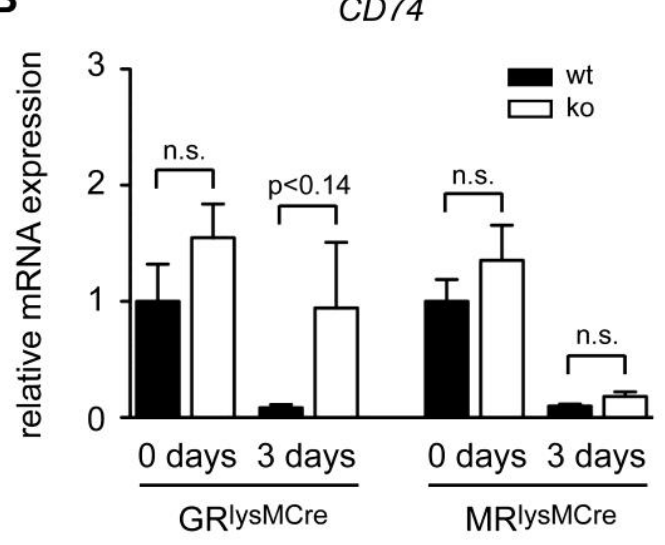

Taken together, my findings suggest that impaired gastric emptying after Dex treatment occurs independently of GC-induced macrophage polarization. 


\subsection{Role of genes specifically expressed in the gastrointestinal tract}

In the previously conducted microarray analysis two genes were found to be profoundly down-regulated after Dex treatment (highlighted in green in Table 9), namely Gasdermin C2 (Gsdmc2) and C3 (Gsdmc3). These two members of the novel Gasdermin gene family are exclusively expressed in epithelial cells of the gastrointestinal tract and skin and are believed to regulate epithelial apoptosis, although their exact function is not yet known (Saeki et al., 2000; Tamura et al., 2007). Hence I wondered whether down-regulation of these tissue-specific genes might contribute to GC-induced gastroparesis. To address this question I made use of my previous finding that GC-treatment of GR ${ }^{\text {dim }}$ mice does not lead to gastroparesis (Figure 12). Furthermore, I predicted that the change in stomach weight should be mirrored by a similar pattern in the change of gene expression being responsible for it. Hence I treated $G^{\text {dim }}$ and $G^{\text {wt }}$ mice with Dex through the drinking water for three days and subsequently analyzed mRNA expression of Gsdmc2 and Gsdmc3 by qRT-PCR in the stomach. Interestingly, both genes were down-regulated after GC-treatment regardless of the genotype (Figure 17).

A

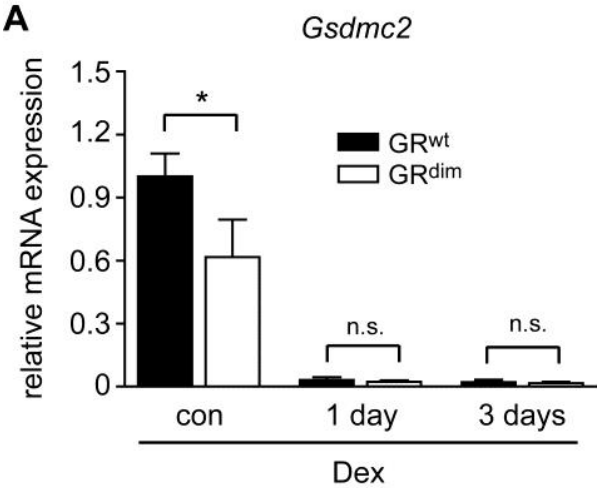

B

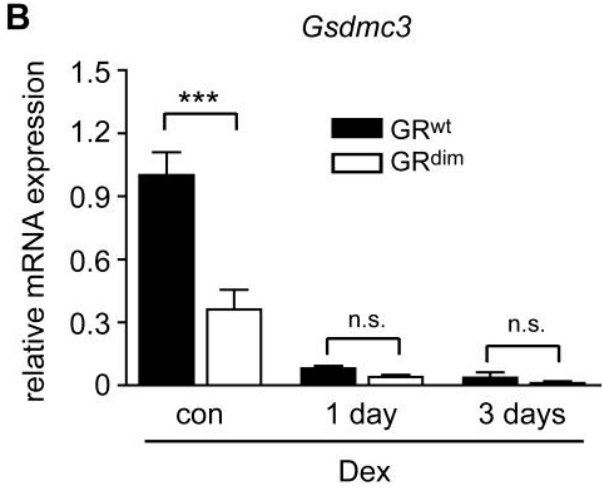

Figure 17. Reduced expression of Gsdmc2 and Gsdmc3 after Dex treatment is not responsible for induction of gastroparesis.

$\mathrm{GR}^{\mathrm{wt}}$ and $\mathrm{GR}^{\mathrm{dim}}$ mice were orally given Dex for either one or three days or the mice were left untreated (con). RNA was isolated from the stomach corpus and mRNA expression of (A) Gsdmc2 or (B) Gsdmc3 was analyzed by qRT-PCR, N =6-11. Relative expression levels were normalized to HPRT. Statistical analysis was performed by 2-way ANOVA followed by Bonferroni multiple comparison test; ${ }^{*}, P<.05 ;{ }^{* *}, P<.001$; n.s., not significant (Reichardt et al., 2014). 


\subsection{Role of genes related to the regulation of gastric motility}

\subsubsection{Expression of kallikrein 1, lipocalin 2 and arginase 2 in the stomach}

Having excluded the aforementioned genes Gsdmc2 and Gsdmc3 as possible candidates being responsible for the induction of gastroparesis by Dex I next focused on identifying genes that execute functions related to the regulation of gastric motility. In this context I found kallikrein 1 (Klk1), lipocalin 2 (Lcn2) and arginase 2 (Arg2) to be involved in the process of NO synthesis. All three of them were up-regulated in the stomach after Dex treatment according to the previously performed microarray analysis (highlighted in yellow in Table 8).

To further investigate whether these genes might indeed play a role in gastroparesis induction by GCs I employed the same strategy as described above, namely to verify whether up-regulation of these genes occurs in both $\mathrm{GR}^{\mathrm{wt}}$ and $\mathrm{GR}^{\mathrm{dim}}$ mice. Hence I isolated RNA from the corpus of mouse stomachs of $\mathrm{GR}^{\text {wt }}$ and $\mathrm{GR}^{\mathrm{dim}}$ mice after one or three days of oral Dex treatment and subsequently analyzed changes in mRNA expression levels of Klk1, Lcn2 and Arg2 employing qRT-PCR. Using this strategy I could confirm a considerable up-regulation of each of the three genes in Dex-treated $\mathrm{GR}^{\mathrm{wt}}$ mice, whereas analysis of mRNA expression levels in $\mathrm{GR}^{\mathrm{dim}}$ mice revealed only a slight increase after Dex treatment as shown in Figure 18.

Following my previous line of argumentation, namely that genes that are differentially regulated in $\mathrm{GR}^{\mathrm{dim}}$ and $\mathrm{GR}^{\mathrm{wt}}$ mice after Dex treatment should represent promising candidates to play a role in gastroparesis induction, these findings strongly suggested that each of the three analyzed genes might potentially be linked to the effect of loss of gastric motility in mice receiving GCs via the drinking water. 
A

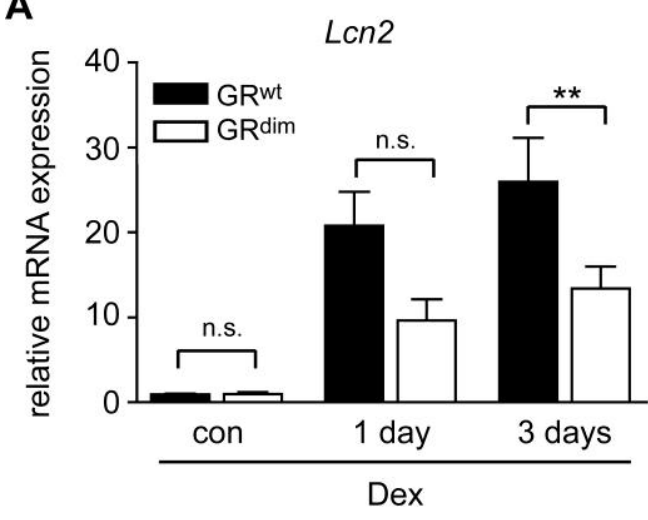

B

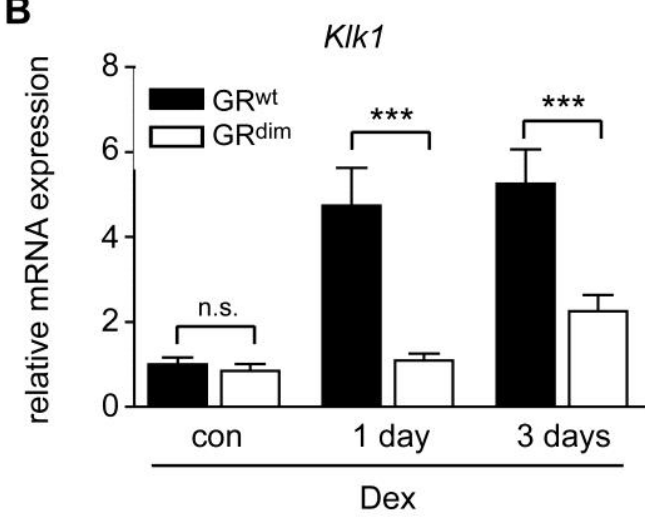

C

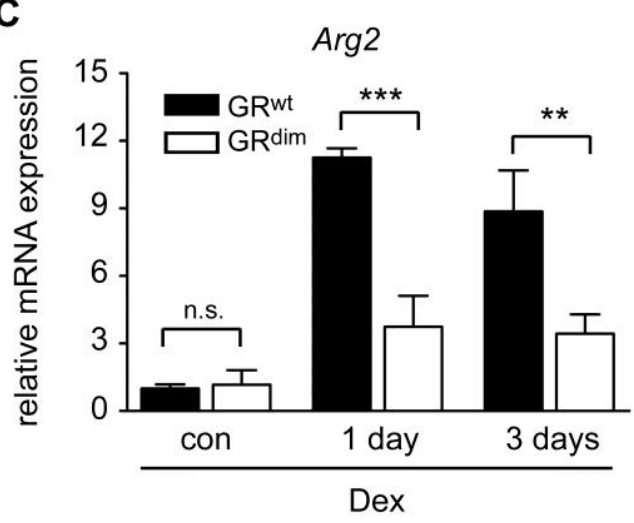

Figure 18. Identification of three GC target genes in the stomach that are differentially regulated in $\mathrm{GR}^{\mathrm{dim}}$ and $\mathrm{GR}^{\mathrm{wt}}$ mice following Dex administration.

$\mathrm{GR}^{\mathrm{dim}}$ mice and $\mathrm{GR}^{\mathrm{wt}}$ littermate controls were orally administered Dex for one or three days, respectively, or left untreated (con). Mice were then sacrificed and RNA was isolated from the corpus of mouse stomachs and analyzed for mRNA expression by qRT-PCR of $(A)$ lipocalin2 (Lcn2), $N=6-11$, (B) kallikrein1 (Klk1), $N=7-13$ and (C) arginase2 (Arg2), $N=6-11$. Data represent relative expression levels normalized to HPRT. Statistical analysis in all panels was performed by 2-way ANOVA followed by Bonferroni multiple comparison test, ${ }^{* \star}, p<.001 ;{ }^{* *} p<.01 ;$ n.s., not significant (Reichardt et al., 2014).

\subsubsection{Role of Lcn2 in gastric motility}

Neutrophil gelatinase-associated lipocalin (Lcn2) is a member of the lipocalin family of transport proteins (Schmidt-Ott et al., 2007) that plays an important role in various defense mechanisms of the innate immune system. During bacterial infections Lcn2 scavenges iron chelators that are produced from bacteria to facilitate uptake of iron, an essential element for all living organisms, from their host 
(Flo et al., 2004). An up-regulation of Lcn2 in the stomach, I therefore speculated, might result in a reduced availability of iron in different cell types.

Gastric motility is a complex process that has been shown to be impaired in the absence of NO (Mashimo et al., 2000). More specifically, NO production by nNOS is required to induce smooth muscle relaxation in the stomach. Importantly, since nNOS is a heme-containing enzyme, the generation of NO is an irondependent process. It is against this background that I hypothesized that the proposed deprivation of iron caused by GC-induced up-regulation of Lcn2 might be responsible for impaired gastric motility.

To investigate whether the mechanism of reduced iron availability indeed contributes to the induction of gastroparesis, the drinking water of female Balb/c mice was supplemented with iron in the form of iron (II) gluconate thus aiming to overcome the proposed iron deficiency caused by up-regulation of Lcn2. In detail, mice were administered an effective dosage of either $150 \mathrm{mg} / \mathrm{kg}^{*} \mathrm{~d}$ or 300 $\mathrm{mg} / \mathrm{kg}^{*} \mathrm{~d}$ via the drinking water starting one day prior to the addition of Dex thus allowing the mice to adjust to the altered taste of their drinking water. As a control some mice were left untreated and some were treated with iron (II) gluconate only, to exclude any potential side-effect of iron supplementation. Following this treatment the mice were sacrificed and the stomachs removed and weighed. My results show that an exogenous substitution with iron can indeed, to some extent, prevent the increase in stomach weight after Dex treatment regardless of the dosage of iron (II) gluconate as shown in Figure 19.

I therefore conclude that iron deficiency caused by up-regulation of Lcn2 might contribute to the induction of gastroparesis after GC treatment although it is presumably not the major mechanism. 


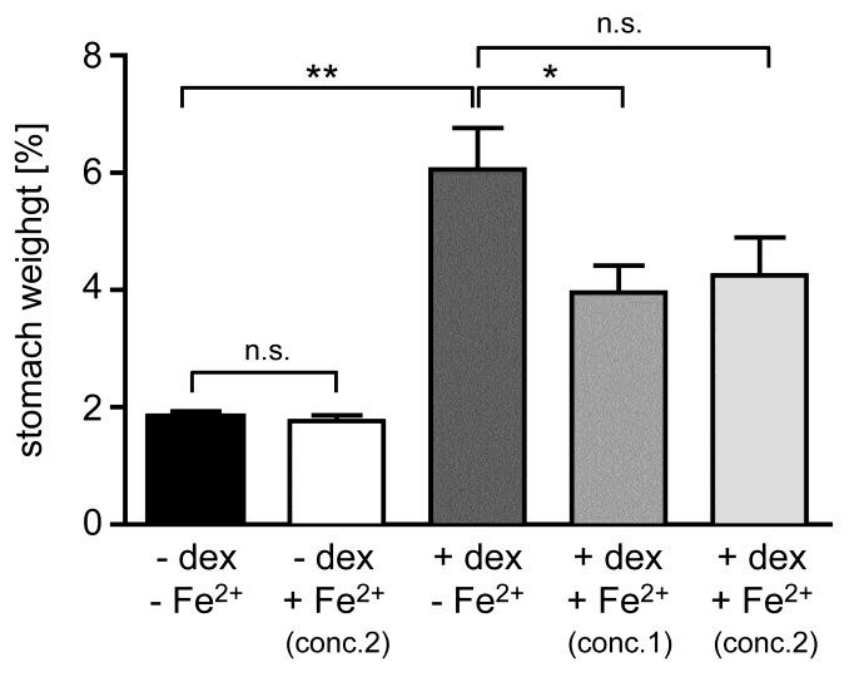

Figure 19. Iron supplementation partially prevents the increase in stomach weight caused by Dex treatment.

Mice were given iron (II) gluconate at a concentration of $600 \mathrm{mg} / \mathrm{L}$ (conc1) and $120 \mathrm{mg} / \mathrm{L}$ (conc2), respectively, via the drinking water starting one day prior to oral administration of $50 \mathrm{mg} / \mathrm{L}$ Dex. As a control some mice were given iron (II) gluconate or Dex only, and some mice were left untreated. After three days the stomach was removed and analyzed. Stomach weights are depicted as percentage of body weight, $\mathrm{N}=4-6$. Statistical analysis by unpaired $t$ test, ${ }^{*}, \mathrm{p}<.01 ;{ }^{*}, \mathrm{p}<.05$, n.s., not significant.

\subsubsection{Role of Arg2 in gastroparesis}

\subsubsection{Regulation of genes related to NO production}

When food enters the stomach it is churned and passed on to the small intestine in a wavelike movement of the stomach consisting of alternating contraction and relaxation of gastric smooth muscle layers, a process called peristalsis. An essential signalling molecule for the relaxation of the gastric muscles is NO (Abrahamsson and Jansson, 1969; Wilbur and Kelly, 1973), a volatile molecule produced by the enzyme family of NOS through oxidation of L-arginine to citrulline with simultaneous production of NO (Stuehr, 1997). However, the enzyme arginase which catalyzes the conversion of L-arginine to ornithine is known to compete with NOS for the same substrate (Wu and Morris, 1998). It is therefore feasible that enhanced gene transcription of Arg2 leads to an increased conver- 
sion of L-arginine to ornithine resulting in a limited availability of substrate for NO production.

There exist two isoforms of arginase that are found in different cell compartments. Arg1 is present in the cytosol whereas Arg2 is localized to the mitochondria. To test my hypothesis that Arg2 impacts gastroparesis through depletion of NO I first set out to exclude a direct effect of GCs on nNOS expression and to investigate a potential role of the cytosolic isoenzyme arginase 1. $G R^{\mathrm{dim}}$ and $G R^{\mathrm{wt}}$ mice were orally administered Dex for three days or left untreated. Afterwards RNA was isolated from the stomach corpus and mRNA expression of arg1 and nNOS were analyzed using qRT-PCR. My analysis indicates that mRNA expression of $\arg 1$ is not altered by Dex treatment in the stomach, neither in $\mathrm{GR}^{\mathrm{wt}}$ nor $\mathrm{GR}^{\mathrm{dim}}$ mice, which rules out a potential role for arg1 in gastroparesis induction (Figure 20A). A similar finding was made concerning nNOS expression, which was unaltered in $\mathrm{GR}^{\mathrm{dim}}$ mice but slightly increased in $\mathrm{GR}^{\mathrm{wt}}$ mice although without reaching statistical significance (Figure 20B). Importantly, however, elevated levels of nNOS would be expected, if at all, to increase NO production rather than diminishing it.

A

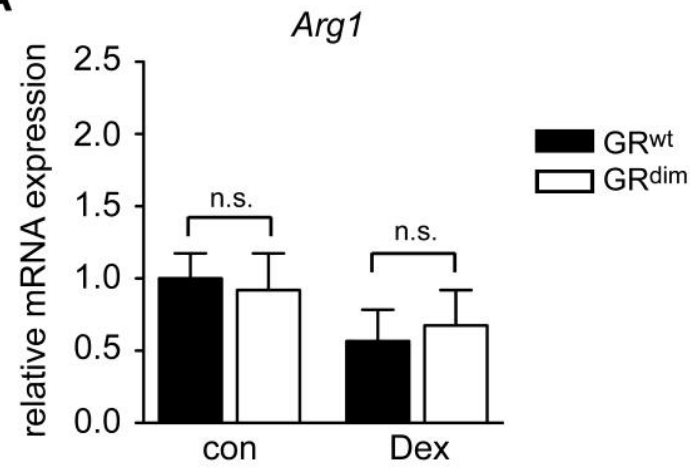

B

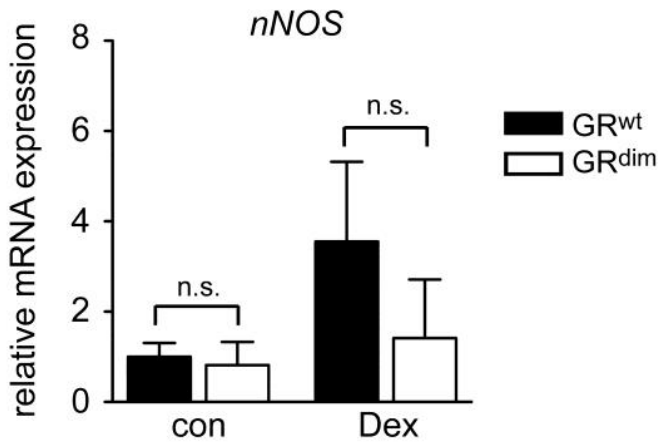

Figure 20. Gene expression of arg1 and nNOS in the stomach after Dex treatment. $\mathrm{GR}^{\mathrm{wt}}$ and $\mathrm{GR}^{\mathrm{dim}}$ mice were treated with Dex for three days or left untreated (con). RNA was isolated from the corpus of mouse stomachs and mRNA expression was determined using qRT-PCR for $(A) \operatorname{Arg} 1(N=5-10)$ and $(B)$ nNOS $(N=3)$. Relative expression levels were normalized to HPRT. Statistical analysis by 2-way ANOVA followed by Bonferroni multiple comparison test, n.s., not significant (Reichardt et al., 2014). 
Altogether, these findings exclude that GC treatment influences NO production by impacting the expression of other genes, at least not via direct effects on Arg1 and nNOS.

\subsubsection{Regulation of Arg2 at the protein level}

To further investigate the role of Arg2 in gastroparesis I set out to test whether the enhanced transcription of Arg2 also translated into higher protein levels. Hence, female Balb/c mice were administered Dex via the drinking water for three days or left untreated. Stomachs were then removed and lysates were prepared. By employing Western Blot analysis I could identify a strong increase in Arg2 protein levels in $\mathrm{GR}^{\mathrm{wt}}$ but not in $\mathrm{GR}^{\mathrm{dim}}$ mice (Figure 21).

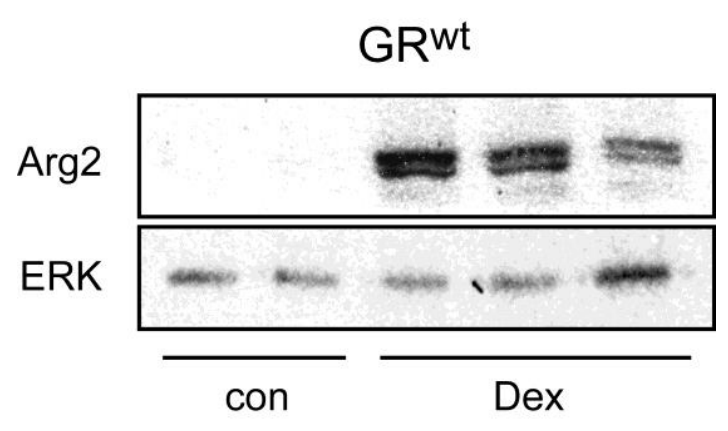

GRdim

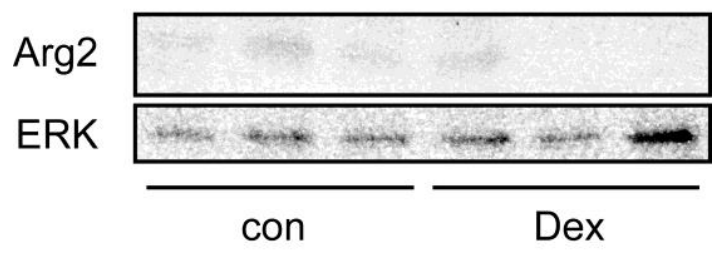

Figure 21. Arg2 protein levels are increased after Dex treatment in $\mathbf{G R}^{\mathrm{wt}}$ but not $\mathrm{GR}^{\mathrm{dim}}$ mice.

Protein was isolated from the stomach of $\mathrm{GR}^{\mathrm{dim}}$ or $\mathrm{GR}^{\mathrm{wt}}$ mice treated with Dex for three days or left untreated (con) and analyzed for Arg2 protein levels by Western Blot. ERK was used as a loading control. One representative experiment is shown (Reichardt et al., 2014).

These findings strongly support my hypothesis that an increase in Arg2 mRNA expression leads to an enhanced translation into Arg2 protein, which in turn presumably leads to an increase of enzymatic capacity for the conversion of $\mathrm{L}$-arginine to ornithine thus depleting the substrate for NO production. 


\subsubsection{L-arginine supplementation prevents GC-induced gastroparesis}

To provide additional evidence for my theory that a shortage in L-arginine was responsible for the induction of gastroparesis, I applied the same strategy as before, namely to overcome the potential limitation of substrate by supplying it exogenously to the mice.

Analogous to my previous experimental setup for the supplementation with iron I added an amount of $1 \% \mathrm{~L}$-arginine to the drinking water of female Balb/c mice one day prior to Dex treatment to ensure acceptance of this medication. Afterwards one group of mice was administered $50 \mathrm{mg} / \mathrm{L}$ Dex together with $1 \% \mathrm{~L}$ arginine via the drinking water whereas a second group orally received $50 \mathrm{mg} / \mathrm{L}$ of Dex only. As a control some mice were left untreated.

As shown in Figure 21, treatment with L-arginine completely prevented the increase in stomach weight as compared to mice treated with Dex only.

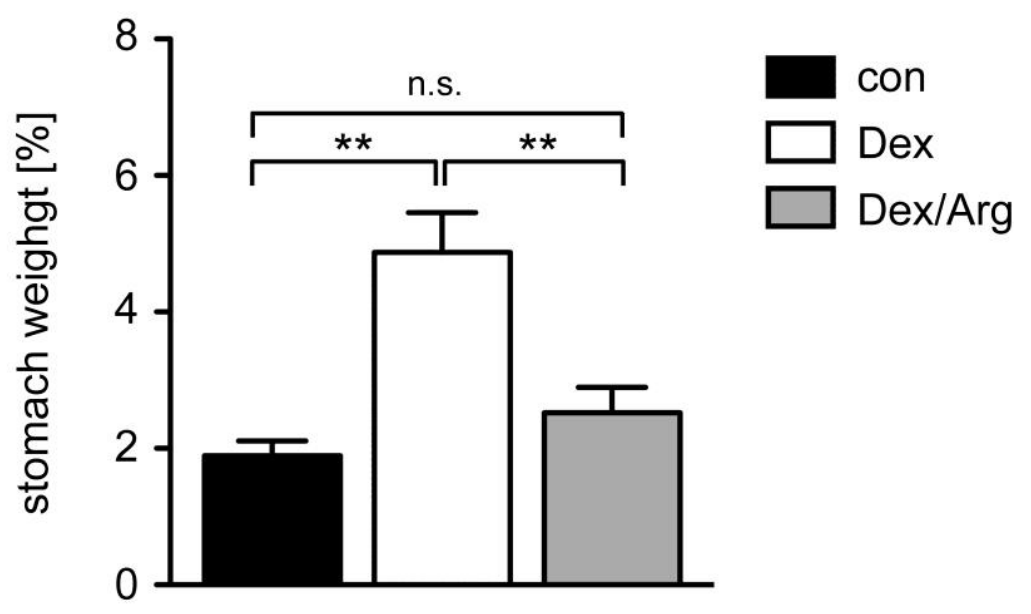

Figure 21. Supplementation of the drinking water with L-arginine prevents the increase in stomach weight after Dex treatment.

Female Balb/c mice either received $50 \mathrm{mg} / \mathrm{L}$ Dex (white bar) or $50 \mathrm{mg} / \mathrm{L}$ Dex plus $1 \%$ L-arginine (Arg, grey bar) via the drinking water or were left untreated (black bar). After three days the mice were sacrificed and the stomachs removed and weighed. The stomach weight is depicted as mean percentage of body weight, $N=4,8$ or 9 . Statistical analysis by unpaired $t$ test. ${ }^{* *}, p<.01$; n.s., not significant (Reichardt et al., 2014). 
To confirm that lack of increase in stomach weight indeed results from restored gastric emptying I subjected mice to exactly the same treatment as described above. In brief, mice were orally administered either Dex or Dex and L-arginine together via the drinking water, or they were left untreated. After three days the mice were fasted for 20 hours before receiving a test meal of methylcellulose stained with phenol red by oral gavage. Mice were sacrificed thirty minutes after force-feeding, the stomach clamped and removed. After homogenization the residual amount of the stained meal in the stomach was determined by measuring absorption of phenol red at a wavelength of $562 \mathrm{~nm}$ using a photometer. As a baseline control some mice were sacrificed immediately after force-feeding and the stomach content determined accordingly. The percentage of gastric emptying was calculated and is depicted in Figure 22.

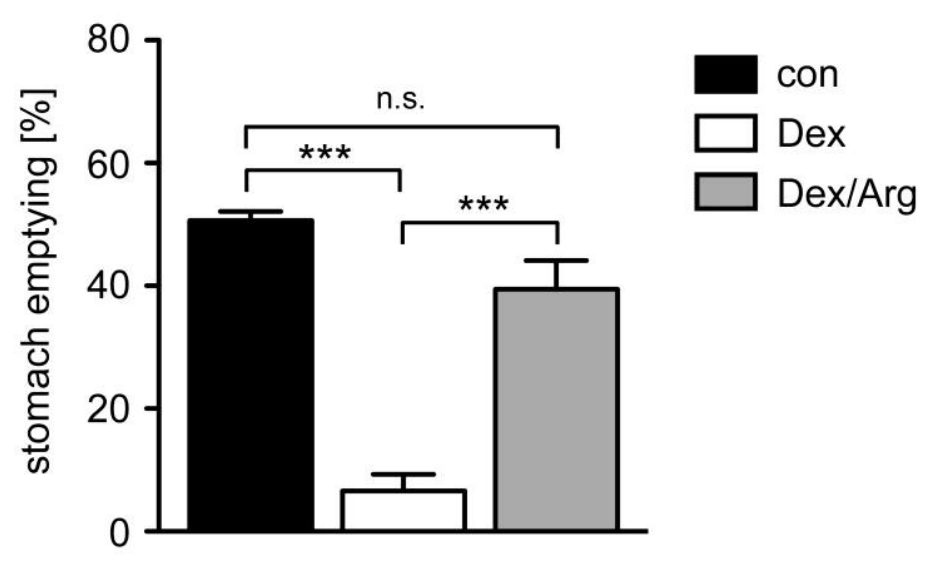

Figure 22. Supplementation with L-arginine restores the normal gastric emptying otherwise impaired by GC treatment.

Female Balb/c mice were treated with either $50 \mathrm{mg} / \mathrm{L}$ Dex (white bar) or $50 \mathrm{mg} / \mathrm{L}$ Dex and $1 \% \mathrm{~L}$-arginine (Arg, grey bar) for three days via the drinking water, or they were left untreated (black bar). After 20 hours of fasting the mice were given a stained test meal by gavage. Mice were sacrificed either immediately (time 0) or after 30 minutes (time 30), and the stomachs clamped, removed and homogenized. The amount of remaining test meal in the stomach was determined by measuring the absorption of the stomach content at $562 \mathrm{~nm}$. Gastric emptying was calculated as the ratio between absorption after $30 \mathrm{~min}$ divided by the absorption at time point $0 \mathrm{~min}$ and is depicted as mean percentage of gastric emptying, ( $N=4,7$ or 11$)$. Statistical analysis by unpaired $t$ test. ${ }^{* * *}, \mathrm{p}<.001$; n.s., not significant (Reichardt et al., 2014). 
As found previously, gastric emptying was strongly impaired after three days of oral Dex treatment. Importantly, the additional administration of L-arginine together with Dex completely restored gastric emptying to normal levels. Hence, this finding is in line with my previous observation that supplementation with $\mathrm{L}$-arginine prevents the increase in stomach weight after GC administration.

Arg2 catalyzes the conversion of arginine to ornithine. The latter is further catabolized by ornithine decarboxylase (Odc) to produce polyamines. Accordingly I hypothesized that increased availability of L-arginine would lead to increased mRNA expression levels of Arg2 and Odc. To test this hypothesis I isolated RNA from the corpus of stomachs of mice that were treated with Dex or a combination of Dex and L-arginine, or left untreated, and subsequently performed a qRT-PCR analysis. In line with my previous findings the expression of Arg2 was increased after Dex treatment. Furthermore, Odc was also higher, presumably as a result of the enhanced enzymatic capacity of Arg2 to produce ornithine leading to an increased substrate availability for Odc. More importantly, however, supplementation of the drinking water with L-arginine led to a further increase in both Arg2 and Odc mRNA expression (Figure 23).

A

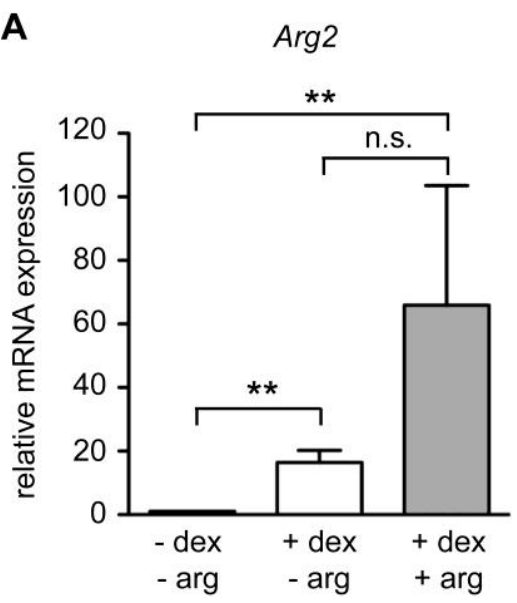

B

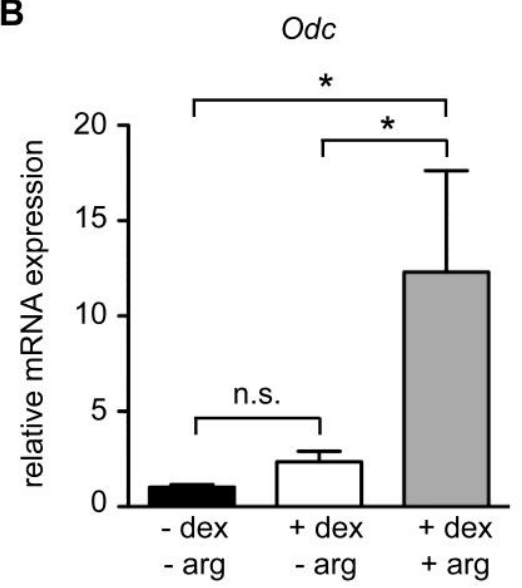

Figure 23. Supplementation with L-arginine leads to enhanced expression of Arg2 and Odc

Mice were treated with Dex \pm L-arginine or left untreated. RNA was isolated from the stomach corpus and mRNA expression levels of $\arg 2(A)$ and odc $(B)$ were determined by qRT-PCR and normalized to HPRT as a housekeeping gene. $N=4,7$, or 9 . Statistical analysis by Mann-Whitney $U$ test. ${ }^{* *}, p<.01$; ${ }^{*}, p<.05$; n.s., not significant (Reichardt et al., 2014). 
These results confirm that L-arginine indeed reaches the stomach and impacts the respective metabolic enzymes. Since the conversion to ornithin and polyamines is increased, one can deduce that also NO production is restored by this measure.

Taken together these findings strongly support the hypothesis that Dex-induced gastroparesis is caused by depletion of L-arginine.

\subsubsection{Inhibition of Arg2 only partially restores gastric emptying}

Another possibility to restore the availability of L-arginine, which is the substrate for nNOS and needed to produce NO in order to allow for proper gastric emptying, is to inhibit the competitive reaction catalyzed by Arg2. In general, inhibition of arginase can be achieved by arginine analogues by blocking the binding site for the substrate. However, under these conditions also NOS is at risk of being inhibited. Therefore I used (S)-(2-Boronoethyl)-L-cystein hydrochlorid (BEC) in my experiments to selectively inhibit arginase but not NOS activity.

In detail, mice were treated with Dex via the drinking water for three days. Throughout the whole duration of the treatment, mice additionally received $0,1 \mathrm{ml}$ of BEC at a concentration of $1 \mathrm{mg} / \mathrm{ml}$ once a day by oral gavage. Upon completion of the treatment, mice were sacrificed and either the stomach weight or gastric emptying was determined (Figure 24A,B). Notably, neither the increase in stomach weight nor gastroparesis could be completely prevented by administration of BEC. Nonetheless, there was a clear effect on both parameters although the reduction of stomach weight as well as the improvement in gastric emptying just missed significance. My finding that the rescue effect of the BEC treatment was not as good as the one of $\mathrm{L}$-arginine supplementation may be due to the fact that BEC could only be applied intermittently while administration of Dex was continuously maintained throughout the whole experiment. Hence, up-regulation of Arg2 by Dex and the presumably resulting higher enzymatic capacity for the conversion of arginine to ornithine could only be counteracted by the inhibition of arginase during limited periods of time. Unfortunately a continuous application of the inhibitor was not possible due to technical reasons. Furthermore, the admin- 
istration of BEC by gavage more often than once daily would have imposed an unacceptable level of stress to the animals and was therefore discarded as an alternative approach.

A

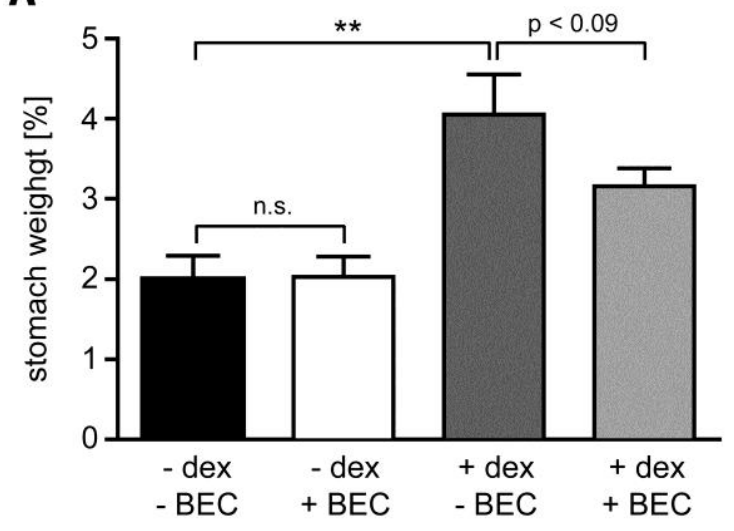

B

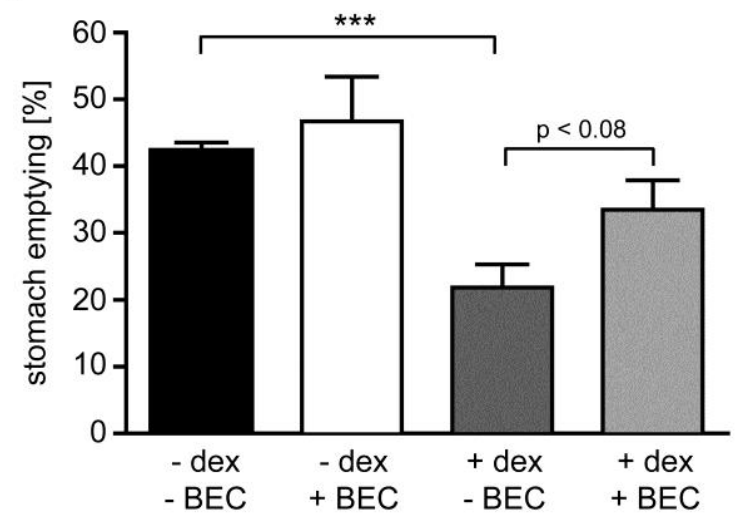

Figure 24. Inhibition of arginase only partially prevents the increase in stomach weight and the reduction in gastric emptying.

Female Balb/c wildtype mice were treated with Dex via the drinking water for three days or left untreated. Some mice additionally received BEC at an effective dosage of 0,4 $\mathrm{mg} / \mathrm{kg}$ by oral gavage once daily. (A) Stomachs were removed and weighed and are depicted as percentage of body weight, $\mathrm{N}=8$ or 14 . (B) To determine gastric emptying mice were fasted for 20 hours before feeding a stained test meal of methyl cellulose by gavage. After 30 min mice were sacrificed, the stomach clamped, carefully removed and homogenized. After centrifugation the absorption of the remains of stained meal in the stomach was measured at $562 \mathrm{~nm}$. Some mice were sacrificed immediately after forcefeeding and analyzed likewise thus providing a baseline control. Gastric emptying was calculated and is depicted as percentage of stomach emptying, $N=7,8$ or 14 . Statistical analysis by unpaired $t$ test, ${ }^{* *}, \mathrm{p}<.001 ;{ }^{* *}, \mathrm{p}<.01$; n.s., not significant.

As a consequence, my results suggest that inhibition of arginase by pharmacological blockade might be a means to interfere with Dex-induced gastroparesis although it would be necessary to explore ways to provide BEC or alternative inhibitors in a more continuous manner. 


\section{Discussion}

\subsection{Adverse effects of glucocorticoids in the gastrointestinal tract}

Despite the fact that pharmacological application of GCs can lead to a plethora of side-effects they are still the gold standard for treating a variety of autoimmune and atopic disorders, other inflammatory conditions such as Graft-versus-host disease as well as neoplastic diseases including leukemia and lymphoma. Typically encountered adverse effects of GCs are hyperglycemia, diabetes, myopathies, elevated blood pressure, osteoporosis, growth retardation and depression. However, there are also side-effects that concern the gastrointestinal tract. In my study I focussed on a novel activity of GCs in the stomach, namely the induction of gastroparesis. Of note, GCs have previously been found to affect the digestive system in several ways. For instance, it is well known that increased levels of endogenous GCs, e.g. during emotional or physical stress, as well as synthetic GCs administered during therapy enhance gastric acid secretion and may therefore foster the formation of peptic ulcers. Furthermore, gastrointestinal bleeding and pancreatitis have been reported to accompany GC therapy as well (Schäcke et al., 2002).

This work now gives evidence that gastroparesis is a so far unknown side-effect of GC therapy. Although impaired gastric motility is well known to occur in the course of diabetes, it has not yet been referred to as an adverse effect of highdose oral GC therapy. Contrariwise, gastrointestinal disturbances in general are frequently reported as symptoms accompanying GC therapy. It may therefore well be that discomfort experienced by patients is in fact caused by gastroparesis but wrongly assigned to enhanced gastric acid secretion and the formation of ulcers.

In recent years considerable effort has been made to dissect beneficial and adverse GC effects. To put it simple, GC actions mediated by transcriptional regulation can be subdivided into two major groups based on their molecular mechanism, namely those relying on trans-activation of genes as opposed to those re- 
sulting from trans-repression of genes. It was long believed that trans-activation was responsible for most of the unwanted physiological effects of GCs, whereas anti-inflammatory properties were thought to be mainly mediated by the transrepression mechanism. A common strategy to reduce side-effects caused by GCs was therefore the development of new drugs that dissociate these two modes of action. A couple of compounds with such properties, e.g. ZK 216348 or Org214007, have been reported over the years but none of them made it into the clinic so far (Schäcke et al., 2004; van Lierop et al., 2012). This is possibly because it has recently become clear that the concept of dissecting trans-activation and trans-repression as a mean to avoid adverse effects had been oversimplified.

Namely, it has been shown that some anti-inflammatory effects of GCs require gene trans-activation (Clark, 2007) whereas some side-effects are the result of the combination of gene trans-activation and trans-repression (Schäcke et al., 2004). One example of a major side-effect of GC therapy that is even exclusively mediated by trans-repression is osteoporosis. This observation was made when treating GR $^{\text {dim }}$ mice with synthetic GCs, which efficiently induced bone loss despite the disruption of GR trans-activation in these mice (Rauch et al., 2010). This example clearly shows that it will not be possible to separate all beneficial from the adverse GC effects by dissociating GC derivatives although it might still be feasible to separate selected anti-inflammatory properties from individual side effects.

Interestingly, many of the adverse effects of GCs in the gastrointestinal tract apparently rely on gene trans-activation by the GR. This includes the enhanced intestinal glucose uptake that contributes to hyperglycemia (Reichardt et al., 2012), the increase in gastric acid secretion and, as identified in this work, the induction of gastroparesis. Currently it is not known whether the treatment of IBD, one of the major therapeutic applications of synthetic GCs in the gastrointestinal tract, requires trans-activation or rather trans-repression of genes by the GR. Nonetheless, it is likely that the trans-repressive mechanism at least plays some role, which would open up the possibility to separate the beneficial GC ef- 
fects in the treatment of IBD at least partially from the adverse ones in the gastrointestinal tract. Despite the fact that none of the new dissociating GR ligands could so far meet the expectations to overcome all side-effects of GC therapy, our study now suggests that the idea to design new drugs specifically aimed to prevent adverse effects in the stomach remains a promising approach.

\subsection{The molecular mechanism of GCs in gastroparesis}

The induction of gastroparesis by high-dose oral GC therapy has to my knowledge not been described before in literature. Accordingly, nothing has been known concerning the underlying molecular mechanism. To tackle this issue several experimental approaches have been taken, including conditional knockout mice, gene expression analysis and physiological assays. First, GR ${ }^{\text {villincre }}$ mice allowed me to exclude that gastroparesis was indirectly caused by GC effects on the intestine. Second, the analysis of $G R^{\text {dim }}$ mice indicated that altered gene transcription and, more specifically, gene trans-activation by the GR was responsible for this effect. Based on these findings it was reasonable to search for genes that were transcriptionally altered by Dex treatment in the stomach. By using this method a number of promising candidates could be identified.

The stomach wall contains a considerable number of macrophages and consequently several genes specific for this cell type were identified to be affected by Dex treatment. Of note, macrophages can polarize to phenotypes designated M1 or M2. Interestingly, the observed changes in the stomach were typical for a M2 polarization, which is generally observed in response to GC action (Varga et al., 2008). Whilst I could confirm the changes in gene expression and thus the $M 2$ polarization by qRT-PCR, neither the deletion of the GR nor of the MR, two receptors which are able to bind GCs, had any effect on the induction of gastroparesis. This suggests that macrophages are not a cause of impaired gastric motility but may rather serve as a repair mechanism in the stomach aimed to counteract other GC effects in the stomach such as ulcers. 
Amongst the genes identified in the mircroarray experiment there were also two genes which are largely restricted to the gastrointestinal tract (Saeki et al., 2000). Gsdmc 2 and 3 were strongly down-regulated after Dex treatment, however this was the case in $\mathrm{GR}^{\mathrm{wt}}$ as well as $\mathrm{GR}^{\mathrm{dim}}$ mice. Since $\mathrm{GR}^{\mathrm{dim}}$ mice do not develop gastroparesis in response to GC therapy it is unlikely that inhibition of Gsmdc 2 and 3 contribute to this adverse effect in the stomach.

In contrast to the two gasdermin genes, Lcn2, Klk1 and Arg2 were up-regulated after Dex treatment and, importantly, this was only the case in $\mathrm{GR}^{\mathrm{wt}}$ but not $\mathrm{GR}^{\mathrm{dim}}$ mice. Hence, the regulation of these genes by Dex parallels the induction of gastroparesis in mice of both genotypes. Lcn2 is known for its capacity to reduce iron availability (Flo et al., 2004), and iron is part of the heme-complex which, in turn, is required for enzymatic activity of NOS. Consequently, enhanced levels of Lcn2 would be expected to impair NOS function and thereby NO production. As outlined below, this is a prerequisite for proper gastric motility. My attempt to exogenously provide iron to overcome a potential shortage of iron due to increased Lcn2 expression normalized gastric motility partially but not completely. This can be interpreted in such a way, that the postulated effect of higher Lcn2 expression indeed contributes to the induction of gastroparesis but does not suffice to explain it.

Gastric motility is a complex process that requires the interaction between the enteric and the central nervous system. Intriguingly, NO, a small volatile molecule, is a key player in the signal transduction pathway that regulates muscle contraction and relaxation in the stomach (Rivera et al., 2011). It is produced through the conversion of $\mathrm{L}$-arginine to citrulline and $\mathrm{NO}$, a reaction catalyzed by nNOS. Due to its volatile nature NO has to be produced on demand and in close vicinity to its target cells where it is immediately inactivated upon reaction with its target (Esplugues, 2002). Thus NO production can only be controlled by regulating its synthesis but not via downstream degrading mechanisms. It is therefore likely that substrate availability is the primary means to control NO biosynthesis. In this context it is noteworthy that L-arginine is also converted to ornithine by Arg1 and 2, which are competing with nNOS for the same substrate. Conse- 
quently, my finding that Arg2 is up-regulated after oral administration of Dex provides a plausible explanation how reduced NO production in the gastric wall might occur as a consequence of reduced substrate availability. I have provided two lines of evidence that this hypothesis is indeed true. First, providing exogenous L-arginine indeed prevents gastroparesis, indicating that a limitation in the amount of available L-arginine is presumably the cause of impaired gastric motility. Second, direct pharmacological inhibition of arginase at least partially prevents the effect of Dex on the stomach. This can be taken as an additional piece of evidence that Arg2 is involved in the induction of gastroparesis. Finally, besides mechanistically explaining the mode of GC action in the stomach, my finding that supplementing the drinking water with L-arginine allows to circumvent gastroparesis now offers a simple method, applicable in clinical practice, to improve tolerability of GC therapy by patients.

\subsection{The anti-emetic effect of GCs}

Chemotherapy-induced nausea and vomiting (CINV) is a major side-effect in cancer patients and is often a limiting factor for the dosage of anti-cancer drugs such as cisplatin in the anti-tumor treatment regimens. The use of anti-emetic drugs is therefore indispensible to reduce CINV and increase tolerability of anticancer therapy (Rao and Faso, 2012). GCs are known to have such an antiemetic effect although the underlying mechanism has been unknown so far. Inhibition of prostanoid synthesis was proposed as a possible mechanism as well as a stabilizing effect on membranes thus hampering the entry of emetic substances into the CNS. However, some of the anti-emetic properties of GCs are not sufficiently explained by the aforementioned modes of action (Tanihata et al., 2004).

In my work I have demonstrated that Dex causes gastroparesis presumably through up-regulation of Arg2, which diminishes the availability of L-arginine for NO synthesis. Interestingly, gastrointestinal side-effects of cisplatin such as reduced colonic motor activity and altered intestinal transit time have been related to changes in NOS activity and thus NO levels as well. Namely, it has been 
shown that cisplatin affects the enteric nervous system by damaging myenteric neurons thus leading to neuronal loss in the myenteric plexus while on the other hand the number of NOS immunoreactive neurons increase after cisplatin treatment (Vera et al., 2011). Moreover, nNOS has been found to be up-regulated by cisplatin, an effect that could be prevented through administration of an nNOS inhibitor (Jung et al., 2009). Altogether, these data suggest that CINV might be caused by increased NO synthesis in the stomach. As our finding indicate that NO levels are reduced after Dex treatment due to limited substrate availability, it appears likely that the anti-emetic effect of GCs is due to its antagonistic activity with regard to NO synthesis in the stomach. 


\section{Summary}

Ever since their first successful application in the treatment of RA patients in the late 1950, GCs have been the gold standard for the treatment of multiple inflammatory and neoplastic diseases. There are, however, also severe adverse effects that denote restrictions upon the use of GCs. In particular oral application of GCs can lead to gastrointestinal complications that may severely affect the patient's quality of life and lead to a reduced tolerability of the therapy. In this work I have described and characterized gastroparesis as a so far unrecognized effect of GCs in the gastrointestinal tract that is mediated via trans-activation of genes. Changes in gene expression characteristic for M2 macrophage polarization proved to be unrelated to gastroparesis. Similarly, an involvement of two genes specifically expressed in the gastrointestinal tract could be ruled out. In contrast, I could confirm that genes related to the regulation of NO production contribute to gastroparesis. A decrease in iron availability through up-regulation of Lcn2 was found to partially impact on gastric motility whereas reduced substrate availability for NO synthesis through up-regulation of Arg2 proved to be responsible for impaired gastric emptying. Hence, GC therapy causes gastroparesis by increasing gene expression in the stomach in a DNA-binding-dependent manner thereby diminishing the availability of NO required for gastric motility. Complete prevention of gastroparesis was achieved by an exogenous supply of $\mathrm{L}$-arginine thus providing a means to overcome the observed effect with the help of a dietary supplement. My study also offers a possible explanation for the anti-emetic effect of GCs that has been used for long to interfere with CINV without knowing the underlying mechanism. Now it appears likely that reducing NO availability in the stomach is the way how GCs counteract CINV, which is accompanied by increased NO production. Unfortunately, further elucidation of this process is impossible in rodent models due to the inability of mice and rats to vomit. Taken together, the identification and characterization of GC-induced gastroparesis sheds new light on both adverse and beneficial activities of GCs in the stomach and may help to optimize therapy in the future for the patients' benefit. 


\section{References}

Abrahamsson, H., and Jansson, G. (1969). Elicitation of reflex vagal relaxation of the stomach from pharynx and esophagus in the cat. Acta Physiol Scand 77, 172-178.

Adcock, I.M., and Barnes, P.J. (2008). Molecular mechanisms of corticosteroid resistance. Chest 134, 394-401.

Andrew, P.J., and Mayer, B. (1999). Enzymatic function of nitric oxide synthases. Cardiovasc Res 43, 521-531.

Bandyopadhyay, U., Biswas, K., Bandyopadhyay, D., Ganguly, C.K., and Banerjee, R.K. (1999). Dexamethasone makes the gastric mucosa susceptible to ulceration by inhibiting prostaglandin synthetase and peroxidase--two important gastroprotective enzymes. Mol Cell Biochem 202, 31-36.

Baschant, U., Frappart, L., Rauchhaus, U., Bruns, L., Reichardt, H.M., Kamradt, T., Brauer, R., and Tuckermann, J.P. (2011). Glucocorticoid therapy of antigeninduced arthritis depends on the dimerized glucocorticoid receptor in $\mathrm{T}$ cells. Proc Natl Acad Sci U S A 108, 19317-19322.

Baumann, S., Dostert, A., Novac, N., Bauer, A., Schmid, W., Fas, S.C., Krueger, A., Heinzel, T., Kirchhoff, S., Schütz, G., et al. (2005). Glucocorticoids inhibit activation-induced cell death (AICD) via direct DNA-dependent repression of the CD95 ligand gene by a glucocorticoid receptor dimer. Blood 106, 617-625.

Beato, M. (1989). Gene regulation by steroid hormones. Cell 56, 335-344.

Beato, M., Herrlich, P., and Schütz, G. (1995). Steroid hormone receptors: many actors in search of a plot. Cell 83, 851-857.

Beato, M., and Klug, J. (2000). Steroid hormone receptors: an update. Hum Reprod Update 6, 225-236.

Burton, J.M., O'Connor, P.W., Hohol, M., and Beyene, J. (2012). Oral versus intravenous steroids for treatment of relapses in multiple sclerosis. Cochrane Database Syst Rev 12, CD006921.

Buttgereit, F., and Scheffold, A. (2002). Rapid glucocorticoid effects on immune cells. Steroids 67, 529-534.

Cannon, W.B. (1898). The movements of the stomach. J Boston Soc Med Sci 2, 59-66.

Cannon, W.B., and Lieb, C. (1911). The receptive relaxation of the stomach. Am J Physiol 29. 
Cato, A.C., Nestl, A., and Mink, S. (2002). Rapid actions of steroid receptors in cellular signaling pathways. Sci STKE 2002, re9.

Cheung, J., and Smith, D.F. (2000). Molecular chaperone interactions with steroid receptors: an update. Mol Endocrinol 14, 939-946.

Clark, A.R. (2007). Anti-inflammatory functions of glucocorticoid-induced genes. Mol Cell Endocrinol 275, 79-97.

Cole, T.J., Blendy, J.A., Monaghan, A.P., Krieglstein, K., Schmid, W., Aguzzi, A., Fantuzzi, G., Hummler, E., Unsicker, K., and Schütz, G. (1995). Targeted disruption of the glucocorticoid receptor gene blocks adrenergic chromaffin cell development and severely retards lung maturation. Genes Dev 9, 1608-1621.

Cooke, A.R., Preshaw, R.M., and Grossman, M.L. (1966). Effect of adrenalectomy and glucocorticoids on the secretion and absorption of hydrogen $\mathrm{i}$ ion. Gastroenterology 50, 761-767.

Croxtall, J.D., Choudhury, Q., and Flower, R.J. (2000). Glucocorticoids act within minutes to inhibit recruitment of signalling factors to activated EGF receptors through a receptor-dependent, transcription-independent mechanism. $\mathrm{Br} \mathrm{J}$ Pharmacol 130, 289-298.

Dahlman-Wright, K., Siltala-Roos, H., Carlstedt-Duke, J., and Gustafsson, J.A. (1990). Protein-protein interactions facilitate DNA binding by the glucocorticoid receptor DNA-binding domain. J Biol Chem 265, 14030-14035.

De Bosscher, K., and Haegeman, G. (2009). Minireview: latest perspectives on antiinflammatory actions of glucocorticoids. Mol Endocrinol 23, 281-291.

Esplugues, J.V. (2002). NO as a signalling molecule in the nervous system. $\mathrm{Br} \mathrm{J}$ Pharmacol 135, 1079-1095.

Evans, R.M. (1988). The steroid and thyroid hormone receptor superfamily. Science 240, 889-895.

Filaretova, L., Bagaeva, T., and Makara, G.B. (2002). Aggravation of nonsteroidal antiinflammatory drug gastropathy by glucocorticoid deficiency or blockade of glucocorticoid receptors in rats. Life Sci 71, 2457-2468.

Flo, T.H., Smith, K.D., Sato, S., Rodriguez, D.J., Holmes, M.A., Strong, R.K., Akira, S., and Aderem, A. (2004). Lipocalin 2 mediates an innate immune response to bacterial infection by sequestrating iron. Nature 432, 917-921.

Ford, A.C., Bernstein, C.N., Khan, K.J., Abreu, M.T., Marshall, J.K., Talley, N.J., and Moayyedi, P. (2011). Glucocorticosteroid therapy in inflammatory bowel disease: systematic review and meta-analysis. Am J Gastroenterol 106, 590599. 
Freedman, N.D., and Yamamoto, K.R. (2004). Importin 7 and importin alpha/importin beta are nuclear import receptors for the glucocorticoid receptor. Mol Biol Cell 15, 2276-2286.

Furness, J.B. (2006). The enteric nervous system. Wiley-Blackwell. Gangula, P.R., Sekhar, K.R., and Mukhopadhyay, S. (2011). Gender bias in gastroparesis: is nitric oxide the answer? Dig Dis Sci 56, 2520-2527.

Gershon, M.D. (2005). Nerves, reflexes, and the enteric nervous system: pathogenesis of the irritable bowel syndrome. J Clin Gastroenterol 39, S184-193.

Gray, S.J., Benson, J.A., Jr., and Reifenstein, R.W. (1951). Chronic stress and peptic ulcer. I. Effect of corticotropin (ACTH) and cortisone on gastric secretion. J Am Med Assoc 147, 1529-1537.

Hernandez-Diaz, S., and Rodriguez, L.A. (2001). Steroids and risk of upper gastrointestinal complications. Am J Epidemiol 153, 1089-1093.

Herrlich, P. (2001). Cross-talk between glucocorticoid receptor and AP-1. Oncogene 20, 2465-2475.

Jung, M., Hotter, G., Vinas, J.L., and Sola, A. (2009). Cisplatin upregulates mitochondrial nitric oxide synthase and peroxynitrite formation to promote renal injury. Toxicol Appl Pharmacol 234, 236-246.

Kassander, P. (1958). Asymptomatic gastric retention in diabetics (gastroparesis diabeticorum). Ann Intern Med 48, 797-812.

Kirwan, J., and Power, L. (2007). Glucocorticoids: action and new therapeutic insights in rheumatoid arthritis. Curr Opin Rheumatol 19, 233-237.

Kleiman, A., Hübner, S., Rodriguez Parkitna, J.M., Neumann, A., Hofer, S., Weigand, M.A., Bauer, M., Schmid, W., Schütz, G., Libert, C., et al. (2012). Glucocorticoid receptor dimerization is required for survival in septic shock via suppression of interleukin-1 in macrophages. FASEB J 26, 722-729.

Lim, H.Y., Müller, N., Herold, M.J., van den Brandt, J., and Reichardt, H.M. (2007). Glucocorticoids exert opposing effects on macrophage function dependent on their concentration. Immunology 122, 47-53.

Luisi, B.F., Xu, W.X., Otwinowski, Z., Freedman, L.P., Yamamoto, K.R., and Sigler, P.B. (1991). Crystallographic analysis of the interaction of the glucocorticoid receptor with DNA. Nature 352, 497-505.

Madison, B.B., Dunbar, L., Qiao, X.T., Braunstein, K., Braunstein, E., and Gumucio, D.L. (2002). Cis elements of the villin gene control expression in restricted domains of the vertical (crypt) and horizontal (duodenum, cecum) axes of the intestine. J Biol Chem 277, 33275-33283. 
Marletta, M.A. (1993). Nitric oxide synthase structure and mechanism. J Biol Chem 268, 12231-12234.

Martinez, A., Elsasser, T.H., Muro-Cacho, C., Moody, T.W., Miller, M.J., Macri, C.J., and Cuttitta, F. (1997). Expression of adrenomedullin and its receptor in normal and malignant human skin: a potential pluripotent role in the integument. Endocrinology 138, 5597-5604.

Mashimo, H., Kjellin, A., and Goyal, R.K. (2000). Gastric stasis in neuronal nitric oxide synthase-deficient knockout mice. Gastroenterology 119, 766-773.

Mulla, A., and Buckingham, J.C. (1999). Regulation of the hypothalamo-pituitaryadrenal axis by cytokines. Baillieres Best Pract Res Clin Endocrinol Metab 13, 503-521.

Mungrue, I.N., Bredt, D.S., Stewart, D.J., and Husain, M. (2003). From molecules to mammals: what's NOS got to do with it? Acta Physiol Scand 179, 123-135.

Olsson, C., and Holmgren, S. (2001). The control of gut motility. Comp Biochem Physiol A Mol Integr Physiol 128, 481-503.

Orihata, M., and Sarna, S.K. (1994). Inhibition of nitric oxide synthase delays gastric emptying of solid meals. J Pharmacol Exp Ther 271, 660-670.

Parkman, H.P., Hasler, W.L., and Fisher, R.S. (2004). American Gastroenterological Association technical review on the diagnosis and treatment of gastroparesis. Gastroenterology 127, 1592-1622.

Picard, D., and Yamamoto, K.R. (1987). Two signals mediate hormonedependent nuclear localization of the glucocorticoid receptor. EMBO J 6, 33333340.

Pithadia, A.B., and Jain, S. (2011). Treatment of inflammatory bowel disease (IBD). Pharmacol Rep 63, 629-642.

Pratt, W.B., and Toft, D.O. (2003). Regulation of signaling protein function and trafficking by the hsp90/hsp70-based chaperone machinery. Exp Biol Med (Maywood) 228, 111-133.

Rao, K.V., and Faso, A. (2012). Chemotherapy-induced nausea and vomiting: optimizing prevention and management. Am Health Drug Benefits 5, 232-240.

Rauch, A., Seitz, S., Baschant, U., Schilling, A.F., Illing, A., Stride, B., Kirilov, M., Mandic, V., Takacz, A., Schmidt-Ullrich, R., et al. (2010). Glucocorticoids suppress bone formation by attenuating osteoblast differentiation via the monomeric glucocorticoid receptor. Cell Metab 11, 517-531. 
Reichardt, H.M., Kaestner, K.H., Tuckermann, J., Kretz, O., Wessely, O., Bock, R., Gass, P., Schmid, W., Herrlich, P., Angel, P., et al. (1998). DNA binding of the glucocorticoid receptor is not essential for survival. Cell 93, 531-541.

Reichardt, H.M., Tuckermann, J.P., Göttlicher, M., Vujic, M., Weih, F., Angel, P., Herrlich, P., and Schütz, G. (2001). Repression of inflammatory responses in the absence of DNA binding by the glucocorticoid receptor. EMBO J 20, 7168-7173.

Reichardt, S.D., Föller, M., Rexhepaj, R., Pathare, G., Minnich, K., Tuckermann, J.P., Lang, F., and Reichardt, H.M. (2012). Glucocorticoids enhance intestinal glucose uptake via the dimerized glucocorticoid receptor in enterocytes. Endocrinology 153, 1783-1794.

Reichardt, S.D., Weinhage, T., Rotte, A., Föller, M., Oppermann, M., Lühder, F., Tuckermann, J.P., Lang, F., van den Brandt, J., and Reichardt, H.M. (2014). Glucocorticoids induce gastroparesis through depletion of L-arginine. Endocrinology 155, 3899-908.

Rivera, L.R., Poole, D.P., Thacker, M., and Furness, J.B. (2011). The involvement of nitric oxide synthase neurons in enteric neuropathies. Neurogastroenterol Motil 23, 980-988.

Rose, A.J., and Herzig, S. (2013). Metabolic control through glucocorticoid hormones: an update. Mol Cell Endocrinol 380, 65-78.

Saeki, N., Kuwahara, Y., Sasaki, H., Satoh, H., and Shiroishi, T. (2000). Gasdermin (Gsdm) localizing to mouse Chromosome 11 is predominantly expressed in upper gastrointestinal tract but significantly suppressed in human gastric cancer cells. Mamm Genome 11, 718-724.

Sanders, K.M. (1996). A case for interstitial cells of Cajal as pacemakers and mediators of neurotransmission in the gastrointestinal tract. Gastroenterology $111,492-515$.

Sandu, C., Artunc, F., Grahammer, F., Rotte, A., Boini, K.M., Friedrich, B., Sandulache, D., Metzger, M., Just, L., Mack, A., et al. (2007). Role of the serum and glucocorticoid inducible kinase SGK1 in glucocorticoid stimulation of gastric acid secretion. Pflugers Arch 455, 493-503.

Schäcke, H., Döcke, W.D., and Asadullah, K. (2002). Mechanisms involved in the side effects of glucocorticoids. Pharmacol Ther 96, 23-43.

Schäcke, H., Schottelius, A., Docke, W.D., Strehlke, P., Jaroch, S., Schmees, N., Rehwinkel, H., Hennekes, H., and Asadullah, K. (2004). Dissociation of transactivation from transrepression by a selective glucocorticoid receptor agonist leads to separation of therapeutic effects from side effects. Proc Natl Acad Sci U S A 101, 227-232. 
Schmid, W., Strähle, U., Schütz, G., Schmitt, J., and Stunnenberg, H. (1989). Glucocorticoid receptor binds cooperatively to adjacent recognition sites. EMBO J 8, 2257-2263.

Schmidt-Ott, K.M., Mori, K., Li, J.Y., Kalandadze, A., Cohen, D.J., Devarajan, P., and Barasch, J. (2007). Dual action of neutrophil gelatinase-associated lipocalin. J Am Soc Nephrol 18, 407-413.

Schubert, M.L. (2008). Gastric secretion. Curr Opin Gastroenterol 24, 659-664.

Schweingruber, N., Reichardt, S.D., Lühder, F., and Reichardt, H.M. (2012). Mechanisms of glucocorticoids in the control of neuroinflammation. $J$ Neuroendocrinol 24, 174-182.

Sellebjerg, F., Frederiksen, J.L., Nielsen, P.M., and Olesen, J. (1998). Doubleblind, randomized, placebo-controlled study of oral, high-dose methylprednisolone in attacks of MS. Neurology 51, 529-534.

Stahn, C., Löwenberg, M., Hommes, D.W., and Buttgereit, F. (2007). Molecular mechanisms of glucocorticoid action and selective glucocorticoid receptor agonists. Mol Cell Endocrinol 275, 71-78.

Stancato, L.F., Chow, Y.H., Hutchison, K.A., Perdew, G.H., Jove, R., and Pratt, W.B. (1993). Raf exists in a native heterocomplex with hsp90 and p50 that can be reconstituted in a cell-free system. J Biol Chem 268, 21711-21716.

Stuehr, D.J. (1997). Structure-function aspects in the nitric oxide synthases. Annu Rev Pharmacol Toxicol 37, 339-359.

Takahashi, T., Nakamura, K., Itoh, H., Sima, A.A., and Owyang, C. (1997). Impaired expression of nitric oxide synthase in the gastric myenteric plexus of spontaneously diabetic rats. Gastroenterology 113, 1535-1544.

Takeuchi, K., Nishiwaki, H., Okada, M., Niida, H., and Okabe, S. (1989). Bilateral adrenalectomy worsens gastric mucosal lesions induced by indomethacin in the rat. Role of enhanced gastric motility. Gastroenterology 97, 284-293.

Tamura, M., Tanaka, S., Fujii, T., Aoki, A., Komiyama, H., Ezawa, K., Sumiyama, K., Sagai, T., and Shiroishi, T. (2007). Members of a novel gene family, Gsdm, are expressed exclusively in the epithelium of the skin and gastrointestinal tract in a highly tissue-specific manner. Genomics 89, 618-629.

Tanihata, S., Oda, S., Nakai, S., and Uchiyama, T. (2004). Antiemetic effect of dexamethasone on cisplatin-induced early and delayed emesis in the pigeon. Eur J Pharmacol 484, 311-321.

Tuckermann, J.P., Kleiman, A., Moriggl, R., Spanbroek, R., Neumann, A., Illing, A., Clausen, B.E., Stride, B., Förster, I., Habenicht, A.J., et al. (2007). Macrophages and neutrophils are the targets for immune suppression by glucocorticoids in contact allergy. J Clin Invest 117, 1381-1390. 
Tuckermann, J.P., Reichardt, H.M., Arribas, R., Richter, K.H., Schütz, G., and Angel, P. (1999). The DNA binding-independent function of the glucocorticoid receptor mediates repression of AP-1-dependent genes in skin. J Cell Biol 147, 1365-1370.

van Lierop, M.J., Alkema, W., Laskewitz, A.J., Dijkema, R., van der Maaden, H.M., Smit, M.J., Plate, R., Conti, P.G., Jans, C.G., Timmers, C.M., et al. (2012). Org 214007-0: a novel non-steroidal selective glucocorticoid receptor modulator with full anti-inflammatory properties and improved therapeutic index. PLoS One 7, e48385.

Vandevyver, S., Dejager, L., Tuckermann, J., and Libert, C. (2013). New insights into the anti-inflammatory mechanisms of glucocorticoids: an emerging role for glucocorticoid-receptor-mediated transactivation. Endocrinology 154, 993-1007.

Varga, G., Ehrchen, J., Tsianakas, A., Tenbrock, K., Rattenholl, A., Seeliger, S., Mack, M., Roth, J., and Sunderkoetter, C. (2008). Glucocorticoids induce an activated, anti-inflammatory monocyte subset in mice that resembles myeloidderived suppressor cells. J Leukoc Biol 84, 644-650.

Vera, G., Castillo, M., Cabezos, P.A., Chiarlone, A., Martin, M.I., Gori, A., Pasquinelli, G., Barbara, G., Stanghellini, V., Corinaldesi, R., et al. (2011). Enteric neuropathy evoked by repeated cisplatin in the rat. Neurogastroenterol Motil 23, 370-378, e162-373.

Vittal, H., Farrugia, G., Gomez, G., and Pasricha, P.J. (2007). Mechanisms of disease: the pathological basis of gastroparesis--a review of experimental and clinical studies. Nat Clin Pract Gastroenterol Hepatol 4, 336-346.

Waddell, D.S., Baehr, L.M., van den Brandt, J., Johnsen, S.A., Reichardt, H.M., Furlow, J.D., and Bodine, S.C. (2008). The glucocorticoid receptor and FOXO1 synergistically activate the skeletal muscle atrophy-associated MuRF1 gene. Am J Physiol Endocrinol Metab 295, E785-797.

Watson, M.L., Baehr, L.M., Reichardt, H.M., Tuckermann, J.P., Bodine, S.C., and Furlow, J.D. (2012). A cell-autonomous role for the glucocorticoid receptor in skeletal muscle atrophy induced by systemic glucocorticoid exposure. Am J Physiol Endocrinol Metab 302, E1210-1220.

Webster, J.I., and Sternberg, E.M. (2004). Role of the hypothalamic-pituitaryadrenal axis, glucocorticoids and glucocorticoid receptors in toxic sequelae of exposure to bacterial and viral products. J Endocrinol 181, 207-221.

Webster, J.I., Tonelli, L., and Sternberg, E.M. (2002). Neuroendocrine regulation of immunity. Annu Rev Immunol 20, 125-163.

Wilbur, B.G., and Kelly, K.A. (1973). Effect of proximal gastric, complete gastric, and truncal vagotomy on canine gastric electric activity, motility, and emptying. Ann Surg 178, 295-303. 
Wu, G., and Morris, S.M., Jr. (1998). Arginine metabolism: nitric oxide and beyond. Biochem J 336 ( Pt 1), 1-17.

Wüst, S., van den Brandt, J., Tischner, D., Kleiman, A., Tuckermann, J.P., Gold, R., Lühder, F., and Reichardt, H.M. (2008). Peripheral T cells are the therapeutic targets of glucocorticoids in experimental autoimmune encephalomyelitis. $\mathrm{J}$ Immunol 180, 8434-8443. 


\section{Appendices}

\subsection{List of abbreviations}

\begin{tabular}{|c|c|}
\hline ACTH & Adenocorticotropic hormone \\
\hline $\operatorname{Arg} 2$ & Arginase 2 \\
\hline BEC & (S)-(2-Boronoethyl)-L-cystein hydrochlorid \\
\hline CD & Crohn's disease \\
\hline CINV & $\begin{array}{l}\text { Chemotherapy-induced nausea } \\
\text { and vomiting }\end{array}$ \\
\hline CNS & Central nervous system \\
\hline $\mathrm{CRH}$ & Corticotropin-releasing hormone \\
\hline DBD & DNA binding domain \\
\hline ENS & Enteric nervous system \\
\hline GC & Glucocorticoid \\
\hline GR & Glucocorticoid receptor \\
\hline GRE & Glucocorticoid response element \\
\hline HPA & Hypothalamic-pituitary-adrenal axis \\
\hline HPRT & $\begin{array}{l}\text { Hypoxanthine-guanine phosphoribosyl- } \\
\text { transferase }\end{array}$ \\
\hline IBD & Inflammatory bowel disease \\
\hline Klk1 & Kallikrein 1 \\
\hline ko & Knock-out \\
\hline LBD & Ligand binding domain \\
\hline Lcn2 & Lipocalin 2 \\
\hline MR & Mineralocorticoid receptor \\
\hline MS & Multiple sclerosis \\
\hline
\end{tabular}




\begin{tabular}{ll}
\hline NANC & Nonadrenergic-noncholinergic \\
\hline NO & Nitric oxide \\
\hline NOS & Nitric oxide synthase \\
\hline Odc & Ornithine decarboxylase \\
\hline RA & Rheumatoide arthritis \\
\hline UC & Ulcerative colitis \\
\hline wt & wildtype \\
\hline
\end{tabular}

\subsection{List of figures}

Figure 1. General structure of steroid hormone receptors. ............................ 2

Figure 2. Mechanisms of GC action......................................................... 3

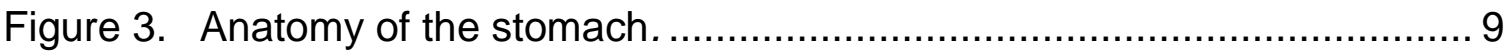

Figure 4. Cells types involved in gastric motility....................................... 12

Figure 5. Proposed mechanism of NO synthesis....................................... 16

Figure 6. Oral Dex treatment leads to an increase in stomach weight and size.

Figure 7. Oral administration of Dex for three days does not alter food intake or dry feces and only leads to a slight increase in water intake.

Figure 8. Oral Dex treatment induces gastroparesis in mice.

Figure 9. Dex induced gastroparesis is dose-dependent.

Figure 10. GR protein expression in the intestine and stomach of $\mathrm{GR}^{\text {villincre }}$ mice.

Figure 11. The GC-induced increase in stomach weight is preserved in enterocyte-specific GR knock-out mice. 
Figure 12. GC-induced gastroparesis is mediated by a DNA-binding dependent mechanism of the GR.

Figure 13. Enhanced gastric acid secretion is not linked to GC-induced gastroparesis.

Figure 14. Oral Dex treatment induces a M2 polarization of macrophages in the stomach.

Figure 15. Induction of gastroparesis by GCs is retained in mice specifically lacking the GR or MR in macrophages.

Figure 16. CD163 and CD74 are differentially regulated in the stomach of myeloid cell-specific GR and MR knock-out mice after Dex treatment

Figure 17. Reduced expression of Gsdmc2 and Gsdmc3 after Dex treatment is not responsible for induction of gastroparesis.

Figure 18. Identification of three GC target genes in the stomach that are differentially regulated in $\mathrm{GR}^{\mathrm{dim}}$ and $\mathrm{GR}^{\mathrm{wt}}$ mice following Dex administration.

Figure 19. Iron supplementation only partially prevents the increase in stomach weight caused by Dex treatment.

Figure 20. Gene expression of arg1 and nNOS in the stomach after Dex treatment.

Figure 21. Arg2 protein levels are increased after Dex treatment in $\mathrm{GR}^{\mathrm{wt}}$ but not $\mathrm{GR}^{\mathrm{dim}}$ mice.

Figure 21. Supplementation of the drinking water with L-arginine prevents the increase in stomach weight after Dex treatment.

Figure 22. Supplementation with L-arginine restores the normal gastric emptying otherwise impaired by GC treatment.

Figure 23. Supplementation with L-arginine leads to enhanced expression of arg2 and Odc

Figure 24. Inhibition of arginase only partially prevents the increase in stomach weight and the reduction in gastric emptying. 


\subsection{Acknowledgements}

I would like to express my sincere appreciation to my supervisor Prof. Dr. Martin Oppermann for his support during this PhD project. While allowing me to work independently I could always rely on his advice when needed.

Many thanks go to my thesis committee members Prof. Dr. Matthias Dobbelstein and PD. Dr. Fred Lühder. I am grateful for their interest in my project and for motivating discussions and encouragement during thesis committee meetings.

Furthermore, I am indebted to our collaboration partners Prof. Dr. Florian Lang and Prof. Dr. Jan Tuckermann, and to former and current lab members of the Institute for Cellular and Molecular Immunology, that I refrain from naming all individually. However, special thanks goes to Toni Weinhage for the set-up work of this project and to Amina Bassibas for expert technical assistance on countless occasions.

I owe my deepest gratitude to my family. To Roxanna, Clara, Alban and Tristan for filling my days with joy, challenge and life. To Holger for his support and encouragement, and for more than I can name. 


\subsection{Curriculum vitae}

\section{Personal data}

Name:

Reichardt, Sybille Dorothee

Date and place of birth: $\quad$ 14.11.1968, Esslingen, a.N.

Nationality:

German

\section{Education and Employment}

$\begin{array}{ll}\text { 04/2012 - 01/2015 } & \begin{array}{l}\text { Doctoral thesis at the Institute for Cellular and } \\ \text { Molecular Immunology, University of Göttingen. } \\ \text { Project:"Physiological and molecular features of glu- } \\ \text { cocorticoid actions in the gastrointestinal tract." }\end{array} \\ 01 / 2011-03 / 2012 & \begin{array}{l}\text { Scientific employee at the Institute for Cellular and } \\ \text { Molecular Immunology, University Medical Center } \\ \text { Göttingen }\end{array} \\ 09 / 1992-08 / 2006 & \begin{array}{l}\text { Chemical engineer in the Department of Research } \\ \text { and Development, Clariant GmbH, Leinfelden. }\end{array} \\ 04 / 1992-09 / 1992 & \begin{array}{l}\text { Internship at the Department of Quality Control at } \\ \text { Clariant GmbH, Leinfelden }\end{array} \\ 10 / 1991-02 / 1992 & \begin{array}{l}\text { Diploma thesis in Biochemistry (in cooperation with } \\ \text { Deutsche Gelatine Fabriken Stoess AG, Eberbach) }\end{array} \\ 10 / 1988-02 / 1992 & \begin{array}{l}\text { Studies in Chemical Engineering at the University of } \\ \text { Applied Sciences in Darmstadt }\end{array} \\ 09 / 1979-05 / 1988 & \begin{array}{l}\text { Allgemeine Hochschulreife at the Immanuel-Kant- } \\ \text { Gymnasium, Leinfelden }\end{array}\end{array}$




\section{Publications}

Gerber, U., Jucknischke, U., Putzien, S., and Fuchsbauer, H.L. (1994). A rapid and simple method for the purification of transglutaminase from Streptoverticillium mobaraense. Biochem J 29, 825-829.

Sbiera, S., Dexneit, T., Reichardt, S.D., Michel, K.D., van den Brandt, J., Schmull, S., Kraus, L., Beyer, M., Mlynski, R., Wortmann, S., et al. (2011). Influence of short-term glucocorticoid therapy on regulatory $T$ cells in vivo. PLoS ONE 6, e24345.

Tischner, D., Theiss, J., Karabinskaya, A., van den Brandt, J., Reichardt, S.D., Karow, U., Herold, M.J., Lühder, F., Utermöhlen, O., and Reichardt, H.M. (2011). Acid sphingomyelinase is required for protection of effector memory $T$ cells against glucocorticoid-induced cell death. J Immunol 187, 4509-4516.

Schweingruber, N., Reichardt, S.D., Lühder, F., and Reichardt, H.M. (2012). Mechanisms of glucocorticoids in the control of neuroinflammation. J Neuroendocrinol 24, 174-182.

Reichardt, S.D., Föller, M., Rexhepaj, R., Pathare, G., Minnich, K., Tuckermann, J.P., Lang, F., and Reichardt, H.M. (2012). Glucocorticoids enhance intestinal glucose uptake via the dimerized glucocorticoid receptor in enterocytes. Endocrinology 153, 1783-1794.

Reichardt, S.D., Weinhage, T., Rotte, A., Föller, M., Oppermann, M., Lühder, F., Tuckermann, J.P., Lang, F., van den Brandt, J., and Reichardt, H.M. (2014). Glucocorticoids induce gastroparesis in mice through depletion of $\mathrm{L}$-arginine. Endocrinology 155, 3899-3908.

Theiss-Suennemann, J., Jörß, K., Messmann, J.J., Reichardt, S.D., MontesCobos, E., Lühder, F., Gröhne, H.J., Tuckermann, J.P., Wolff, H.A., Dressel, R., Strauß, G., and Reichardt, H.M. (2014). Glucocorticoids attenuate acute graftversus-host disease by suppressing the cytotoxic capacity of CD8+ T cells. Journal of Pathology (doi: 10.1002/ path.4475). 